\title{
The European Histamine Research Society 48th Annual Meeting, May 15-18th, 2019 Kraków, Poland
}

Editor: G. Sturman

In cooperation with:
K. Barrett (San Diego)
D. Bell (Belfast)
N. Carruthers (San Diego)
P. L. Chazot (Durham)
M. Ennis (Belfast)
L. Kay (Sheffield)

This supplement was not sponsored by outside commercial interests. It was funded entirely by the publishers. 


\title{
Meeting Report of the European Histamine Research Society
}

\author{
G. Sturman
}

This years' meeting was in the old capital of Poland, Krakow at the kind invitation of Professor Katarzyna KiećKononowicz and her colleagues. The society has met three times previously in Poland: in Lodz (2013, 1998 and 1978) but this was the first time it was held in Krakow. The Jagiellonian University was founded in 1364 by Casimir III the Great and is the second oldest university in Central Europe with Nicolaus Copernicus being a student here. Our meeting was held in International Culture Centre which is located in the mediaeval Market Square. This meeting was jointly organised by our society with the Polish Society for Medicinal Chemistry, Faculty of Pharmacy of Jagiellonian University, Committee on Therapy and Drug Research Polish Academy of Sciences and the Polish Histamine Research Society.

This year there were 110 participants giving over 80 presentations. The participants came from most of the countries in Europe but also from the Americas, Middle and Far East. Some regular attendees could not attend and they were missed but a big welcome was made to all the new visitors, who we hope will return to future meetings. Most of the delegates arrived on the Wednesday. The Council met as usual later that afternoon. At 18.00, the 48th meeting of our society was opened by Professor Katarzyna Kieć-Kononowicz and our president, Ekaterina Tiligada before listening the opening two lectures. The Opening Lecture was delivered by Professor Chlopicki (Krakow) and was entitled 'Towards endothelial profiling in vivo' and this was followed by a lecture from one of our Honorary members, Professor Henk Timmerman (Amsterdam) who talked about 'Histamine, an unfinished symphony or how an ugly duckling became an attractive swan'. After this we attended a welcome reception.

Thursday started with the Opening Ceremony for the 48th meeting of our society and we were welcomed by our host, Katarzyna Kieć-Kononowicz, the president of the Polish Histamine Research Society, Agnieszka Fogel and our president, Ekaterina Tiligada. They all thanked the helpers and the sponsors. The programme was outlined. Ekaterina then gave out bursary certificates to 6 of our student members. Then we started the scientific sessions; the first being on histamine and allergy and this was dedicated to the memory of Professor Kenji Tasaka, a pioneer of histamine research in Japan who had died during the year. Mitsunobu Mio gave us a very informative talk about
Kenji and the scientific discoveries that he had made. This was followed by a lecture from Hiroyuki Fukui on combination therapy in allergic rhinitis. The next session was on histamine in the gastrointestinal tract where there were 3 lectures/oral presentations. Immediately before the coffee break, we had a group photo taken. Then we started the third session (Neuronal Histamine) with 2 plenary lectures: the first given by Beatrice Passani (Florence, Italy) on 'What's histamine got to do with memory, stress and appetite?' and then Joanna Mika (Krakow, Poland) on 'Pharmacological Modulation of glia attenuates neuropathic pain and enhances opioid effectiveness'. This was followed by 3 oral presentations on neuronal histamine. After the lunch break, a plenary lecture was given by Pertti Panula (Helsinki, Finland) on 'Plasticity of the brain histamine system in health and disease' followed by 4 oral presentations on neuronal histamine plus an invited lecture on histamine $\mathrm{N}$-methyl transferase given by Kanzuhiko Yanai (Sendai, Japan). Then there was an informal session ('Meet the Experts') for young investigators to interact with experts asking them questions etc. After this we met outside in the Market Square where we taken in small groups, each with a guide around the old Jagiellonian University Collegium Maius and we were all amazed at the centuries old teaching facilities for the students and how the university staff lived. Then we were taken across the Market Square for a visit to the Museum of Pharmacy, which was another fascinating experience. In the evening, we dined on a boat (C. C. Stefan Batory) which was anchored in the River Vistula close to the famous Wawel Castle.

On Friday, there was the first of the four 'poster flashes presentations' where all the poster presenters had only 3 min each to highlight their findings. The next session was dedicated to the memory Professor Armin Buschauer. Steffen Pockes of the University of Regensburg gave a moving presentation about Armin and his interest in the G-protein coupled receptors, especially the histamine ones. After this there were 3 more presentations on some clinical aspects of histaminergic substances and the possible therapeutic potential in neurodegenerative diseases. This was followed by the second 'poster flash' session before continuing with the 2 invited speakers and 2 oral presentation in the 'biological active compounds' session. The first of the invited speakers was another of our Honorary 
Members, Rob Leurs from Amsterdam who told us about some of the new tools which were being developed for histamine research. The other invited speaker was Jonas Dyhrfjeld-Johnsen from Sensorion Pharma, who spoke about the use of seliforant in vertigo. After lunch there were the final 'flash poster' presentations. All the poster presenters of this meetings were congratulated in keeping to the very short time scale given for their presentations as this is not an easy task. To complete the afternoon, we were divided into groups and given a guided walking tour around the city of Krakow. We were taken into little alleys to see some of the very old structures which are part of the buildings of the old town and heard about life several centuries ago in Krakow. Most groups even walked round the castle and we all agreed that Krakow is a very interesting place. To finish the day, we were taken to a concert of ultra-modern music by the Karol Szymanowski Philharmonic of Krakow. It was very different from the usual type of classical concert music.

On our final morning (Saturday), the first session was devoted to judging five young researchers for the Young Investigator Award (2019). The talks ranged from the photoswitchable potential of ligands acting on histamine receptors to the involvement of histamine in pain/nociception and other brain actions! Whilst the YIA judges deliberated, there was a final time to examine the posters and talk to their authors. Then there was the annual G. B. West lecture, which this year was given by Francesca Levi-Schaffer of Hebrew University, Israel and it was entitled 'Inhibition activation or activated inhibition of mast cells and eosinophils: which weapon is better to fight allergic diseases?' where she tried to illustrate the complexity of allergy. After this excellent lecture where we heard and learnt of the interaction of so many chemicals during allergy, Francesca was given a present and a copy of Geoff West's autobiography-'A Handful of Luck'. [Geoff West was one of the founding members of our society.] Then there were 9 oral presentations concerned with allergy and inflammation as well an invited talk by Liam O'Mahony (Cork, Ireland) on the role of histamine derived from micro-organisms in mucosal inflammation. During the afternoon coffee break, it was possible to take a final look at the posters before we held our General Assembly.
The situation concerning the modification of our statues was extensively discussed as well the future meetings of the EHRS, especially as we will be celebrating the 50th anniversary of our society in 2021 !

This was then followed by our gala dinner at the Morskie Oko Restaurant in the centre of Krakow. After a lovely Polish meal, certificates and prizes were given out to the YIA and poster prize winners. The YIA panel (Madeleine Ennis, Jonas Dyhrfjeld-Johnen, Pertti Panula and Steffen Pockes) had had a difficult job in differentiating these excellent presentations but eventually the first prize went to Tamara Mocking from The Netherlands with her presentation entitled 'Photoswitchable ligands as tools for dynamic modulation of histamine receptors' and the second prize went to Katarzyna Popiolek-Barczyk from Poland for her presentation 'Antinociceptive effects of a novel histamine $\mathrm{H}_{3}$ receptor antagonist in mouse model of neuropathic pain'. The other three finalists (Alaa Alachkar from the United Arab Emirates, Roberto De Luca from the United States and Mariaconcetta Durante from Italy) were awarded Highly Commended Certificates. Similarly, the poster jury (Jerzy Jochem, Beatrice Passani, Asrid Sasse and Holger Stark) had a difficult job deciding who their winners were. The first prize went to Ulla Seibel (Germany), with both Yanrong Zheng (China) and Alessandra Franceschini (Italy) being awarded 'Special Commendations'. Then, as usual we had our singing session beginning with 'Anita's Thank You Song' (sung to the tune of 'Oh, Susanna') as a big thank you to Katarzyna and her team for the excellent and very well organised meeting and then after this we sung our EHRS Anthem, before saying 'au revoir' to our many 'histaminergic' friends.

Our thanks are given to all of the Krakow group for this memorable meeting. Our next meeting, the 49th Annual Meeting of the EHRS, will be 21st-23rd May 2020 and is being organised by Professor Holger Stark of the Institute of Pharmaceutical and Medicinal Chemistry, Heinrich Heine University Düsseldorf, Germany.

Department of Pharmacology and Therapeutics, School of Biomedical and health Sciences, King's College London, London SE1 1UL. E-mail: sturman.gill@gmail.com 


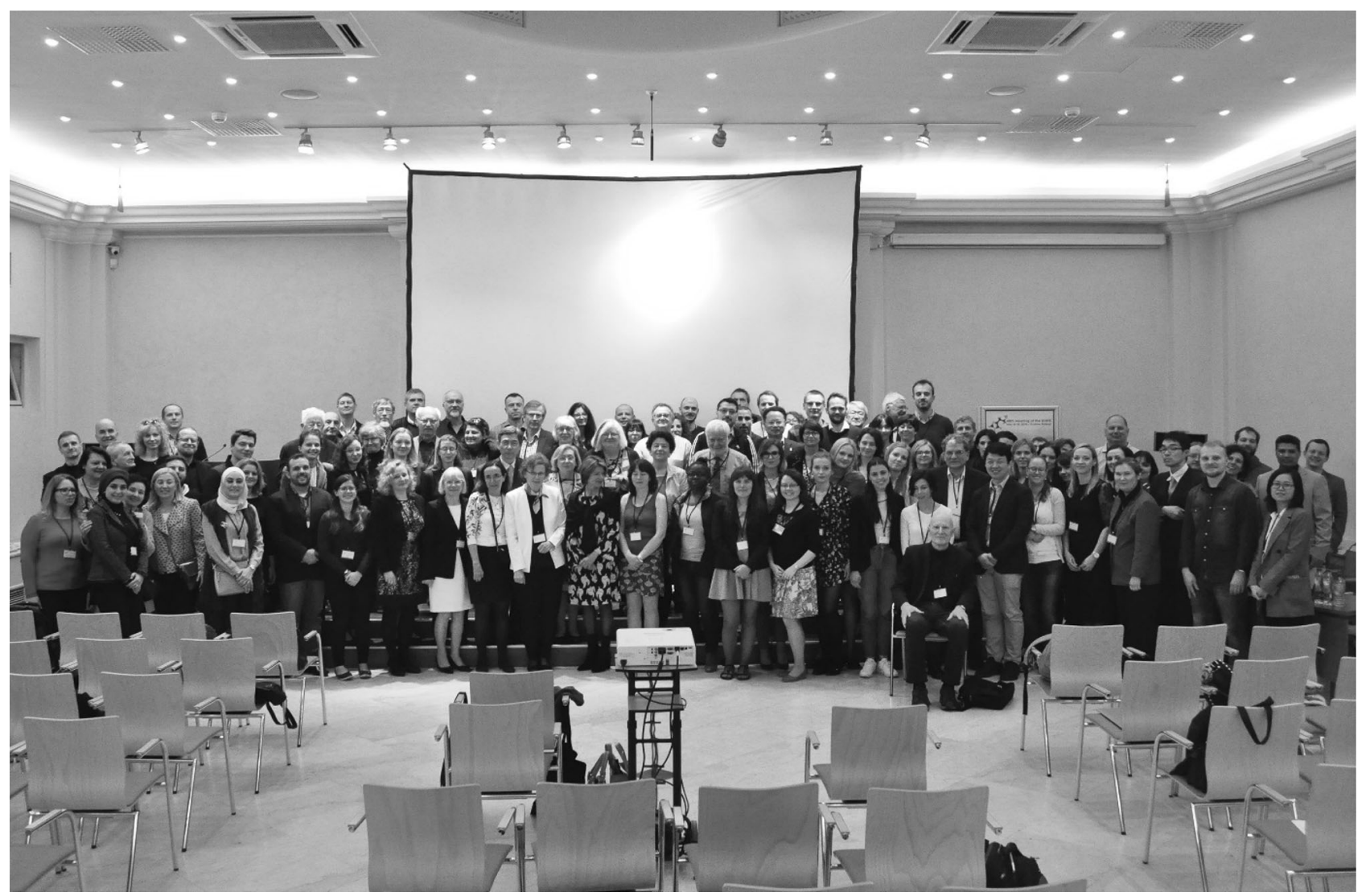

The participants of the 2019 meeting of the EHRS 


\section{Kenji Tasaka, A Pioneer of Histamine Research in Japan}

M. Mio

Professor Kenji Tasaka (January 16, 1929-October 7, 2018) left behind many excellent research publications and mentored many students with his generosity and noble attitude.

After graduating from Okayama University Medical School in 1952, his research career started at the laboratory of Prof. Hidemasa Yamasaki, a founder of histamine research in Japan. After several years of research in Okayama, Kenji became a research fellow at the Mayo Clinic, USA in 1963, and then became a lecturer at Virginia Medical School in 1966. In 1970, he returned to Japan and was promoted to Professor of Pharmacology, Faculty of Pharmaceutical Sciences, Okayama University in 1971.

Kenji's research interests extended widely including immunology, allergology, hematology and neurology, but his main passion was histamine; histamine release from mast cells, histamine in allergy, histamine-induced neutrophil differentiation, and histamine in learning and memory. He led the research team and had many outstanding achievements. He was awarded EHRS best poster presentation in 1985, 1987, 1988, 1990 and 1992, the
Copernicus Medal from the Polish Academy of Science in 1994 and an honorary membership of Polish Histamine Research Society in 1989.

In 1979, Kenji and the late Prof. Hiroshi Wada, Osaka University decided to organize an annual meeting on histamine research. This meeting was a training camp for young scientists, included many leading researchers, and led to the establishment of the Japanese Histamine Research Society. In 1981, Kenji and the late Prof. Börje Uvnäs organized the 1st International Histamine Symposium in Okayama as a satellite symposium of 8th International Congress of Pharmacology in Tokyo. He also organized Asian Histamine Research Society Meetings in 1989 and 1992 in Okayama.

The government awarded Kenji the Order of the Sacred Treasure, Gold Rays with Neck Ribbon in acknowledgement of his many years of achievement in education and research and contributions to academia in Japan.

Shujitsu University, Okayama City, 703-8516, Japan. E-mail:mio@shujitsu.ac.jp 


\title{
Armin Buschauer-an Interdisciplinary Minded Pharmaceutical Researcher and Mentor
}

\author{
S. Pockes
}

In 1993, Armin Buschauer became Professor for Pharmaceutical/Medicinal Chemistry at Regensburg University at the age of 38. He studied pharmacy at the University of Mainz where he also received his doctoral degree in 1984. He then moved to the FU Berlin as a post-doctoral researcher under the late Professor Walter Schunack (an honorary member of the EHRS) and obtained his Habilitation in 1990 . He was a regular attendee at the meetings of the EHRS, accompanied by very enthusiastic and able students. He has produced remarkable footsteps that will keep our memories of him alive during these 24 years working in Regensburg. Following his passion for teaching, he founded a new Master program in Medicinal Chemistry, which is continuously attracting students around the globe. Furthermore, he initiated two research training groups (GRK 760 and GRK 1910) focusing on selective ligands for G-protein coupled receptors, especially for histamine receptors and neuropeptide $\mathrm{Y}$ receptors. He got interested in this scientific topic during his own $\mathrm{PhD}$ work and he was obviously fascinated by throughout his whole scientific life. During his time as a mentor 80 students received their $\mathrm{PhD}$ degrees under his supervision yielding a total of 300 scientific papers. He served as Dean, Vice-Dean and senator.

Armin Buschauer was an indigenous and modest character, who was generous and supportive to all his coworkers and collaborators, despite all the success along his academic career. His ultimate guidelines with respect to his academic career were scientific precision and reproducibility of experimental results. Whenever scientific standards were put in jeopardy, he said so-loud and clear-and took any effort to get things right. With this attitude he has set an example of scientific demeanor that should be contemplated as his legacy just as much as his gentle personality. Remembering Armin Buschauer must not leave out his very special sense of fine humor and his passion for it as well as for science till the very end.

University of Regensburg, Regensburg, 93053, Germany. E-mail: steffen.pockes@ur.de 
Neurological aspects of histamine 


\section{WHAT'S HISTAMINE GOT TO DO WITH MEMORY, STRESS AND APPETITE?}

\section{B. Passani}

Early observations indicate that subsets of histaminergic neurons respond selectively to different acute stressors, and both acute and chronic stress increase brain histamine turnover. Brain histamine is a major regulator of memory consolidation, retrieval and extinction in various behavioural tasks such as inhibitory avoidance, fear conditioning, object recognition and spatial recognition. Also, the hypophagic effect of endogenous anorexiant factors is mediated by the brain histaminergic system. In this respect, histaminergic neurons seem to "sense" peripheral signals to orchestrate the appropriate homeostatic response. Some of these internal mediators, such as the fat sensing lipid oleoylethanolamide, affect also memory consolidation of fear memory by activating the brain histaminergic system.

Hence, a new role for the brain histaminergic system is emerging, as a gateway between peripheral signals and the elaboration of not only homeostatic responses but also aversive memories.

How can a small collection of neurons in the posterior hypothalamus afford all these functions? We hypothesize that brain histamine serves as a relay station integrating peripheral signals and central functions to influence the emotional value of different experiences and to control energy expenditure and behavioural responses. One way of controlling different behavioural outputs is to allocate the appropriate histaminergic activation in different, selected brain regions and/or at different time point during the unfolding of behavioural or homeostatic responses. In addition, different subtypes of histamine receptors, in particular $\mathrm{H}_{1} \mathrm{R}$ and $\mathrm{H}_{2} \mathrm{R}$, are activated in different mnemonic tasks in different brain areas. This hypothesis entails heterogeneous physiological properties of histaminergic neurons. Early results from our laboratory, and more recent demonstrations from other researchers', strongly support this hypothesis.

Ambrosiac-JPI A healthy diet for a healthy life; Fondazione ente cassadi risparmio.

Department of Health Sciences, University of Florence, viale Pieraccini 6 50139, Florence, Italy. E-mail: beatrice.passani@unifi.it

\section{ACTIVATION OF NEUROKININ-1 RECEPTOR PATHWAY IN CENTRAL HISTAMINERGIC NEURONS}

\author{
R. De Luca, H. L. Haas, O. A. Sergeeva
}

Neuropeptides play an important role in the regulation of wakefulness. Previous studies suggested that the neurokinin (NK) Substance P (SP) may promote arousal. SP is released in the brain in response to environmental stressors and excites target neurons, mainly through the activation of the NK1 receptor (NK1R). Histaminergic (HA) neurons located in the tuberomamillary nucleus (TMN) show faster firing during waking and negligible activity during sleep. Moreover, it has been reported that HA neurons synthesize $\mathrm{SP}$ and receive SP-ergic innervation. We explore now expression (single-cell RT-PCR) and function (electrophysiology in mouse brain slices) of NK1R in HA neurons. In cell-attached voltage-clamp recordings in vitro bathapplication of a NK1R agonist, GR73632 (10 nM), excites $89 \%$ of HA neurons, an effect abolished in the presence of the NK1R antagonist, CP99994 (100 nM). Furthermore, we demonstrate, that the NK1R in HA neurons activates phosphatidylinositol specific phospholipase (PI-PLC), PI3 kinase and mitogen-activated protein kinase (MAPK). We detect transcripts encoding for the NK1R and the precursor of SP (pre-SP) in most of the HA neurons (67\% and 63\%, respectively). In addition, immunohistochemical analysis reveals that $85 \%$ of them are immunopositive for NK1R. Taken together these data suggest that activation of NK1R on HA neurons could be important in the promotion of arousal. Interestingly, clinical studies reported that chronic application of Vestipitant, a NK1R antagonist, efficiently combats insomnia, facilitating sleep. Future in vivo studies will be necessary to determine the role of NK1R on HA neurons for the sleep-promoting effects of this medication.

This presenter was a finalist for the Young Investigator Award (2019).

This study was supported by the graduate school iBrain (Heinrich-Heine University, Düsseldorf).

Heinrich-Heine University, Medical Faculty, Institute of Neural and Sensory Physiology, Molecular Neurophysiology, D-40225 Duesseldorf, Germany. E-mail: rdeluca@bidmc.harvard.edu 


\section{HISTAMINE-INDUCED PLASTICITY AND GENE EXPRESSION IN A MOUSE MODEL WITH INBORN HYPERAMMONEMIA}

\section{H. L. Haas, O. A. Sergeeva, A. N. Chepkova, B. Görg, D. Häussinger}

Hyperammonemic conditions are associated with fatigue, especially during extreme exercise or liver pathology. Histamine $\mathrm{H}_{3}$ receptor $\left(\mathrm{H}_{3} \mathrm{R}\right)$ antagonists/inverse agonists increase vigilance and may, thus, have therapeutic value in liver diseases accompanied by excessive day time sleepiness. We studied modifications within brain histaminergic pathways under hyperammonemia and the transcriptome of receptors and their signalling cascades, to provide a rationale for the development of wake-promoting therapies. We analysed the expression of selected genes in cortex and dorsal striatum in a mouse model of inborn hyperammonemia (liver specific glutamine synthetase knockout: LGS-KO), and performed an electrophysiological analysis of histamine-induced long-lasting depression of corticostriatal synaptic transmission (LLDhist). As the expression of dopamine 1 receptors $\left(D_{1} R\right)$ is upregulated in LGS KO striatum and $\mathrm{D}_{1} \mathrm{R}-\mathrm{H}_{3} \mathrm{R}$ dimers were discovered here, we investigated actions of $\mathrm{H}_{3} \mathrm{R}$ - and $\mathrm{D}_{1} \mathrm{R}$ - agonists and antagonists. LGS-KO mice showed a significant reduction of the initial, but not the late, phase of LLDhist. Neither pharmacological activation nor inhibition of $\mathrm{D}_{1} \mathrm{R}$ significantly affected LLDhist in WT striatum, while in LGS-KO mice $D_{1} R$ activation suppressed LLDhist. Receptors and enzymes involved in histaminergic signalling were found unchanged at the transcriptional level. Our findings provide a rationale for the development of wake-promoting therapeutics directed towards aminergic neurotransmission in hyperammonemic diseases.

This study was supported by the German Research Foundation (Deutsche Forschungsgemeinschaft, DFG) through Collaborative Research Center 974 "Communication and Systems Relevance in Liver Injury and Regeneration" (Düsseldorf).

Heinrich-Heine University, Medical Faculty, Institute of Neural and Sensory Physiology, Molecular Neurophysiology,D-40225 Duesseldorf, Germany.E-mail: haas@uniduesseldorf.de

\section{WAKENING COCKTAIL AND NORADRENERGIC MODULATION OF HISTAMINERGIC AND DOPAMINERGIC NEURONS}

\section{O. A. Sergeeva and F. R. Almeida}

Synergistic activation of aminergic nuclei in control of cortical arousal demands excitation by partner-transmitters and inhibition by their own one (through the autoinhibitory receptor). In the majority of arousal controlling neurons, firing activity correlates with periods of waking, with the strictest correlation reported for histaminergic (HA) neurons of the tuberomammillary nucleus (TMN) and lowest or no correlation for the mesencephalic dopaminergic (DA) neurons. Paradoxically, psychostimulants enhance vigilance by increasing levels of dopamine and noradrenaline. To answer the question, which systems differentially activate DA and HA neurons during wake, we tested the action of a wakening cocktail (WC: mixture of neurotransmitters promoting arousal) and its components on firing rate of ventral tegmental area (VTA) DA neurons and TMN HA neurons in mouse brain slices. NMDA, AMPA and kainate excited HA and DA neurons whereas carbachol excited VTA, but not TMN neurons. Among the WC components, noradrenaline (NA) evoked most heterogeneous responses. NA excited silent $\mathrm{HA}$ neurons with an $\mathrm{EC}_{50} 2.7 \mu \mathrm{M}$ $(\mathrm{n}=27)$ and spontaneously firing cells with $\mathrm{EC}_{50} 0.8 \mu \mathrm{M}$ $(n=23)$, whereas either inhibitory or excitatory responses were recorded in DA neurons. In the presence of the dopamine type 2 receptor (D2R) antagonist sulpiride, NA excited the majority of the DA neurons ( 65 out of 79 cells) with an $\mathrm{EC}_{50} 0.7 \mu \mathrm{M}$. NA-excitation was unchanged in the presence of glutamate- and $\mathrm{GABA}_{\mathrm{A}}$-receptor antagonists. Adrenergic $\alpha_{1}$ and $\alpha_{2}$ receptors were detected in aminergic neurons with single-cell RT-PCR and pharmacological evidence of their expression was obtained. Inhibitory (through $\mathrm{DA}_{2}$ receptors) or excitatory (through adrenoceptors) responses to the wake-promoting transmitter noradrenaline may explain the lack of correlation between VTA DA neuron firing and wake-EEG in contrast to the high correlation found for HA neurons.

Heinrich-Heine University, Medical Faculty, Institute of Clinical Neurosciences and Medical Psychology, D-40225 Duesseldorf, Germany. E-mail: olga.sergeeva@uniduesseldorf.de 


\section{LOCAL ADMINISTRATION OF HISTAMINE- BINDING PROTEIN EV131 ATTENUATES NEUROPATHIC PAIN AND ITCH IN MICE: COMPARISION TO SYSTEMIC EFFECTS}

I. Alrashdi, A. Alsubayiel, M. Nunn, W. Weston-Davies, P. L. Chazot, I. Obara

EV131 is a novel centrally-sparing and high-affinity recombinant histamine binding protein that naturally occurs in tick saliva to block the host's immunological response at the tick-feeding site. Recently, we identified the analgesic/antinociceptive efficacy of EV131 after systemic administration. Here, we extended our study into examination of anti-nociceptive and anti-pruritic effects produced by EV131 via targeting the peripheral histaminergic system with peripheral localized injections of EV131. In adult male C57BL/6 J mice ( $n=6-9 /$ group) subjected to the chronic constriction injury model of neuropathic pain, EV131, injected i.pl. (directly into the plantar surface of injured hind-paw) at a lower dose range than compared to systemic treatment, produced antinociceptive effects observed in mechanical hypersensitivity testing using von Frey filaments (AUC [g days]-0.25 mg: $21.2 \pm 1.1[\mathrm{SEM}], 0.075 \mathrm{mg}: 13.8 \pm 0.7[\mathrm{SEM}], 0.025 \mathrm{mg}:$ $10.1 \pm 0.6[\mathrm{SEM}], \quad 0.0075 \mathrm{mg}: \quad 6.1 \pm 0.5[\mathrm{SEM}]$, saline: $3.8 \pm 0.2[\mathrm{SEM}] ; \mathrm{F}(4,25)=93.4, \mathrm{P}<0.0001)$ and only moderately affected thermal hypersensitivity measured in the Hargreaves test (AUC [g days]-0.25 mg: $94.2 \pm 2.9[\mathrm{SEM}], 0.075 \mathrm{mg}: 92.2 \pm 2.7[\mathrm{SEM}], 0.025 \mathrm{mg}$ : $89.9 \pm 2.8[\mathrm{SEM}], 0.0075 \mathrm{mg}: 88.3 \pm 3.6[\mathrm{SEM}]$, saline: $65.2 \pm 2.0[\mathrm{SEM}] ; \mathrm{F}(4,25)=17.1, \mathrm{P}<0.0001)$. Interestingly, i.pl. EV131 did not affect nociceptive threshold in sham animals or on the uninjured paw. We also assessed anti-pruritic properties of EV131 in histaminergic itch induced by compound 48/80. EV131, injected s.c. directly into the site of itch at the lower dose range than compared to systemic treatment, produced anti-pruritic effect (number of scratches-0.3 mg/kg: $237.7 \pm 38.8[\mathrm{SEM}], 1 \mathrm{mg} /$ $\mathrm{kg}: 207.7 \pm 23.4[\mathrm{SEM}], 3 \mathrm{mg} / \mathrm{kg}: 175.2 \pm 42.9[\mathrm{SEM}]$, $10 \mathrm{mg} / \mathrm{kg}$ : $\quad 168.5 \pm 14.3[\mathrm{SEM}], \quad$ saline: $377.6 \pm 25.9[\mathrm{SEM}] ; \mathrm{F}(5,33)=7.8, \mathrm{P}<0.0001)$. Taken together, our findings provide the first evidence for targeting the peripheral histamine system by a recombinant histamine binding protein as a novel strategy for the control of peripheral neuropathies and acute itch.

Supported by the funding from Akari Therapeutics, UK. Supports our Patent: P071712WO:HRG/AEL/JNE.

Institute of Neuroscience, Newcastle University, Newcastle upon Tyne, NE1 7RU, UK. E-mail: I.Alrashdi2@newcastle.ac.uk
THE ANTAGONIST OF CCR4 (C021) INFLUENCES LEVEL OF SPINAL NOCICEPTIVE FACTORS AND ENHANCES MORPHINE ANTINOCICEPTIVE POTENCY IN A RAT MODEL OF NEUROPATHIC PAIN

J. Kujacz, K. Popiotek-Barczyk, W. Makuch, A. Ciechanowska,E. Rojewska, J. Dobrogowski, A. Przeklasa-Muszynska, J. Mika

Neuropathic pain is a significant clinical problem because it is a chronic condition often resistant to available therapy. Recently, studies indicate that chemokines signaling pathways are crucial in neuropathy development, however, the role of CCR4 has not been studied so far. The aim of this research was to investigate the influence of C021 (CCR4 antagonist) on the development of neuropathic pain symptoms in the animal model of neuropathy (Chronic Constriction Injury (CCI) performed in Wistar male rats (n 10/group). Repeated, intrathecal (i.th.) C021 (20 $\mu \mathrm{g} /$ $5 \mu \mathrm{l})$ administrations were conducted $16 \mathrm{~h}$ and $1 \mathrm{~h}$ before $\mathrm{CCI}$ and then after nerve ligation daily for 8 days. Moreover, we performed single i.th. administration of morphine $(2.5 \mu \mathrm{g} / 5 \mu \mathrm{l})$ at day 8 after CCI to evaluate the influence of tested antagonists on opioid effectiveness. The mechanical (von Frey test) and thermal (cold plate test) hypersensitivity were measured on day 8 post-CCI. Using Western blot, we analysed the CCI-induced changes in protein levels of cell markers (Iba1, GFAP, CD4, CD8) and selected nociceptive factors (IL-1beta, IL-18, IL-6, IL-10) in the spinal cord. The behavioural data are presented as the mean \pm SEM. One-way analysis of variance (ANOVA) was used to evaluate the experimental results and Bonferroni's post hoc test was used to analyze the differences between the groups $(* * \mathrm{p}<0.01$ and $* * * \mathrm{p}<0.001$ indicates the differences between the naïve animals and the V-or C021-treated CCI-exposed animals;

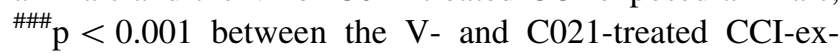
posed animals; ${ }^{+++} \mathrm{p}<0.001$ between the $\mathrm{V}+\mathrm{M}-$ and $\mathrm{C} 021+$ M-treated CCI-exposed animals; \&\&\&p $<0.001$ between the $\mathrm{V}$ - and $\mathrm{V}+\mathrm{M}$-treated CCI-exposed animals; and ${ }^{\$ \$} \mathrm{p}<0.001$ between the $\mathrm{V}+\mathrm{C} 021$ and $\mathrm{M}+\mathrm{C} 021-$ treated CCI-exposed rats). For the protein analysis data, $* \mathrm{p}<0.05, * * \mathrm{p}<0.01$ and $* * * \mathrm{p}<0.001$ indicate the differences between the naïve rats and the $\mathrm{V}$ - or $\mathrm{C} 021$-treated CCI-exposed rats and ${ }^{\#} \mathrm{p}<0.05,{ }^{\# \#} \mathrm{p}<0.01$ and

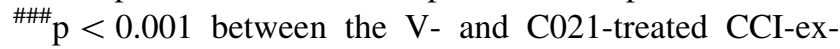
posed rats. We revealed that $\mathrm{C} 021$ significantly reduced CCI-induced hypersensitivity and, in parallel, reduced Iba1-positive cells activation, but not GFAP, CD4 and CD8. Moreover, the spinal level of pronociceptive interleukins IL-1beta and IL-18 were also diminished by C021, while the levels of IL-6 and IL-10 were not affected. The 
CCR4 antagonist not only attenuated mechanical and thermal hypersensitivity, but also enhanced the antinociceptive properties of morphine. This research supports the hypothesis that the pharmacological modulation of neuroimmunological interactions via CCR4 may represent a novel approach for effective poly-therapy with morphine under neuropathic pain.

Supported by the National Science Centre, Poland (OPUS 11 2016/21/B/NZ4/00128) and by statutory funds from the Institute of Pharmacology Polish Academy of Sciences, Department of Pain Pharmacology. Joanna Kujacz acknowledges the support of InterDokMed project no. POWR.03.02.00-00-I013/16.

Institute of Pharmacology, Polish Academy of Sciences, Department of Pain Pharmacology, Krakow, 31-343, Poland. E-mail: joanna.kujacz@gmail.com, kujacz@ifpan.krakow.pl

\section{PHARMACOLOGICAL BLOCKADE OF CCR1 AND CCR5 DIMINISHED NEUROPATHIC PAIN AND ENHANCED MORPHINE/BUPRENORPHINE EFFECTIVENESS}

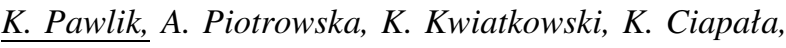 W. Makuch, J. Mika}

Millions of people suffer from neuropathic pain, however there is still no effective treatment. An important element of the development of neuropathy is glia activation combined with pronociceptive chemokines production. The chemokine receptors (CCR) are present on various types of cells (including neurons and glia). Based on the literature, we hypothesized that blocking CCR 1 and CCR 5 contribute to relief of neuropathy. Therefore, the aim of study was to investigate the impact of J113863 (CCR1 antagonist) and maraviroc (CCR5 antagonist) on the development of neuropathy. Using male Wistar rats, the antagonists were administrated intrathecally (i.t.), preemptively-before chronic constriction injury (CCI) and then once daily for 7 days. Single i.t. injections of morphine or buprenorphine were given after last J113863 or maraviroc administration. Behavioral tests (5-10 rats per group) were performed using von Frey and cold plate tests to measure mechanical and thermal hypersensitivity, respectively. Then, tissues from spinal cord (SC) and dorsal root ganglia (DRG) were collected to perform the Western blot analysis of protein levels of IBA-1, GFAP, IL-1beta and IL-1RA. We showed that both $\mathrm{J} 113863(0.1 \mu \mathrm{g} / 5 \mu \mathrm{l})$ and maraviroc $(20 \mu \mathrm{g} / 5 \mu \mathrm{l})$ attenuate symptoms of thermal and mechanical hypersensitivity which developed on the day 7 th post-CCI $(\mathrm{p}<0.01 ; \mathrm{p}<0.001)$. Intensification of morphine $(\mathrm{p}<0.05 ; \mathrm{p}<0.001)$ and buprenorphine $(\mathrm{p}<0.05$; $\mathrm{p}<0.01 ; \mathrm{p}<0.001)$ antinociception were observed as the result of combination with tested antagonists. Western blot analysis (5-8 samples per group) showed that maraviroc significantly diminished level of IBA-1 in SC and DRG ( $\mathrm{p}<0.01$ ), while J113863 only in SC ( $<<0.01)$. Moreover, only the CCR5 antagonist significantly reduced GFAP levels in SC and DRG ( $\mathrm{p}<0.01)$. Additionally, both tested drugs attenuated the level of pronociceptive IL1beta in DRG $(\mathrm{p}<0.05)$, while in the SC a significant downregulation was seen only after maraviroc injection $(\mathrm{p}<0.001)$. Moreover, both antagonists enhanced the level of antinociceptive IL-1RA in the SC and DRG $(\mathrm{p}<0.05 ; \mathrm{p}<0.001)$. Our results give evidence that CCR1 and CCR5 blockade may bring some analgesic/ antinociceptive activity to neuropathic pain.

This work was supported by the National Science Centre, Poland (OPUS 11 2016/21/B/NZ4/00128) and by statutory funds from the Institute of Pharmacology Polish Academy of Sciences, Department of Pain Pharmacology. Institute of Pharmacology, Polish Academy of Sciences, Department of Pain Pharmacology, Krakow, 31-343, Poland.E-mail: pawlik@if-pan.krakow.pl

\section{EXPRESSION AND FUNCTION OF OPIOID RECEPTORS IN MOUSE HISTAMINERGIC NEURONS OF THE TUBEROMAMILLARY NUCLEUS}

\section{K. Mazur, H. Haas, O. A. Sergeeva}

Histaminergic (HA) neurons of the tuberomamillary nucleus (TMN) regulate many physiological functions, including alertness, thermoregulation, locomotion, cognition, circadian and feeding rhythms, learning, endocrinium and pain perception. Their activity correlates with waking. We have shown previously that rat histaminergic neurons are inhibited by nociception, but excited by morphine indicating expression of different opioid receptor (OPR) types in HA neurons. Our aim was now to determine the expression of OPR in HA neurons identified by red fluorescence in Tmt-HDC mice, and the pharmacological correlates of the OPR expression. We found gender- and age-specific patterns of expression: DOP (delta OPR) transcripts were detected in $29 \%$ of juvenile, but not in adult HA neurons. HA neurons were inhibited by nociceptin (9 out of 10), whereas NOP (nociceptin OPR) transcripts were detected only in $38 \%$ of neurons (14 juvenile and 42 adult neurons were investigated). Dynorphin A inhibited $(n=8)$ or excited $(n=4)$ HA neurons. Transcripts encoding for kappa OPR (KOP) were detected in $50 \%$ of neurons. The MOP ( $\mu$ OPR) ligand DAMGO had inhibitory $(n=14)$ or excitatory $(n=3)$ actions in male 
mice (transcripts detected in 9 out of 27 neurons, 33\%); MOP detection rate was significantly higher in male than in female neurons $(p=0,0027)$. About $23 \%$ of all neurons lacked OPR expression, whereas two (or three) OPR types were simultaneously detected in $51 \%$ of OPR-positive neurons. Co-expression analysis and electrophysiological experiments indicated that dimers of different receptor types may exist. The identified OPR expression on HA neurons could be involved in nociceptive processing, however further studies at the behavioral level are necessary to shed more light on their role.

K.M. is an associated member of iBrain (interdisciplinary graduate school for brain research and translational neuroscience, Heinrich-Heine University of Düsseldorf). Heinrich-Heine University, Medical Faculty, Institute of Clinical Neurosciences and Medical Psychology, D-40225 Duesseldorf, Germany. E-mail: Karolina.Mazur@uniduesseldorf.de

\section{PARTHENOLIDE ATTENUATES NEUROPATHIC PAIN SYMPTOMS AND ENHANCES MORPHINE ANTINOCICEPTION IN A RODENT MODEL OF NEUROPATHY}

\section{A. Ciechanowska, K. Popiołek-Barczyk, K. Ciapała, W. Makuch, J. Mika}

Neuropathic pain is initiated by a lesion or disease of the somatosensory nervous system and causes countless suffering. Analgesics in use do not satisfy the clinical needs because of the modest efficacy and serious side effects. The goal of our studies was to examine the influence of parthenolide (PTL), an active compound of feverfew (Tanacetum parthenium), on neuropathic pain development and morphine effectiveness. Male Albino-Swiss CD-1 mice $(\underline{\mathbf{M}}) *(20-25 \mathrm{~g})$ and Wistar rats $(\underline{\mathbf{R}}) *(200-350 \mathrm{~g})$ were housed in groups of 8-10 and chronic constriction injury (CCI) of the sciatic nerve was performed. In ( $\underline{\mathbf{R}}$, PTL was administered intrathecally (i.t.) and preemptively (16 and $1 \mathrm{~h}$ before CCI) and then once daily for 7 days. Moreover, $(\underline{\mathbf{R}})$ received a single, i.t. morphine injection 7 days post-CCI. In ( $\underline{\mathbf{M}})$, PTL was administered repeatedly, intraperitoneally (i.p.), and preemptively (16 and $1 \mathrm{~h}$ before CCI) and then twice daily for 7 days. Additionally, we performed single i.p. administration of PTL at day 14th after CCI. Hypersensitivity to mechanical and thermal stimuli was measured by von Frey and cold plate tests, respectively. After treatment behavioural tests were performed and tissue for biochemical analyses was collected for assessment of glia activation and changes in expression of polarization markers. (M) the behavioral data are presented as the mean \pm SEM of $(\underline{\mathbf{M}})$ per group. The results of the experiments were statistically evaluated using t-student test. ${ }^{*} \mathrm{p}<0.05 ; * * \mathrm{p}<0.01 ; * * * \mathrm{p}<0.001$ indicates significant differences in comparisons with vehicletreated CCI-exposed $(\mathbf{M})$. ( $(\mathbf{R})$ the behavioral data are presented as the mean \pm SEM of $8-10 / 10-20$ (․ㅛ) per group. The results of the experiments were statistically evaluated using one-way analysis of variance (ANOVA). All of the differences between the treatment groups were further analyzed with Bonferroni's post hoc test $(* \mathrm{p}<0.05 ; \quad * * \mathrm{p}<0.01 ; \quad * * * \mathrm{p}<0.001)$. In $(\underline{\mathbf{R}})$, PTL administration attenuated mechanical and thermal hypersensitivity after injury and potentiates morphine antinociception. PTL administration increased the protein level of microglial (IBA1), but not astroglial (GFAP), marker, and in parallel reduced the protein level of M1 (IL1, IL-18) and enhanced M2 (IL-10, TIMP1) factors. In (M), repeated and single i.p. PTL administration attenuated mechanical and thermal hypersensitivity after injury. These findings provide an evidence that PTL may play a significant role in the neuropathic pain by modulating spinal neuroimmune interactions by promoting M2 microglia polarization state. The obtained results suggest that it may be an important substance for effective poly-therapy with morphine under neuropathic pain.

This work was supported by the National Science Centre, Poland (OPUS 11 2016/21/B/NZ4/00128) and by statutory funds from the Institute of Pharmacology Polish Academy of Sciences, Department of Pain Pharmacology. Institute of Pharmacology, Polish Academy of Sciences, Department of Pain Pharmacology, Krakow, 31-343, Poland. E-mail: agata.ciechanowska7@wp.pl

\section{THE IN VITRO ADMET PARAMETERS EVALUATION OF E-98 AND E-162-THE HISTAMINE $\mathrm{H}_{3} R$ ANTAGONISTS WITH PROMISING ANTINOCICEPTIVE EFFECTS IN MICE}

\section{G. Latacz, A. Lubelska, M. Kaleta, K. Kieć-Kononowicz}

For many years, the search for more efficacious treatments of pain is a current topic of pharmaceutical sciences. The histamine $\mathrm{H}_{3}\left(\mathrm{H}_{3} \mathrm{R}\right)$ and $\mathrm{H}_{4}\left(\mathrm{H}_{4} \mathrm{R}\right)$ receptors have been recently found to play a role in modulation of nociceptive transmission. Thus, their blockade has become a new target for the development of new analgesics. Indeed, in our recent in vivo studies we observed the antinociceptive potency of two $\mathrm{H}_{3} \mathrm{R}$ antagonists: E-162 with $\mathrm{H}_{3} \mathrm{R} K_{i}=-$ $55 \mathrm{nM}$ and E-98 with $\mathrm{H}_{3} \mathrm{R} \quad K_{i}=180 \mathrm{nM}$ (unpublished data). Taking into account the aforementioned results, we decided to perform the comprehensive in vitro studies to determine the ADMET properties of both $\mathrm{H}_{3} \mathrm{R}$ antagonists. 
The bioavailability was determined using artificial membranes (PAMPA, Corning) and by evaluation of compounds' influence on P-glycoprotein (Pgp) activity (Pgp-Glo ${ }^{\mathrm{TM}}$, Promega). The metabolic stability was investigated using mouse liver microsomes (MLMs). The CYP3A4 P450-Glo ${ }^{\mathrm{TM}}$ assay (Promega) was used to determine the influence on CYP3A4 activity. Moreover, two cell cultures in vitro: HEK-293 and HepG2 were used for preliminary evaluation of compounds' safety.

The calculated permeability coefficient $P e=8.44 \times 10^{-6} \mathrm{~cm} / \mathrm{s}$ for E-162 showed its very good permeability. Unfortunately, the $P e$ of E-98 was not estimated due to its low solubility $>100 \mu \mathrm{M}$. No significant effect on Pgp activity was observed for both compounds. The presence of slight amount of two metabolites of E-162 after incubation with MLMs was found, whereas no metabolites of E-98 were determined. The CYP3A4 slight inhibitory effect at $10 \mu \mathrm{M}(62.9 \%$ of control) was observed for E-162. Both compounds were toxic for HepG2 and HEK-293 cells at the highest used dose $100 \mu \mathrm{M}$. However, a toxic effect of E-98 on HEK-293 viability at $10 \mu \mathrm{M}$ was also observed.

In conclusion, E-162 showed very satisfying ADMET activity, whereas moderate toxicity against HEK-293 and low solubility of E-98 was determined.

Financial support of K/ZDS/007121 is kindly acknowledged

Department of Technology and Biotechnology of Drugs, Jagiellonian University Medical College, Krakow, Poland, Medyczna 9, 30-688 Krakow, Poland. E-mail: glatacz@cm-uj.krakow.pl

\section{NOVEL AND SPECIFIC TARGET FOR SCHIZOPHRENIA-LIKE NEGATIVE SYMPTOMS: HISTAMINE $H_{1}$ RECEPTOR IN BASAL FOREBRAIN CHOLINERGIC NEURONS}

\section{Cheng, L. Wang, W.-W. Hu, Z. Chen}

Currently, all treatments, including second-generation antipsychotics and the newly developed antipsychotics are not highly-efficient or exclusive for the treatment of negative symptoms. Therefore, the challenge remains to identify the exact neuronal function that is critically affected in schizophrenia and what patterns of disconnection lead to the expression of negative symptoms.

The aim of present study is to explore the cell type specific role of histamine $\mathrm{H} 1$ receptor $\left(\mathrm{H}_{1} \mathrm{R}\right)$ in the pathogenesis of negative symptoms in schizophrenia.

We used the Cre-LoxP system to generate mice with a targeted deletion of $\mathrm{H}_{1} \mathrm{R}$ in glutamatergic neurons (CaMKII $\left.\alpha-C r e ; H r h l^{f l / f}\right), \quad$ dopaminergic neurons (DAT-
$\left.\mathrm{Cre} ; \mathrm{Hrhl}^{f l / f l}\right)$, or cholinergic neurons $\left(\mathrm{ChAT-Cre} ; \mathrm{Hrh} \mathrm{l}^{\mathrm{flfl}}\right.$ ) and subjected mice to a battery of behavioral tests for schizophrenia. The underlying circuit mechanism was then studied by the selective re-expression of $\mathrm{H}_{1} \mathrm{R}$ in cholinergic neurons, as well as the chemogenetic approaches.

We report that a selective deletion of the $\mathrm{H}_{1} \mathrm{R}$ in cholinergic neurons resulted in functional deficiency of cholinergic projections from the basal forebrain (BF) to the prefrontal cortex and in the formation of schizophrenia-like negative symptoms, which were rescued by re-expressing $\mathrm{H}_{1} \mathrm{R}$ or by chemogenetic activation in cholinergic neurons in the BF. Direct chemogenetic inhibition of cholinergic neurons not only produced negative symptoms, but also increased susceptibility of experimental mice to positive symptoms. Over-expression of $\mathrm{H}_{1} \mathrm{R}$ in cholinergic neurons in the $\mathrm{BF}$ selectively reversed the negative symptoms in MK-801-induced schizophrenia models. Meanwhile, neither deletion of $\mathrm{H}_{1} \mathrm{R}$ gene in the glutamatergic nor in the dopaminergic neurons evokes such schizophrenia-like behaviors.

Our results suggest that $\mathrm{H}_{1} \mathrm{R}$ could serve as a novel and selective therapeutic target given that functional deficiency of this receptor in $\mathrm{BF}$ cholinergic neurons is crucial for the genesis of negative symptoms in schizophrenia.

This work was supported by the National Natural Science Foundation of China (81872844, 81673405, 81722045), the Zhejiang Provincial Natural Science Foundation of China under Grant No. R17H310002. Institute of Pharmacology \& Toxicology, NHC and CAMS Key Laboratory of Medical Neurobiology, College of Pharmaceutical Sciences, School of Medicine, Zhejiang University, Hangzhou, Zhejiang 310058, P. R. China. Email: chenzhong@zju.edu.cn

\section{HISTAMINE $\mathrm{H}_{2}$ RECEPTOR IN OLIGODENDROCYTE INHIBITS ITS DIFFERENTIATION IN HYPOXIC-ISCHEMIC WHITE MATTER INJURY IN NEONATAL MICE}

\section{Jiang, Z. Chen, W. Hu}

Neonatal hypoxic-ischemic encephalopathy (HIE) leads to life-long cognitive and neurobehavioral dysfunction. The demyelination in the white matter is one of major pathological changes, while the remyelination is quite limited such that effective neurological recovery can not be obtained. The aim of this work is to study the role of histamine $\mathrm{H}_{2}$ receptor $(\mathrm{H} 2 \mathrm{R})$ in hypoxic-ischemic white matter injury in neonatal mice.

Immunofluorescence and RNAscope in situ hybridization were used to confirm the expression of H2R. To investigate the role of $\mathrm{H} 2 \mathrm{R}$ on oligodendrocyte lineage, we 
used adeno-associated virus-mediated overexpression or knockdown of H2R and selective knockout of H2R in preoligodendrocytes (CNPase-Cre; $\left.\mathrm{Hrh}^{f / f f}\right)$ in mice $(n=6-10)$ to explore the role of H2R in oxygen-glucose deprivation injury in vitro and lysolecithin (LPC)-induced demyelination or neonatal hypoxic-ischemic white matter injury model in vivo. We found that the H2R is expressed in all stages of oligodendrocyte in vivo and in vitro. H2R regulates oligodendrocyte differentiation following oxygen-glucose deprivation in vitro and lysolecithin (LPC)induced demyelination in mice, by using adeno-associated virus mediated overexpression or knockdown of the H2R. Selective knockout of $\mathrm{H} 2 \mathrm{R}$ in pre-oligodendrocytes $\left(\mathrm{CNPase}-\mathrm{Cre} ; \mathrm{Hrh}^{f / / f}\right)$ promoted remyelination in a LPCinduced demyelination model by an improvement of oligodendrocyte differentiation, which can be reversed by re-expression of $\mathrm{H} 2 \mathrm{R}$ in pre-oligodendrocytes. CNPase$\mathrm{Cre} ; \mathrm{Hrh}^{f l / f}$ mice $(\mathrm{n}=6)$ also showed improved oligodendrocyte differentiation, myelination, and functional recovery following hypoxia-ischemia. Moreover, activation of H2R inhibits oligodendrocyte differentiation through binding with Axin2 that leads to activate the Wnt/ $\beta$-catenin signaling pathway. Also, we found that $\mathrm{H} 2 \mathrm{R}$ antagonists alleviate the white matter injury and the impairment of cognition and motor coordination following hypoxia-ischemia by a promotion of oligodendrocyte differentiation.

Therefore, we proposed that the H2Rs in oligodenrocytes are a novel target for the treatment of hypoxicischemic white matter injury in neonates through regulating oligodendrocyte differentiation and the $H 2 R$ antagonists have a potential therapeutic value.

This work was supported by the National Natural Science Foundation of China $(81673405,81722045)$, the Zhejiang Provincial Natural Science Foundation of China under Grants No. LR17H310001 and LY18H310003, the Fundamental Research Funds for the Central Universities (2018XZZX002-13).

Department of Pharmacology, NHC and CAMS Key Laboratory of Medical Neurobiology, School of Basic Medical Science, College of Pharmaceutical Sciences, Zhejiang University, Hangzhou, Zhejiang 310058, P. R. China. Email: huww@zju.edu.cn

\section{HISTAMINE N-METHYLTRANSFERASE IN THE BRAIN}

\section{T. Yoshikawa, T. Nakamura, K. Yanai}

Brain histamine is a neurotransmitter and regulates diverse physiological functions. Previous studies have shown the involvement of histamine depletion in several neurological disorders, indicating the importance of drug development targeting the brain histamine system. Histamine $\mathrm{N}$-methyltransferase (HNMT) is a histamine-metabolising enzyme expressed in the brain. Although pharmacological studies using HNMT inhibitors have been conducted to reveal the direct involvement of HNMT in brain functions, HNMT inhibitors with high specificity and sufficient blood-brain barrier permeability have not been available until now. Recently, we reported the phenotyped HNMTdeficient mice to elucidate the importance of HNMT in the central nervous system. HNMT disruption resulted in a robust increase in brain histamine concentration, demonstrating the essential role of HNMT in the brain histamine system. Recent clinical studies suggested that single nucleotide polymorphisms of the human HNMT gene are associated with several brain disorders such as Parkinson's disease and Attention Deficit Hyperactivity Disorder (ADHD). Postmortem studies also have indicated that HNMT expression was altered in human brain diseases. These findings suggest that an increase in brain histamine levels by novel HNMT inhibitors could contribute to the improvement of brain disorders.

Department of Pharmacology, Tohoku University Graduate School of Medicine, Japan. E-mail:yanai@med.tohoku.ac.jp

\section{HISTAMINE $\mathrm{H}_{1}$ RECEPTOR OCCUPANCY MEASURED BY PET IN THE HUMAN BRAIN AFTER ORAL ADMINISTRATION OF DESLORATADINE}

\section{T. Nakamura, T. Yoshikawa, M. Tashiro, N. Okamura, K. Yanai}

Several histamine $\mathrm{H}_{1}$ receptor (H1R) antagonists have sedative side effects, which are caused by the blockade of the neuronal transmission of histamine in the brain. Desloratadine is a newly-marketed antihistamine for the treatment of allergy in Japan, but its sedative properties have not been examined by positron emission tomography (PET) until now. We examined the brain H1R binding potential ration (BPR), H1R occupancy (H1RO) and the subjective sleepiness after oral administration of desloratadine in comparison of loratadine, which is the prodrug of desloratadine. Eight healthy male volunteers (age: $23.2 \pm 1.3$ years old) underwent PET imaging with $\left[{ }^{11} \mathrm{C}\right]$ doxepin, a PET tracer for H1Rs, after a single oral administration of desloratadine $(5 \mathrm{mg})$, loratadine $(10 \mathrm{mg})$, or placebo in a double-blind crossover study. BPRs and H1ROs in the cerebral cortices regions were calculated. Subjective sleepiness was quantified by the Line Analogue Rating Scale and the Stanford Sleepiness Scale. We found 
that after loratadine administration, BPR was significantly lower than placebo administration (loratadine vs. placebo; $\mathrm{p}<0.05$ ), but BPR after desloratadine was not significantly different from that of placebo. Plasma concentration of loratadine was significantly correlated with BPR in subjects treated with loratadine. There was no significant difference, however, between brain H1RO after desloratadine administration (mean $\pm \mathrm{SD}, 6.5 \pm 10.5 \%$ ) and loratadine administration $(13.8 \pm 7.0 \%)$. The subjective sleepiness was not significantly different among the two antihistamines and placebo. At the therapeutic dose, desloratadine did not bind to brain H1Rs and did not cause any significant sedation when compared to loratadine.

This study was funded by Kyorin Pharmaceutical Co., LTD (Tokyo, Japan).

Division of Pharmacology, Faculty of Medicine, Tohoku Medical and Pharmaceutical University, Sendai, Japan. Email: yanai@med.tohoku.ac.jp

\section{PITOLISANT TREATMENT FOR CHILDREN WITH PRADER-WILLI-SYNDROME - A PATIENT STUDY}

\section{L.C. Pullen, M.Picone, L.Tan, C.Johnston, H.Stark}

The EMA has given market approval for pitolisant $\left(\right.$ Wakix $^{\circledR}$ ) for the treatment of narcolepsy with or without cataplexy in 2016 and the FDA is actually considering it as a breakthrough therapy. Published studies suggest that pitolisant has an excellent safety profile with documented adverse events including headache, irritability, anxiety and nausea. From the published pharmacological profile, we hypothesized that pitolisant may be able to improve sleepiness and quality of life in children with PraderWilli-Syndrome (PWS)and tracked patient experience data with pitolisant. Prader-Willi Syndrome (PWS) is another rare disease that is frequently identified by its hallmark symptoms of obesity and hyperphagia. Our database includes ten children (ages 2-16) in the United States who have obtained pitolisant from Europe via personal importation allowed at the discretion of the FDA. The families agreed to document their experience on the TREND Community platform, some for more than two years. Dosing for children with PWS (4.5-31 mg/day) is, in many cases, higher than the $18 \mathrm{mg}$ tested in European clinical trials of children with narcolepsy. All children with PWS started with the lowest possible dose of $4.5 \mathrm{mg} /$ day and increased the dose gradually, as necessary, to combat excessive daytime sleepiness. The children experienced decreased daytime sleepiness, improved night time sleep, as well as improved cognition as evidenced by increased processing speed and improved mental clarity. The promising patient-reported experience suggests that pitolisant may represent a novel therapeutic option to relieve the substantial PWS disease burden.

C. Pullen, M. Picone, L. Tan, C. Johnston, H. Stark. Cognitive Improvements in Children with Prader-WilliSyndrom Following Pitolisant Treatment-Patient Reports J Pediatr Pharmacol Ther2019;24(2): in press. H. Stark. 9thInternational Prader-Willi-Syndrom Organisation Conference (IPWSO), Toronto, Canada (July20-24, 2016), Scientific Abstract Booklet, p. 26 (4.7)

Institute of Pharmaceutical and Medicinal Chemistry, Heinrich Heine University Düsseldorf, Duesseldorf, 40225, Germany.E-mail: h.stark@hhu.de

\section{ENHANCEMENT OF HISTAMINERGIC AND OREXINERGIC SYSTEM ATTENUATES CISPLASTIN-INDUCED ANOREXIA IN MICE}

\section{K. Yamamoto, A. Yamatodani}

Cisplatin-based cancer chemotherapy often induces anorexia. Its insufficient control leads to refusal of subsequent courses of chemotherapy. We report that hypothalamic tumor necrosis factor-alpha (TNF- $\alpha$ ) mRNA expression via histamine $\mathrm{H}_{4}$ receptors contributes to cisplatin-induced anorexia in mice, however, its precise mechanisms remain unclear. It is known that orexin is a neuropeptide that regulates appetite and wakefulness in the hypothalamus. Furthermore, it has been reported that orexin excites the histaminergic neurons and that TNF- $\alpha$ impairs the orexinergic system. From these findings, we investigated the involvement of orexinergic and histaminergic system in the therapeutic effect of an $\mathrm{H}_{4}$ receptor antagonist against cisplatin-induced anorexia.

Mice received cisplatin and JNJ7777120 $\left(\mathrm{an}_{4}\right.$ receptor antagonist) with or without JNJ10397049 (an orexin $\mathrm{OX}_{2}$ receptor antagonist), and their food intake was measured. Additionally, we examined the effect of YNT-185 (an OX receptor agonist), ciproxifan (a histamine $\mathrm{H}_{3}$ receptor inverse agonist), or VUF5681 (an $\mathrm{H}_{3}$ receptor neutral antagonist) on cisplatin-induced anorexia. Finally, we examined the effect of JNJ7777120 on the cisplatin-induced hypothalamic expression of prepro-orexin (PPO) mRNA, which encodes precursors of orexin.

The treatment with JNJ7777120 inhibited cisplatin-induced anorexia in mice, but its therapeutic effect was antagonized by JNJ10397049. Although we observed that both YNT-185 and ciproxifan also inhibited the cisplatininduced anorexia, we found that the inhibitory effect of the YNT-185 was antagonized by VUF5681. Cisplatin decreased the hypothalamic expression of PPO mRNA and the period of expression decreased in parallel with the 
onset of anorexia, however, the treatment with JNJ7777120 completely inhibited the decrease in expression.

The activation of the orexinergic and histaminergic pathway is involved in the therapeutic effect of an $\mathrm{H}_{4}$ receptor antagonist against cisplatin-induced anorexia.

JSPS KAKENHI (Grant Number JP17K08951).

Department of Medical Science and Technology, Division of Health Sciences, Graduate School of Medicine, Osaka University, Suita, Osaka 5650871, Japan. E-mail: kouichi@sahs.med.osaka-u.ac.jp

\section{WHOLE-BRAIN MAPPING OF NEURONAL ACTIVATION IN HISTAMINERGIC NEURONS DURING AVERSIVE MEMORY PHASES}

\author{
A. Franceschini, A. Costa, I. Costantini, B. Rani, \\ G. Mazzamuto, A. P. Di Giovanna, P. Blandina, \\ M. B. Passani, F. S. Pavone, L. Silvestri
}

The understanding of neuronal and molecular behavioural mechanisms that concern fear and stress have received wide coverage in the last years and various preclinical studies have addressed the treatment for patients affected by mental disorders. The central histaminergic system is an important modulator of memory related to adverse events and the use of antihistaminic drugs in the treatment of the abovementioned diseases is being currently studied.

In this context, it is essential to understand the spatiotemporal frames allowing the central histaminergic system to organize behavioural responses associated with adverse events. For this purpose, we analyze whole-brain neuronal activation patterns involved in aversive memory at singlecell resolution, and with special focus on histaminergic neurons.

To this end, we use a transgenic mouse model (FosTRAP) expressing fluorescent protein (tdTomato) in neurons under the c-fos promoter. Mice undergoing a "stepthrough", a standard fear memory paradigm, as mice learn to avoid an electrified cage compartment, are analysed at selected time points (immediately after foot shock, after 1 day, after 1 week). To quantify the presence of c-fospositive cells in an unbiased and comprehensive way, we use the light-sheet microscopy coupled with chemical tissue clearing. This approach does not require sample cutting and allows achieving the three-dimensional extensive mapping of activated neuronal connections of the whole mouse brain. Finally, we selectively label histamine-positive neurons in the clarified Fos-TRAP brains with wholemount immunohistochemistry. In this way, we quantify the number of histaminergic neurons recruited during different memory phases and localize them with high-throughput algorithms.
The combination of behavioral, transgenic, optical and computational methods presented here, represents an important tool to understand which histaminergic pathways are activated during memory formation, consolidation and retrieval.

European Commission, H2020 Research and Innovation Programme, Grant Agreements n. 720270 (HBP-SGA1) and 785907 (HBP-SGA2). Italian Ministry of Education University and Research, Flagship Project "NanoMAX", ESFRI Research Infrastructure Project Euro-Bioimaging, Ente Cassa di Risparmio di Firenze (private foundation). European Laboratory for Non-linear Spectroscopy, 50019, Sesto Fiorentino, Italy. E-mail: franceschini@lens.unifi.it

\section{OLEOYLETHANOLAMIDE REQUIRES BRAIN HISTAMINE TO PREVENT COGNITIVE IMPAIRMENTS INDUCED BY CHRONIC STRESS}

\section{B. Rani, A. Romano, S. D. Schmidt, J. B. Koczwara, P. Blandina, S. Gaetani, M. B. Passani, A. Costa}

Stress is a potent modulator of cognitive function such as learning and memory. Oleoylethanolamide (OEA), a satiety factor secreted by enterocytes that communicates with the brain via afferent vagal fibers, improves memory consolidation in the inhibitory avoidance test and the contextual fear conditioning paradigm. Evidence suggests that endogenous histamine is required for OEA to exerts these central effects.

Here, we investigated the effects of OEA (10 mg/kg i.p.) on altered cognitive functions induced by chronic stress and whether these involve the brain histaminergic system. To this end, mice unable to synthesize histamine due to disruption of the histidine decarboxylase gene $\left(\mathrm{HDC}^{-/-}\right)$ and wild type littermates $\left(\mathrm{HDC}^{+/+}\right)$were subjected to 21 days of Chronic Social Defeat Stress (CSDS). In the CSDS, mice were defeated by an aggressive congener for 21 days and then tested in Social Interaction and Object Recognition (ORT) tests. Mice were treated daily with OEA or vehicle starting on day 10 of stress. Following the CSDS, stressed mice spent less time interacting with the social stimulus compared to non-stressed controls. OEA administration decreased stress-induced social avoidance and ameliorated cognitive performance in the ORT in wildtype mice, but these effects were not observed in $\mathrm{HDC}^{-1-}$ mice. Preliminary data indicate that OEA treatment in stressed animals stimulates oxytocin neurosecretion from the paraventricular nucleus $(\mathrm{PVN})$ of $\mathrm{HDC}^{+/+}$animals, but not of $\mathrm{HDC}^{-/-}$mice.

In conclusion, our data suggest that the integrity of the central histaminergic system is required for OEA to 
prevent cognitive deficits and social aversion induced by chronic stress.

Ambrosiac-JPI a healthy diet for a healthy life. Department of Neurosciences, Psychology, Drug Research and Child Health, University of Florence, 50139, Florence, Italy.E-mail: barbara.rani@unifi.it

\section{HISTAMINE $H_{1}$ RECEPTORS IN NEURAL STEM CELLS ARE REQUIRED FOR THE PROMOTION OF NEUROGENESIS CONFERRED BY $\mathrm{H}_{3}$ RECEPTOR ANTAGONISM FOLLOWING TRAUATIC BRAIN INJURY}

\section{Y. Zheng, R. Liao, X. Zhang, W-W. Hu}

The neurological recovery following traumatic brain injury (TBI) is limited, largely due to a deficiency in neurogenesis. Although histamine has been shown to activate neurogenesis, the role of cell type-specific histamine receptors in neurogenesis is still unclear. Moreover, the direct application of histamine is clinically limited.

The present study explores the effects of histamine $\mathrm{H}_{3}$ receptor $\left(\mathrm{H}_{3} \mathrm{R}\right)$ antagonism on $\mathrm{TBI}$ and mechanisms related to neurogenesis.

Two experimental TBI (cryogenic brain lesion model and controlled cortical impact model) models were employed to investigate the effect of $\mathrm{H}_{3} \mathrm{R}$ antagonism on TBI. Furthermore, we used the Cre-LoxP system to generate mice with a selective deletion of $\mathrm{H}_{1} \mathrm{R}$ and $\mathrm{H}_{2} \mathrm{R}$ in neural stem cells $\left(H r h 1^{f / f} ; \mathrm{Nestin}^{\mathrm{CreERT2}}\right.$ and $H r h 2^{f / f}$; Nestin $^{\text {CreERT2 }}$ ) to investigate which histamine receptors were involved in $\mathrm{H}_{3} \mathrm{R}$ antagonism-induced neurogenesis.

The $\mathrm{H}_{3} \mathrm{R}$ antagonism or $H 3 R$ gene knockout alleviated neurological injury in the late phase of TBI, and also promoted neuroblast differentiation to enhance neurogenesis through activation of the histaminergic system. Histamine $\mathrm{H}_{1}$ receptor, but not $\mathrm{H}_{2}$ receptor, in neural stem cells is essential for this promotion by using $H r h 1^{f l f f}$;Nestin ${ }^{\text {CreERT2 }}$ and Hrh2 $2^{\text {fl/f }} ;$ Nestin $^{\text {CreERT2 }}$ mice. Moreover, increase in mature and functional neurons at the penumbra area conferred by $\mathrm{H}_{3} \mathrm{R}$ antagonism was abrogated in $\mathrm{Hrhl}^{\mathrm{fl}}$ ${ }^{A} ;$ Nestin $^{\text {CreERT2 }}$ mice.

$\mathrm{H}_{3} \mathrm{R}$ antagonism provides neuroprotection against TBI in the late phase through the promotion of neurogenesis, and the $\mathrm{H}_{1}$ receptor in neural stem cells is required for this action. $\mathrm{H}_{3} \mathrm{R}$ may serve as a new target for clinical treatment of TBI.

This work was supported by the National Natural Science Foundation of China (81473186, 81673405, 81722045), the Zhejiang Provincial Natural Science Foundation of China under Grants No. LR17H310001 and
LY18H310003, the Fundamental Research Funds for the Central Universities (2018XZZX002-13).

Department of Pharmacology, NHC and CAMS Key Laboratory of Medical Neurobiology, School of Basic Medical Science, College of Pharmaceutical Sciences, Zhejiang University, Hangzhou, Zhejiang 310058, P. R. China. E-mail:yanrong_zh@zju.edu.cn

\section{ACTIVITY-BASED ANOREXIA IN FEMALE WISTAR RATS-A PILOT STUDY}

M. Kurnik-Łucka, P. Podlasz, P. Stach, K. Skowron, V. Aleksandrovych, K. Wasowicz, A. Baranowska, K. Gil

Routtenberg and Kuznesof (1967) observed that rodents have a tendency to self-starvation when exposed to restricted feeding and voluntary physical activity. As hyperactivity can be observed in a considerable subset of patients with anorexia nervosa (AN), animal models using the combination of a time-restricted feeding schedule and unrestricted physical activity are used to mimic AN.

The aim of the present study was to establish the model of activity-based anorexia (ABA) in our laboratory investigating food intake, voluntary running wheel activity and body weight in female Wistar rats.

Animals weighing 170-220 g upon arrival were housed under controlled conditions and fed with standard chow (Labofeed B, Kcynia, Poland). The study was conducted in accordance with the institutional guidelines (65/2017). After an acclimatization period, rats were randomly assigned to one of the groups ( $\mathrm{n}=8$ each): (1) no extra activity + ad libitum feeding, (2) voluntary activity + ad libitum feeding, (3) no extra activity + restricted feeding, (4) ABA group: voluntary activity + restricted feeding. All cages contained environmental enrichment and bedding material, and were placed adjacent to each other to provide sight, acoustic and odor contact. Body weight, food intake and running activity were monitored until the body weight of the ABA group reached $75 \%$ of their initial weight. Results were analyzed using ANOVA and expressed as mean $\pm \mathrm{SD}$.

ABA rats showed a significant reduction in body weight $(\mathrm{p}<0.01)$ and a reduced daily food intake in comparison to other groups. Physical activity was significantly increased in ABA rats $(24105.4 \pm 7248, \mathrm{p}=0.00786$ vs. $6217.1 \pm 495$ wheel rotations per day).

The ABA model combines voluntary physical activity and time-restricted feeding to reduce body weight. Our data suggest the usefulness of the model to explain pathophysiological alterations occurring in $\mathrm{AN}$, with special regard to the role of biogenic amines in the enteric nervous system. 
Department of Pathophysiology, Faculty of Medicine, Jagiellonian University Medical College, Krakow, Poland. E-mail: magdalena.kurnik@uj.edu.pl

\section{THE INFLUENCE OF KISSPEPTIN ON THE NEUROCHEMICAL PROFILE OF ANORECTIC RATS}

\section{K. Skowron, K. Jasiński, M. Kurnik-Łucka, W. Weglarz, K. Gil}

Anorexia nervosa (AN) is a severe condition affecting $0,9 \%$ of adult females in developed countries. It essentially consists of a restriction of energy intake, intense fear of gaining weight and distortion of the body image. Hypothalamus plays a major role in the regulation of our metabolism sensing peripheral and central signals and activating orexigenic/anorexigenic neuronal responses, mainly mediated by excitatory (e.g. glutamate) or inhibitory (GABA) neurotransmitters. It has been reported, that kisspeptin, a neuropeptide that promotes cooperation of the neurons in hypothalamus region, plays a role in the regulation of the hypothalamic-pituitary-gonadal axis and influences the reproductive functions of the body. Thus, we hypothesized that kisspeptin may form a crucial link between the energy balance of the body and the normal function of gonads in anorectic patients.

Based on the role of the hypothalamus in processes that are believed to be crucial in the development of AN, we focused our research on the metabolic status of this particular region in anorectic rats. We adopted an animal model of AN induced by voluntary physical activity in female Wistar rats and established so-called 'neurochemical profile' of hypothalamus in controls and AN rats using magnetic resonance spectroscopy. We then investigated the effect of subcutaneous administration of kisspeptin $(20 \mathrm{nmol} / \mathrm{rat})$ on the selected metabolites.

Anorexia impaired glutamatergic neurotransmission, leading to a decrease in glutamate concentration and an increase in the glutamine-to-glutamate ratio. A significant decrease was also observed in GABA levels. These changes were accompanied by increased concentrations of glutathione and inositol. Kisspeptin seems to partially restore glutamate and GABA signaling as well as alleviate the fluctuations of other metabolites. These results support our hypothesis that the reduced concentration of kisspeptin participates in the multifactorial pathogenesis of anorexia nervosa.

Department of Pathophysiology, Jagiellonian University Medical College ul. Czysta 18, 31-121 Kraków, Poland. Email: kamil.skowron@uj.edu.pl

\section{TRANSLATIONAL DEVELOPMENT OF SELIFORANT FOR THE TREATMENT OF VERTIGO}

\section{J. Dyhrfjeld-Johnsen}

The current standard of care for acute vestibular vertigo includes a number of drugs which predominantly relieve patients' symptoms through sedation during the crisis. Not only does sedation interfere with normal functioning, but it also delays the mechanism of central vestibular compensation, which is essential for long term recovery of vestibular deficits. Chief amongst currently used drugs are histamine $\mathrm{H}_{1}$ receptor antagonists like meclizine and dimenhydrinate, which are not only sedative but may also interfere directly with central compensation by blocking endogenous histamine agonism of $\mathrm{H}_{1}$ receptors in the vestibular brainstem nuclei.

Seliforant (SENS-111) is a novel, clinical stage, first-inclass histamine $\mathrm{H}_{4}$ receptor antagonist under development for the treatment of acute vestibular vertigo. Preclinical studies have identified the $\mathrm{H}_{4}$ receptor as a promising target for modulation of vestibular ganglion neuron activity, which translates into reduction of vestibular deficit and vertigo symptoms in vivo. Seliforant has demonstrated the ability to significantly reduce translationally valid measures of vestibular imbalance in a rodent model of acute onset vertigo without sedation. The preclinical PK/PD relationships were subsequently confirmed in a phase $1 b$ study in healthy volunteers, using caloric irrigation of the ear canal to induce mild vertigo. Recently, the lack of sedation by Seliforant at exposures consistent with preclinical anti-vertigo activity have been confirmed in a phase $2 \mathrm{a}$, double-blind crossover design study calibrated with meclizine in healthy volunteers. An ongoing phase $2 \mathrm{a}$ double-blind, placebo controlled clinical trial in patients suffering acute unilateral vestibulopathy (AUV) is scheduled to read out in the second half of 2019.

The lecture covered the development of Seliforant from in vitro and in vivo preclinical vertigo models up until the current proof-of-concept, clinical trial stage.

Sensorion Pharma, Montpellier, France. E-mail:jonas.dyhrfjeld-johnsen@sensorion-pharma.com

\section{MAINTAINING CENTRAL HISTAMINE FOR DELIRIUM: AN OPINION}

\section{N. Young, P. L. Chazot, E. Mcauley, L. Johnston, S. Bonner}

Delirium is a very common, but refractory clinical state, notably present in intensive care and in the growing ageing community, with significant occurrence and hospital 
mortality rates of $14-56 \%$ and $25-33 \%$, respectively, as well as functional decline and high morbidity. It is characterized by fluctuating disturbances in a number of key behavioural features, namely cognition, mood, attention, arousal, and self-awareness. Arousal stems from the wakefulness of a person and awareness is the individual's ability to perceive his/her environment.

Histamine is arguably the most pleotropic neurotransmitter in the mammalian/human brain, and we propose that this neuroactive amine plays a key role in modulating the characteristic features of, and provide a rationale for treating, delirium. For example, diminished alertness, delayed reaction times, and somnolence are common manifestations of allergy treatments with the use of classic first-generation (CNS-penetrating) histamine $\mathrm{H}_{1}$ antagonists. Therefore, giving evidence that histamine is required for arousal/wakefulness and awareness/attention. While centrally-penetrating histamine $\mathrm{H}_{1}$ and $\mathrm{H}_{2}$ receptor antagonists have pro-delirium potential and are often avoided in the clinic, we provide an anatomical, pharmacological and physiological rationale for developing a CNS-permeable $\mathrm{H}_{3}$ histamine receptor antagonist/inverse agonist (e.g. Wakix $^{\mathrm{TM}}$ ) as a strategy for combatting the full range of delirium symptoms. Cortical activation (EEG desynchronization) is one of the salient signs of wakefulness, attention and enhanced cognitive function, and requires high histaminergic, and cholinergic, noradrenergic, and serotonergic tones, controlled by $\mathrm{H}_{3}$ auto- and heteroreceptor action, respectively. The histamine $\mathrm{H}_{4}$ receptor may also have an indirect inflammatory neuroglial role which requires further exploration.

Department of Biosciences, Durham University, Durham, DH13LE,UK.E-mail: paul.chazot@durham.ac.uk 
Immunological aspects of histamine 


\section{INHIBIT ACTIVATION OR ACTIVATE INHIBITION OF MAST CELLS AND EOSINOPHILS: WHICH WEAPON IS BETTER TO FIGHT ALLERGIC DISEASES?}

\section{F. Levi-Schaffer}

The pivotal effector cells of allergic inflammation are mast cells and eosinophils. Mast cells, as activated by $\operatorname{IgE}$ mechanisms via allergens, are the recognized primum movens while eosinophil infiltration and persistence in the inflamed tissue with the mast cells are the accepted features of the late stage and of the chronic outcome of allergy.

Over the years we have defined a pro-inflammatory cross-talk between these two cells that we have named the Allergic Effector Unit (AEU). We found that mast cell/ eosinophil interactions result in increased eosinophil chemotaxis, survival, degranulation, cytokine production and in mast cell survival, IgE-dependent and independent degranulation and cytokine production. These effects are mediated by both released mediators (soluble interactions) and by receptor/ligands binding (physical interactions). Prominent players of the activating "physical" AEU are the two activating receptors (ARs)/ligands CD48 and 2B4. Nevertheless, we have also described the presence and functional activity of two inhibitory receptors (IRs), i.e. CD300a and Siglec-7, on mast cells and on eosinophils that can indicate a possible anti-inflammatory or even pro-resolution activity within the AEU and globally as mediated by mast cells and by eosinophils.

The goal of our research is to define potential new targets for immunopharmacological intervention in allergic diseases by blocking ARs, i.e. CD48, or by activating IRs, i.e. CD300a and Siglec-7. We indeed found that CD48 is significantly upregulated in human and murine asthma on mast cells and eosinophils and in the presence of S. aureus, the prominent bacteria infecting atopic tissues. We have therefore studied CD48 modulation in vitro and in vivo and the outcome of its blockade and found that CD48 is a key player in allergic diseases. Similarly, we have found that CD300a and Siglec-7 are expressed by eosinophils and mast cells of allergic patients and described their role in downregulating these cell functions.

Thus, our strategy is to treat allergy by inhibiting activation and/or by activating inhibition of mast cells, eosinophils and the AEU. Translationally this strategy will have to take into account the allergic patient endotype.

The Hebrew University of Jerusalem, Jerusalem, Israel. Email: francescal@ekmd.huji.ac.il

\section{COMBINATION THERAPY OF ALLERGIC RHINITIS TO A HIGH-DEGREE BY SUPPRESSING HISTAMINE $H_{1}$ RECEPTOR-PKC DELTA AND NFAT SIGNALINGS}

\author{
H. Fukui, H. Mizuguchi, Y. Kitamura, N. Takeda
}

Antihistamines are used for the therapy of allergic rhinitis by suppressing histamine $\mathrm{H}_{1}$ receptor (H1R) signaling. However, their drug effects are not satisfactory. Allergic rhinitis was thought to consist of antihistamine-sensitive and -insensitive mechanisms. H1R-mediated up-regulation of H1R was discovered through H1R gene expression and was thought to exacerbate rhinitis symptoms.

Correlation between nasal symptom scores and H1R mRNA level at nasal mucosa was observed via clinical trial with pollinosis patients, thereby suggesting the H1R gene to be rhinitis-sensitive. The treatment of allergic rhinitis in a rat model with either the anti-histamine, epinastine, or Kujin, an anti-allergic Kampo medicine, showed a similar alleviation, thereby, suggesting a common drug efficacy of the two medicines. The molecular mechanism of H1R upregulation was elucidated. Protein kinase C-delta showed an important role in up-regulation due to the complex of protein kinase C-delta and heat shock protein 90 being targeted by (-)maackiain, an active compound of Kujin. However, only partial alleviation of allergic rhinitis, by the treatment of antihistamine, was observed in the rhinitis rat model, although, H1R mRNA level was reversed to control level. The remaining symptoms were supposed to reflect antihistamine-insensitive mechanism. Combination treatment of either Awa-tea or lotus extract and an antihistamine highly alleviated symptoms in the rat model. Up-regulation of IL-9 mRNA was observed, with both Awa-tea and lotus extract suppressing up-regulation, suggesting that IL-9 gene is the second rhinitis sensitive-gene. Two active compounds were identified from Awa-tea and lotus extract. Pyrogallol isolated from Awa-tea, suppressed IL-9 gene expression in RBL-2H3 cells.

Combination treatment with suppressors of H1R gene expression and IL-9 gene expression are potential novel therapies of allergic rhinitis.

Tokushima University Graduate School of Biomedical Sciences, Tokushima, 770-8503, and Osaka Ohtani University, Faculty of Pharmaceutical Sciences, Tondabayashi, 584-8540, Japan.E-mail: hfukui@tokushimau.ac.jp 


\section{ROLE OF MICROBIAL-DERIVED HISTAMINE IN MUCOSAL INFLAMMATION}

\section{O'Mahony}

The microbiota on mucosal surfaces is increasingly being recognized to play an essential role in host development and in particular for inducing immune homeostatic networks. In addition to the taxonomic diversity of the microbiota, its metabolic activity has profound effects on the induction of immune tolerance. Accumulating evidence suggests that certain bacterial strains and their associated metabolites may provide disease protective signals while other bacterial strains may stimulate aggressive and tissue damaging immune responses. Thus, the activity of the mammalian immune system seems to be governed by the balance between symbiotic and pathogenic factors derived from our microbial inhabitants. Histamine and its four receptors represent a complex system of immunoregulation with distinct effects dependent on receptor subtype expression and activity. The role for differential expression or activation of histamine receptors on immune competent cells in chronic inflammatory diseases is still poorly described to date and further examination of this potent immunoregulatory network will likely lead to a better understanding of these disorders. Interesting, many gut resident bacterial strains produce histamine and their levels are increased in the gut of asthma patients. More accurate endotyping of asthma patients (and other chronic inflammatory disorders) may be assisted by further analysis of the composition and metabolic activity of an individual's microbiome and future clinical studies of new therapeutic agents should consider performing microbiome and metabolite analysis to determine if specific microbiome features correlate with responses to treatment. In addition, therapeutics directly targeting microbiome activities, such as histamine secretion, may be considered as complementary to existing drugs.

University College Cork, Ireland. E-mail: liam.omahony@ucc.i.e.

\section{LYSOPHOPHATIDIC ACID INDUCES HISTAMIE RELEASE FROM HUMAN BASOPHILS}

\section{B. F. Gibbs, M. M. Limberg, N. H. Meyer, B. Homey,} A. U. Bräuer, U. Raap

There is increasing evidence to suggest that the phospholipid derivative lysophosphatidic acid (LPA) regulates itch and inflammation. LPA has recently been considered as a biomarker for asthma and has been reported to stimulate histamine release from mast cells. Since basophils are also a major source of histamine and other pro-allergic and pruritic mediators, such as IL-31, our aims were to address whether LPA affects basophil activation and mediator release. Human primary basophils were isolated from buffy coat blood and purified to over $90 \%$ purity by Ficoll-density centrifugation followed by immunomagnetic cell sorting. Basophils were prewarmed at $37^{\circ} \mathrm{C}$ for $15 \mathrm{~min}$ before stimulation with either LPA $(0.1-10 \mu \mathrm{M})$, anti-IgE $(1 \mu \mathrm{g} / \mathrm{ml})$, fMLP $(1 \mu \mathrm{M})$ or buffer alone for $30 \mathrm{~min}$, after which histamine releases were assessed by spectrofluorometric autoanalysis. Our results demonstrate that LPA $(\geq 1 \mu \mathrm{M})$ resulted in significant release of histamine from basophils (maximally $21 \%$ net histamine release; $p<0.01$, $\mathrm{n}=7$ ). This was comparable to anti-IgE-induced histamine release in some donors but less than that seen with fMLP. Interestingly, basophils expressed the transient receptor potential vanilloid 1 (TRPV1) ion channel which, in addition to LPA receptors, is known to be activated by LPA. This suggests that basophils share key activation pathways with sensory nerves involved in pruritus. Overall, our findings indicate that LPA plays an important role in basophil activation and further underlines the potential inflammatory and pruritic input of basophils in allergic inflammation and other basophil-dependent disorders.

Division of Experimental Allergology and Immunodermatology, Carl von Ossietzky University of Oldenburg, 26129 Oldenburg, Germany. E-mail: bernhard.gibbs@unioldenburg.de

\section{A NEW CLASS OF HYBRID COMPOUNDS WITH ANTI-INFLAMMATORY AND CARBONIC ANHYDRASE INHIBITION EFFECTS}

\section{Lucarini, M. Durante, S. Sgambellone, A. Nocentini,} S. Bua, C. T. Supuran, E. Masini

Carbonic anhydrases (CA), the enzymes catalyzing the hydration of $\mathrm{CO}_{2}$ to bicarbonate and protons, have been identified as potential therapeutic targets for the treatment of several inflammatory diseases. Hybrid molecules composed of nonsteroidal anti-inflammatory drug molecules and carbonic anhydrase inhibitor hybrids (NSAIDs-CAIs) exhibit anti-inflammatory effects in terms of potency and time when compared to the reference drug ibuprofen.

The aim of this study was to investigate the pharmacological profile of novel NSAID-CAIs in the modulation of inflammation, through COX-1 and COX-2 inhibition, and histamine release.

The macrophage cell line (RAW 264.7) was incubated for $18 \mathrm{~h}$ with LPS $(1 \mu \mathrm{g} / \mathrm{mL})$ and pre-treated or not with different concentrations of the studied drugs $(1 \mu \mathrm{M}$ to $100 \mu \mathrm{M})$. Prostaglandin $\mathrm{E}_{2} \quad\left(\mathrm{PgE}_{2}\right)$ production was 
quantified in macrophage medium. Thromboxane $\left(\mathrm{TXB}_{2}\right)$ levels and the inhibition of platelet aggregation were measured in human platelet-rich plasma (PRP).

Guinea pigs were sensitized with ovalbumin and serosal mast cells, collected 15 days after sensitization, were exposed to drugs for $30 \mathrm{~min}$ at $37{ }^{\circ} \mathrm{C}$ and stimulated for 30 min with ovalbumin, to evaluate the role of these hybrid molecules in histamine release.

Our results show that $\mathrm{PgE}_{2}$ production is lowered dosedependently $(p<0.05)$ in LPS-stimulated RAW 264.7 cells treated with NSAID-CAI compounds, while, even at the highest concentrations tested $(100 \mu \mathrm{M})$, these drugs do not modify the inhibition of platelet aggregation and the production of $\mathrm{TXB}_{2}$ in comparison with the reference molecules. The SB2-120B compound, one of the most active drugs derived from ibuprofen, decreased the immunological release of histamine from serosal mast cells.

In conclusion, our findings provide evidence that these NSAID-CAI hybrid compounds are valuable tools for the management of inflammation, suggesting a novel therapeutic approach to prevent inflammatory diseases.

Department of NEUROFARBA, Section of Pharmacology and Toxicology, Section of Pharmaceutical and Nutraceutical Sciences, University of Florence, Florence, Italy.E-mail: laura.lucarini@unifi.it

\section{HISTAMINE UP-REGULATES ONCOSTATIN M EXPRESSION IN HUMAN MACROPHAGES}

\section{S. Mommert, M. Hüer, K. Schaper-Gerhardt, R. Gutzmer, T. Werfel}

Human monocyte derived M1 macrophages develop in relation to growth factors, bacterial products and cytokines in a local microenvironment. M1 macrophages produce pro-inflammatory mediators, in particular, oncostatin $\mathrm{M}$ (OSM) which is secreted from the cells in response to the active complement component C5a. Since C5a fosters the release of histamine from human mast cells and shows immune modulatory functions similar to histamine in the regulation of IL-12 cytokine family expression, we investigated the influence of histamine on OSM expression in human M1 macrophages. The cytokine expression was analyzed by real time quantitative PCR and ELISA technique. Normal human epidermal keratinocytes were stimulated with supernatants from activated M1 macrophages and phosphorylation of STAT3 was assessed by flow cytometry in 6 independent experiments from 6 different donors.

OSM mRNA expression was highly up-regulated by histamine $(\mathrm{p}<0.05)$ and agonists targeting the H1R, H2R and H4R $(10 \mu \mathrm{M})$ in human M1 macrophages as well as by C5a $(10 \mathrm{ng} / \mathrm{ml})$ which was used as control stimulus. OSM ( $p<0.01)$ and also IL-6 ( $<<0.05)$ were up-regulated by histamine $(10 \mu \mathrm{M})$ at protein level. Supernatants from histamine-stimulated fully differentiated M1 macrophages were able to phosphorylate STAT3 to a higher degree in normal human epidermal keratinocytes $(\mathrm{p}<0.05)$ when compared to supernatants from non-stimulated M1 macrophages.

The up-regulation of OSM expression in response to histamine and $\mathrm{C} 5 \mathrm{a}$ shown in this study provides further evidence that histamine and C5a targeting their G-protein coupled receptors have almost equal functional effects in cells of the monocyte lineage. Both mediators OSM and IL-6 have the capability to activate human keratinocytes. These effects may have an influence on the course of inflammatory skin diseases.

This study was supported by grants from the Deutsche Forschungsgemeinschaft DFG: Gu434/6-2. Funding for this research was provided by Janssen Research \& Development, LLC.

Division of Immunodermatology and Allergy Research, Department of Dermatology and Allergy, Hannover Medical School, Hannover, German. E-mail:mommert.susanne@mh-hannover.de

\section{IMPLICATION OF CIRCULATING HISTAMINE IN PSORIASIS: BASIC AND CLINICAL PERSPECTIVE}

\section{K. Gerasimidou, A. Kavallari, M. Kakolyri, E. Tiligada}

Approximately $2 \%$ of the global population is affected by psoriasis with an estimated prevalence in Europe of $\sim 2$ to $4 \%$. The pathogenesis of psoriasis lies in the functional dysregulation of immune cells, whereas the role of histamine and of circulating blood cells in inflammatory diseases is well-established. This study aimed (i) to compare the histamine levels in the peripheral whole blood and plasma of patients with psoriasis and of healthy volunteers; and (ii) to evaluate the association between circulating histamine levels, peripheral complete blood count (CBC) and the clinical manifestations of the disease. Peripheral whole blood and plasma were collected from psoriasis patients (Group $A, n=6$ ) and healthy volunteers, serving as control (Group $\mathrm{B}, \mathrm{n}=10$ ), after obtaining written informed consent. Healthy volunteers reported no disease or medication intake in the recent past. The samples were stored at $-80{ }^{\circ} \mathrm{C}$ until the fluorophotometric histamine qualification. CBC was tested by an ISO 9001:2008 certified diagnostic laboratory. The results were analyzed using IBM SPSS v.25. Whole blood and plasma histamine levels were lower $(P<0.05)$ in Group A $(11.4 \pm 5.2 \mathrm{ng} / \mathrm{mL} \&$ 
$3.5 \pm 2.1 \mathrm{ng} / \mathrm{mL}$, respectively) compared to Group B $(21.4 \pm 11.1 \mathrm{ng} / \mathrm{mL} \& 6.4 \pm 2.3 \mathrm{ng} / \mathrm{mL}$, respectively). In Group A, whole blood histamine levels were significantly higher $(P<0.05)$ than the respective plasma levels. No significant differences $(P>0.05)$ were observed in the CBC between Groups A and B, apart from the neutrophilic profile of psoriasis patients with respect to the white blood cell count. Data analysis showed that the distribution of basophil counts differed across Groups A and B. The reduced whole blood and plasma histamine levels in patients with psoriasis are indicative of the implication of a putative peripheral histamine secretion modulatory mechanism, whereas, the CBC findings suggest that basophils may contribute to the pathobiology of the disease.

This work was supported by NKUA SARG 10441. National and Kapodistrian University of Athens, Athens, 11527, Greece.E-mail: gerkorina@gmail.com

\section{WHY IT IS A GOOD IDEA TO PERFORM PHARMACOLOGICAL STUDIES ON HUMAN PRIMARY CELLS-THE STORY OF DL-76 THE HISTAMINE $\mathrm{H}_{3}$ LIGAND}

\section{Grosicki, M. Adam, C. Micheloni, S. Chtopicki, D. Łażewska, M. Więcek, K. Kieć-Kononowicz}

DL-76 is a newly synthesized piperidine derivative with nanomolar concentration affinity towards the histamine $\mathrm{H}_{3}$ receptor $\left(\mathrm{H}_{3} \mathrm{R}\right)$. Using in vivo assays, this compound acted as a potent $\mathrm{H}_{3} \mathrm{R}$ antagonist (e.g. modulating $\mathrm{N}^{\tau}$-methylhistamine level in the brain cortex of Swiss mice after oral treatment). Furthermore, this compound exhibited low affinity towards $\mathrm{H}_{4} \mathrm{R}$. These data show that DL-76 is an interesting compound, which could be used for further drug development. However, more studies are required.

Since the $\mathrm{H}_{3} \mathrm{R}$ is closely related to $\mathrm{H}_{4} \mathrm{R}$, the activity of DL-76 against $\mathrm{H}_{4} \mathrm{R}$ was examined using the human eosinophils adhesion to endothelium assay. Furthermore, these studies were backed up with additional in vivo tests.

For the adhesion assay, a highly purified eosinophil population was isolated from human peripheral blood. The compound's effect on eosinophil adhesion to endothelium was evaluated during eosinophil co-culture with the human Ea.hy.926 endothelial cell line, under static conditions. DL-76 was also studied in a murine model of skin inflammation and pruritus.

Unexpectedly, DL-76 significantly and in a dose-dependent manner downregulated the number of adherent eosinophils to endothelial cells. The investigated compound was active both in the presence and in the absence of histamine in the assay $\left(\mathrm{IC}_{50}=72,79 \mathrm{nM}\right.$ in presence of histamine and $\mathrm{IC}_{50}=211,9 \mathrm{nM}$ in the absence of histamine respectively). The results were in the complete opposition with $\mathrm{H}_{3} \mathrm{R}$ ligand used in the assay-pitolisant. Interestingly, DL-76 activity was confirmed by in vivo anti-inflammatory and anti-pruritic effects. DL-76 significantly reduced croton oil induced ear edema and pruritus in CD-1 mice These data clearly demonstrate the usefulness of primary human cell studies, which can provide additional data on the evaluated ligands. Furthermore, this is the first report that DL-76 exhibits anti-inflammatory properties.

Supported by: DEC/2014/13/N/NZ7/00897 and DEC/ 2011/02/A/NZ4/00031.

Jagiellonian University Medical College, Faculty of Pharmacy, Department of Technology and Biotechnology of Drugs, 30-688 Cracow, Poland. E-mail: grosicki@gmail.com

\section{CD300a EXPRESSION IS MODULATED IN ATOPIC DERMATITIS AND COULD INFLUENCE THE INFLAMMATORY REPSONSE}

\author{
L. Karra, R. S. Gangwar, P. G. Puzzovio, N. Fyhrquist, \\ Y. Minai-Fleminger, N. Landolina, T. Levi, D. Mankuta, \\ H. Simon, H. Alenius, V. Leibovici, D. Simon, \\ F. Levi-Schaffer
}

CD300a is an inhibitory receptor (IR) expressed and functional on mast cells (MCs) and eosinophils (Eos), pivotal cells together with $S$. aureus (SA) in atopic dermatitis (AD). However, CD300a expression and function have not yet been explored in AD.

We aimed to study CD300a expression in AD lesional skin (LES) and peripheral blood, and in vitro on human MCs and Eos. Moreover, CD300a role was investigated in a murine model of $\mathrm{AD}$ and of staphylococcal enterotoxin $\mathrm{B}$ (SEB)-induced peritonitis.

LES from AD patients $(n=91)$ or normal skin (NS) from healthy volunteers $(\mathrm{n}=126)$, and peripheral blood (PB) leukocytes (control $\mathrm{n}=14-20$, AD $\mathrm{n}=8-10$ ) were stained for cell-specific CD300a expression. AD skin biopsies were also stained for HIF-1 $\alpha$ and PECAM1. Human cord blood-derived MCs (CBMCs) and PBEos were incubated under hypoxia or with SA toxins $(10 \mu \mathrm{g} /$ $\mathrm{ml}$ ), and CD300a expression was evaluated. Murine models of $\mathrm{AD}$ (epicutaneous sensitization with Ovalbumin/SEB, $2 \mathrm{mg} / \mathrm{ml}$ and $100 \mu \mathrm{g} / \mathrm{ml}$ respectively) or SEB-peritonitis $(0.005 \mu \mathrm{g} / \mu \mathrm{l})$, were induced in Wild Type (WT) and

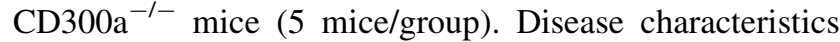
and inflammatory parameters were assessed.

CD300a expression on Eos in AD LES in comparison to NS was significantly higher $(p<0.0001)$, together with increased HIF- $1 \alpha$ expression on Eos $(p<0.0001)$ and augmented vascularity $(\mathrm{p}<0.01)$. In $\mathrm{PB}$ of $\mathrm{AD}$ patients, 
CD300a increased on B cells and decreased on NK cells. SA toxins upregulated CBMCs and PBEos CD300a expression. In murine $\mathrm{AD}, \mathrm{CD} 300 \mathrm{a}^{-1-}$ mice presented increased Eos $\left(\mathrm{CD}_{300 \mathrm{a}^{-1-}} \mathrm{OVA} / \mathrm{SEB}=19.94 \pm 0.69\right.$; $\mathrm{WT} \mathrm{OVA} / \mathrm{SEB}=11.66 \pm 1.16)$ and $\mathrm{MC}\left(\mathrm{CD} 300 \mathrm{a}^{-/-}\right.$ OVA/SEB $=17.12 \pm 1.2 ; \quad$ WT $\quad$ OVA/SEB $=10.78 \pm$ $0.68)$ numbers and thickened dermis $\left(\mathrm{CD}_{300 \mathrm{a}^{-/}} \mathrm{OVA} /\right.$ $\mathrm{SEB}=510.7 \pm 25.17 \mu \mathrm{m} ; \quad \mathrm{WT} \quad$ OVA/SEB $=400.7 \pm$ $45.34 \mu \mathrm{m})$, together with higher levels of Th2 cytokines. Moreover, due to its role in keratinocytes differentiation and skin barrier function, we also examined expression of IL-22 in the AD model. Interestingly, no expression of IL22 was found in any of the experimental groups. In murine
SEB-induced peritonitis, higher total cells and Eos numbers were found in CD300a $\mathrm{a}^{-1-}$ mice.

In conclusion, CD300a expression and function are modulated in the AD microenvironment. We can infer that CD300a has a downregulatory role in AD inflammation.

Support from Israel Science Foundation (ISF, 472/15) and Rosetrees Trust (UK) to F.L-S is gratefully acknowledged.

Pharmacology and Experimental Therapeutics Unit, Institute for Drug Research, School of Pharmacy, Faculty of Medicine, The Hebrew University of Jerusalem, Jerusalem, 91120, Israel.E-mail:piergio.puzzovio@mail.huji.ac.il 
Histamine $\mathrm{H}_{3}$ and $\mathrm{H}_{4}$ receptor 


\section{PLASTICITY OF THE BRAIN HISTAMINE SYSTEM IN HEALTH AND DISEASE}

\section{P. Panula}

Brain histamine neurons increase in number in narcoleptic patients whereas the hypocretin neuron numbers decrease. In Parkinson's disease, histamine levels increase in those areas where dopaminergic neurons degenerate. It is currently unknown if these changes are neuroprotective or harmful, and the mechanisms are poorly understood. We have addressed these questions using zebrafish as a tool. The results indicate that translation inhibition of tyrosine hydroxylase 2 , which decreases dopamine levels to $50 \%$ of normal, induces an increase in the number of histamine neurons. Treatment of the zebrafish larvae with dopamine precursor L-DOPA or dopamine receptor agonists decreases the number of histamine neurons. These results support the concept that dopamine directly or indirectly regulates the number of histamine neurons. Experiments with zebrafish lacking presenilin 1, a component of the gammasecretase complex, regulates the number of histamine neurons throughout the lifespan of zebrafish. To test the possibility that the increase of histaminergic neurons in narcolepsy is causally related to degeneration of hypocretin neurons, and which histamine receptor is responsible for interactions between these cells, we counted histamine neurons in histamine $\mathrm{H}_{3}$ receptor (hrh3) knock-out zebrafish. There were fewer hypocretin neurons in larval hrh3 KO fish than in wild-type fish at the same stage. This suggests that hrh3 may be important in histaminergic control of hypocretin neurons. Our current studies are aimed at understanding the role of hypocretin neurons in regulation if histaminergic system using a conditional hypocretin $\mathrm{KO}$ zebrafish model, and similar experiments using different mouse models.

Supported by the Academy of Finland, Jane and Aatos Erkko Foundation, Sigrid Juselius foundation, Finska Läkaresällskapet, Magnus Ehrnrooth's Foundation.

Department of Anatomy, University of Helsinki, Haartmaninkatu 8, 00290 Helsinki, Finland. E-mail:pertti.panula@helsinki.fi

\section{LACK OF HISTAMINE $\mathrm{H}_{4}$-RECEPTOR EXPRESSION PROTECTS MICE FROM CHEMICALLY INDUCED INFLAMMATION ASSOCIATED WITH COLON CARCINOMA}

\section{T. Rother, B. Schirmer, R. Seifert, D. Neumann}

Patients suffering from inflammatory bowel diseases (IBD) have an increased risk to develop colorectal cancer (CRC).
In our previous studies, we demonstrated that the blockade of the histamine $\mathrm{H}_{4}$ receptor $\left(\mathrm{H}_{4} \mathrm{R}\right)$ function by either genetic or pharmacological manipulation ameliorates the outcome of dextran sodium sulfate (DSS)-induced colitis in mice, a model for IBD. In the present study, we aimed to analyze whether the $\mathrm{H}_{4} \mathrm{R}$ function also affects the course of colitis-associated CRC.

CRC was induced in wild type (WT) and in $\mathrm{H}_{4} \mathrm{R}$-deficient (KO) mice by i.p. application of a single dose of azoxymethan (AOM) followed by three 7-day cycles of DSS feeding separated by 14 days without treatment. Parameters indicative for disease activity were monitored throughout the whole treatment period. At the end of the third DSS cycle, the mice were killed and cola were prepared for analyses. Colonic tumor burden and markers indicative for tumors (COX2, NOS2) and inflammation (CXCL1, CXCL2) were analyzed.

Lack of $\mathrm{H}_{4} \mathrm{R}$ expression led to reduced overall disease activity in the AOM + DSS-treated mice. Moreover, the number and the diameter of tumors in the distal cola significantly were reduced in $\mathrm{KO}$ mice as compared to WT mice (total number of tumors: $12 \pm 2$ vs. $42 \pm 11$, respectively; number of tumors with diameter $>2 \mathrm{~mm}$ : $10 \pm 2$ vs. $29 \pm 11$, respectively). Similar results were obtained for the relative mRNA expression of COX2 (KO: $1.1 \pm 0.9$; WT: $4.8 \pm 0.9$ ) and of NOS2 (KO: $0.5 \pm 0.3$; WT: $1.6 \pm 0.5$ ), and, albeit statistically not significant, of CXCL1 and CXCL2.

We conclude that the $\mathrm{H}_{4} \mathrm{R}$ is functionally involved in the tumorigenesis of experimental CRC in mice. Whether the $\mathrm{H}_{4} \mathrm{R}$ may serve as a useful target in the therapy of human $\mathrm{CRC}$ has to be elucidated in the future.

Institute of Pharmacology, Hannover Medical School, D-30625 Hannover, Germany. E-mail: neumann.detlef@MH-Hannover.de

\section{ANTINOCICEPTIVE EFFECTS OF A NOVEL HISTAMINE $\mathrm{H}_{3}$ RECEPTOR ANTAGONISTS IN MOUSE MODEL OF NEUROPATHIC PAIN}

K. Popiolek-Barczyk, D. Lażewska, G. Latacz, A. Olejarz, H. Stark, W. Makuch, K. Kieć-Kononowicz, J. Mika

The weakening effect of the analgesics in neuropathic pain therapy has led scientists to seek new drugs. Histamine $\mathrm{H}_{3}$ receptor has emerged as promising targets for pharmacological intervention. The aim of our study was to investigate the impact of newly synthesized $\mathrm{H}_{3} \mathrm{R}$ antagonists E-162 (1-(5-(naphthalen-1-yloxy)pentyl)piperidine) and/or E-98 (1-(7-(4-chlorophenoxy)heptyl)-3-methylpiperidine) on mechanical (von Frey) and thermal (cold plate) stimuli in preclinical model of neuropathy (CCI, 
chronic constriction injury) in mice (Albino Swiss), along with the possible participation of $\mathrm{H}_{1} \mathrm{R}$ in these effects. Then, we analyzed the effect of $\mathrm{H}_{3} \mathrm{R}$ antagonists on the effectiveness of morphine and buprenorphine. Differences between males and females in nociceptive perception have been suggested, therefore, here we also analysed sex-dependent action of $\mathrm{H}_{3} \mathrm{R}$ antagonist. We investigated the effects of repeated E-98 injections on the symptoms of neuropathy and in biochemical study (protein analysis by Western blot) we evaluated its effect on the microglia activation in the spinal cord of mice. Single intraperitoneal (i.p.) injections of E-162 (1, 5, 10, $20 \mathrm{mg} / \mathrm{kg}, \mathrm{n}=6-8)$ and E-98 $(1,10,20 \mathrm{mg} / \mathrm{kg}, \mathrm{n}=5-8)$ compounds reduced nociception. Moreover, E-98 (10 mg/kg, i.p., $\mathrm{n}=7-8)$ increased the effectiveness of morphine $(5 \mathrm{mg} / \mathrm{kg}$, i.p., $\mathrm{n}=8)$, but not buprenorphine $(1 \mathrm{mg} / \mathrm{kg}$, i.p., $\mathrm{n}=7)$, in neuropathic animals. We also revealed that intrathecal (i.t.) administration of E-98 (30 $\mu \mathrm{g} / 5 \mu \mathrm{l} ; \mathrm{n}=7-8)$ also has antinociceptive properties. $\mathrm{H}_{3} \mathrm{R}$ antagonist-induced antinociception was reversed after pyrilamine $\left(\mathrm{H}_{1} \mathrm{R}\right.$ antagonist; $10 \mu \mathrm{g} / 5 \mu \mathrm{l}$, i.t., $\mathrm{n}=7$ ) pretreatment. Moreover, E-162 $(10 \mathrm{mg} / \mathrm{kg}$, i.p., $\mathrm{n}=7)$ has stronger and long-lasting antinociceptive effects in females. E-98 $(10 \mathrm{mg} / \mathrm{kg}$, i.p., $\mathrm{n}=8$ ) administered repeatedly for 6 days also showed antinociceptive effects. Biochemical analysis $(n=6-8)$ showed that it decreased the level of Iba-1 protein (a marker of microglial cells activation) at the level of the spinal cord. Our research provided evidence of the antinociceptive effects of $\mathrm{H}_{3} \mathrm{R}$ antagonists, and also showed that targeting $\mathrm{H}_{3} \mathrm{R}$ can potentiate morphine antinociception, which is consistent with multimodal pain therapy. We have also evaluated sex-dependent differences in E-162 action, which has stronger and long-lasting analgesic effects in neuropathic females. Moreover, reduced activation of microglial cells after repeated $\mathrm{H}_{3} \mathrm{R}$ antagonist administrations suggest that this receptor may modulate neural-glial interactions.

This student was the runner-up in the Young Investigators Award (2019).

This work was financed by grants from the National Science Center, Poland (MAESTRO 2011/02/A/NZ4/ 00031 and OPUS 2016/21/B/NZ4/00128).

Institute of Pharmacology, Polish Academy of Sciences, Department of Pain Pharmacology, Krakow, 31-343, Poland.E-mail: popiolek@if-pan.krakow.pl

\section{CROSS-TALK BETWEEN HISTAMINE $\mathrm{H}_{4}$ RECEPTOR $\left(\mathrm{H}_{4} \mathrm{R}\right)$ AND $\mathrm{A}_{3}$ ADENOSINE RECEPTOR (A A $\left._{3} \mathrm{AR}\right) \mathrm{ON} \mathrm{CD4}^{+} \mathrm{T}_{\text {CELLS IN }}$ RESOLUTION OF NEUROPATHIC PAIN STATES}

\author{
M. Durante, L. Lucarini, MD. Sanna, C. Ghelardini, \\ L. Di Cesare Mannelli, R. Thurmond, E. Masini
}

Neuropathic pain is a severe clinical problem and a chronic debilitating condition which is very difficult to treat. Deregulation of adenosine signalling at the $\mathrm{A}_{3}$ adenosine receptor subtype $\left(\mathrm{A}_{3} \mathrm{AR}\right)$ contributes to the development of neuropathic pain states, suggesting $\mathrm{A}_{3} \mathrm{AR}$ agonists as a novel approach for neuropathic pain management. There is limited therapeutic use of $\mathrm{A}_{1} \mathrm{AR}$ and $\mathrm{A}_{2 \mathrm{~A}} \mathrm{AR}$ agonists in these conditions due to their cardiovascular side effects. However, the $\mathrm{A}_{3} \mathrm{AR}$ agonists have advanced in clinical trials for non-pain indications and show a good safety profile. Moreover, the central histaminergic system has been implicated in the regulation of pain perception and recent studies have demonstrated that $\mathrm{H}_{4} \mathrm{R}$ agonists induce relief from painful peripheral neuropathy. Both $\mathrm{A}_{3} \mathrm{ARs}$ and $\mathrm{H}_{4} \mathrm{Rs}$ are expressed on $\mathrm{CD}^{+}{ }^{+} \mathrm{T}$ cells and they mitigate chronic inflammation via an IL-10-mediated pathway.

The aim of the study is to investigated a possible synergistic action between $\mathrm{A}_{3} \mathrm{AR}$ and $\mathrm{H}_{4} \mathrm{R}$ signalling pathways in modulating neuropathic pain conditions.

Male WT and $\mathrm{H}_{4} \mathrm{R}^{-1-}$ mice $(\mathrm{n}=20)$ were subjected to Chronic Constriction Injury (CCI), a model of neuropathic pain, and were treated systemically with IB-MECA, a selective $A_{3} A R$ agonist, ( $1 \mathrm{mg} / \mathrm{kg}$; i.p.) during peak of mechanical allodynia. Our results demonstrate that IBMECA treatment completely reversed neuropathic pain in WT mice ( $\mathrm{p}<0.001$ vs $\mathrm{H}_{4} \mathrm{R}^{-1-}$ treated with IB-MECA). However, mice lacking $\mathrm{H}_{4} \mathrm{Rs}$ had partially reverse mechanical allodynia in response to the $\mathrm{A}_{3} \mathrm{AR}$ agonist's treatment. Adoptive transfer of $\mathrm{CD} 4^{+} \mathrm{T}$ cells isolated from WT donors restore the beneficial effects of $\mathrm{A}_{3} \mathrm{AR}$ agonists in $\mathrm{H}_{4} \mathrm{R}^{-1-}$ mice ( $\mathrm{p}<0.001$ vs $\mathrm{D} 8$ after CCI surgery). To support the behavioural data, the plasma levels of different cytokines such as IL-6, IL-10 and TNF- $\alpha$ were evaluated by a bead-based multiplex immunoassay.

Our data suggest an involvement of $\mathrm{H}_{4} \mathrm{Rs}$ in the mechanism of action of $\mathrm{A}_{3} \mathrm{AR}$ agonists and selective stimulation of neuronal $\mathrm{H}_{4}$ Rs together with non-toxic doses of $\mathrm{A}_{3} \mathrm{AR}$ agonists could have clinical relevance for the treatment of neuropathic pain.

The presenter of this abstract was highly commended in the Young Investigator Award (2019).

Dept. of NEUROFARBA, Section of Pharmacology, University of Florence, Florence, Italy. E-mail: mariaconcetta.durante@unifi.it 


\section{A DYNAMIC MASS REDISTRIBUTION ASSAY FOR THE HISTAMINE $\mathrm{H}_{4}$ RECEPTOR}

\section{U. Seibel, A. Buschauer, G. Bernhardt, A. Straßer}

Since its discovery, the histamine $\mathrm{H}_{4}$ receptor $\left(\mathrm{H}_{4} \mathrm{R}\right)$ has been considered as an auspicious target for the treatment of allergy and immune disorders inter alia asthma, host defense and even cancer, impelling the development of novel $\mathrm{H}_{4} \mathrm{R}$ ligands for both pharmacological investigations and clinical use.

However, the extraordinary high constitutive activity of the receptor associated with low signal-to-background ratios in the available assays (e.g. $\left[{ }^{35} \mathrm{~S}\right] \mathrm{GTP} \gamma \mathrm{S}$, luciferase reporter gene) impairs a precise functional characterization of $\mathrm{H}_{4}$ ligands. As an alternative method, the label-free dynamic mass redistribution (DMR) technology was adapted to the $\mathrm{hH}_{4} \mathrm{R}$, stably expressed by HEK293T cells. $\mathrm{N}$-terminal fusion of the receptor with the signalling sequence of the $5-\mathrm{HT}_{3 \mathrm{~A}}$ receptor should facilitate the correct insertion of the receptor into the cell membrane and, thus, enhance receptor expression which was confirmed by saturation binding experiments using a radiolabelled tracer.

In DMR experiments with the endogenous ligand histamine, concentration dependent optical traces were recorded, with an excellent signal-to-background ratio. The functional parameters determined for histamine and a set of $\mathrm{H}_{4}$ standard (inverse) agonists, including UR-PI294 and thioperamide, were in good agreement with data obtained from conventional assays with various readouts. Furthermore, the application of the DMR technology confirmed a major contribution of the $G_{i}$ protein to the holistic DMR response, although at present the involvement of additional signalling pathways cannot be excluded.

In conclusion, the DMR technology represents a robust and versatile alternative for the functional characterisation of $\mathrm{H}_{4}$ ligands.

This abstract won the Poster Competition (2019). Institute of Pharmacy, University of Regensburg, 93053 Regensburg, Germany.E-mail:ulla.seibel@ur.de

\section{HISTAMINE $\mathrm{H}_{3}$ RECEPTORS AGGRAVATE CEREBRAL ISCHEMIC INJURY BY HISTAMINE- INDEPENDENT MECHANISMS}

\section{Zhang, H. Yan, W. Hu, H. Ohtsu, Z. Chen}

The aims of this study were to investigate the roles of histamine $\mathrm{H}_{3}$ receptor (H3R) in cerebral ischemia/reperfusion (I/R)-induced injury.
Transient middle cerebral artery occlusion was used to mimic the cerebral I/R either in wild-type, $H 3 R^{-/-}$, $H D C^{-1-}$ (histidine decarboxylases), and $A \operatorname{tg} 5^{+/-}$(autophagy related gene 5) mice. The brain infarct volumes and neurological deficit score were determined to reveal the brain injury. Primary cultured cortical neurons from wild-type, $H 3 R^{-/-}$and $\mathrm{Atg} 5^{-/-}$mice were subjected to oxygen-glucose deprivation and reperfusion (OGD/R). Thioperamide, A331440 and clobenpropit were used as H3R antagonists and immepip was used as H3R agonist. Pyrilamine, cimetidine and $\alpha$-FMH were used to inhibit the H1R, H2R and HDC, respectively. The 3-methyladenosine was used to inhibit autophagy.

The H3R was upregulated after OGD/R in wild-type neurons. H3R antagonists showed significant neuroprotective effects against ischemia-induced brain injury and neuronal apoptosis. This neuroprotection can be reversed by immepip and H3R knockout. Interestingly, H1R, H2R antagonists or HDC blockage did not counteract the benefits of H3R antagonism, suggesting H3R antagonism conferred its neuroprotection independent of regulating histamine release. Alternatively, we found H3R antagonism activated the Akt/GSK3 $\beta / \mathrm{mTOR}$ signaling pathway in OGD/R neurons, which further activated autophagy. Autophagy activation abolished ischemia-induced neuronal apoptosis, which was blocked by 3-methyladenosine and Atg5 knockout. In addition, autophagy activation by H3R antagonism involved the interaction of H3R and CLIC4 in OGD/R neurons. Disrupting the H3R-CLIC4 binding reduced autophagy activation and led to more extensive ischemic neuronal death.

H3R aggravated ischemic brain injury while its antagonism showed neuroprotection via histamine-independent mechanisms that involve suppressing H3R-CLIC4 bindingactivated autophagy. Therefore the H3R could be a therapeutic target for cerebral ischemia.

This project was supported by the National Natural Science Foundation of China (81822044, 81773703, 81102429).

Institute of Pharmacology and Toxicology, College of Pharmaceutical Sciences, Zhejiang University. Hangzhou, 310058 China. E-mail: xiangnan_zhang@zju.edu.cn 
MODULATORY EFFECTS OF HISTAMINE $\mathrm{H}_{3} \mathrm{R}$ / $\mathrm{H}_{4}$ R ANTAGONISTS LINS01005 AND LINS01007 ON THE INFLAMMATORY RESPONSE IN MURINE ASTHMA MODEL

\author{
A. M. Balbino, L. J. S. Lima, G. A. B. Fernandes, \\ M. F. Corrêa, M. A. V. Landgraf, J. P. S. Fernandes, \\ R. G. Landgraf
}

Histamine is an important chemical transmitter involved in inflammatory processes, including asthma and other chronic inflammatory diseases. Its inflammatory effects involve mainly the $\mathrm{H}_{4} \mathrm{R}$, whose role in several studies has already been demonstrated. Our group have prepared 5-substituted 1-[(2,3-dihydro-1-benzofuran-2yl)methyl]piperazines (LINS01 series), which showed interesting results as $\mathrm{H}_{3} \mathrm{R} / \mathrm{H}_{4} \mathrm{R}$ antagonists. LINS01005 exhibited poor affinity for $\mathrm{H}_{4} \mathrm{R}$ while LINS01007 showed nanomolar affinity for this receptor $\left(\mathrm{p} K_{\mathrm{i}} 6.06\right)$, and both showed antagonistic activity. Considering the different affinity profile and anti-inflammatory potential of both compounds, we did a more focused evaluation of the modulatory effects in a murine asthma model. LINS01005 and LINS01007 compounds were prepared as previously described and given i.p. (1-7 $\mathrm{mg} / \mathrm{kg}$ ) to ovalbumin sensitized C57BI/6 male mice (12 weeks old) $30 \mathrm{~min}$ before the antigen challenge, and after $24 \mathrm{~h}$ bronchoalveolar lavage (BAL) was performed for cell analysis. The lungs were removed for evaluation by Western blot analysis of COX2, 5-LOX, NF- $\mathrm{kB}$ and STAT3 expression. Treatment with the more potent antagonist LINS1007 caused a significant decrease in the total cell and eosinophil counts in the BAL at the doses of 7,5 and $3 \mathrm{mg} / \mathrm{kg}$, while the less potent LINS01005 reduced these counts only at 7 and $5 \mathrm{mg} / \mathrm{kg}$ doses. None of the compounds altered significantly these counts at $1 \mathrm{mg} / \mathrm{kg}$. Expression of COX-2, 5-LOX, NF- $\mathrm{\kappa B}$ and STAT3 in lung tissue was significantly reduced after treatment with LINS01007 at $3 \mathrm{mg} / \mathrm{kg}$. LINS01005 reduced the expression of these proteins only at the dose of $5 \mathrm{mg} / \mathrm{kg}$. Our results showed a superior anti-inflammatory activity of LINS01007 compared to compound LINS01005 in a dose dependent manner, suggesting the involvement of $\mathrm{H}_{4} \mathrm{R}$ in this activity. In summary, the compounds modulated the inflammatory cell infiltration, expression of COX2 and 5-LO as well as the signaling pathways in murine asthma model.

This work was supported by São Paulo Research Foundation-FAPESP (grants 2016/25028-3, 2017/054416, 2012/51104-8, 2017/02042-3 and 2016/23139-2), National Council for Scientific and Technological Development-CNPq (grants 455411/2014-0 and 306055/20183 ) and CAPES (financial code 001).
Department of Pharmaceutical Sciences, Universidade Federal de São Paulo, Diadema-SP 09913-030, Brazil. Email: joao.fernandes@unifesp.br

\section{GILZ AND HISTAMINE $\mathrm{H}_{4}$ RECEPTOR INHIBITION IN AN INFLAMMATORY MODEL OF LUNG FIBROSIS IN MICE}

S. Sgambellone, L. Lucarini, M. Durante, A. Pini,

S. Bruscoli, C. Riccardi, E. Masini

Pulmonary fibrosis is the most common form of interstitial lung disease. Effective therapies are not yet available and novel therapeutic strategies are required for counteracting fibrosis. The histamine $\mathrm{H}_{4}$ receptor $\left(\mathrm{H}_{4} \mathrm{R}\right)$ is predominantly expressed on immune cells and is involved in immunomodulatory responses. $\mathrm{H}_{4} \mathrm{Rs}$ mediate chronic airway inflammation by regulating the activation of $\mathrm{CD}^{+}{ }^{+} \mathrm{T}$ cells in producing Th2-type cytokines. Glucocorticoidsinducible leucine zipper (GILZ), a dexamethasone-inducible gene, is an important molecular player in the antiinflammatory effects of glucocorticoids (GCs). GILZ mediates $\mathrm{CD}^{+} \mathrm{T}$ cell activation and differentiation through its ability to dimerize with $\mathrm{NF}-\kappa \mathrm{B}$, leading to a switch from Th1 to Th2 immune phenotypes.

This study investigated the possible interactions between histaminergic system and GILZ in the pathogenesis of the inflammatory process and glucocorticoid modulation.

WT and GILZ $^{-1-}$ mice were treated with bleomycin (0.05 IU) or saline, both delivered by intra-tracheal injection. After surgery, mice received two daily intraperitoneal injection of vehicle, JNJ7777120 (2 mg/kg b.wt), or dexamethasone ( $2 \mathrm{mg} / \mathrm{kg}$ b.wt) for 21 days. We assayed airway resistance to inflation and lung samples were processed to measure $\mathrm{H}_{4} \mathrm{R}$ and GILZ expression and pro-inflammatory cytokines production, moreover we isolated and analysed the percentage of lymphocytes. Fibrosis and airway remodelling were evaluated by measuring TGF- $\beta$ production and $\alpha$-SMA deposition.

Our results indicate that in WT mice, but not in $\mathrm{GILZ}^{-/-}$mice, GCs and JNJ decrease airway resistance to inflation (vehicle $22 \pm 3 \mathrm{~mm}$, WT JNJ $14 \pm 4 \mathrm{~mm}$, ** $\mathrm{p}<0.005 ;$ GILZ $^{-/-}$JNJ $18 \pm 2 \mathrm{~mm}, * \mathrm{p}<0.05$ WT JNJ vs $\mathrm{GILZ}^{-/-} \mathrm{JNJ}$ ) and the levels of pro-inflammatory cytokine IL-4 $\left(* \mathrm{p}<0.05 \mathrm{JNJ} \mathrm{GILZ}^{-/-}\right.$vs JNJ WT) and pro-fibrotic TGF- $\beta(* * \mathrm{p}<0.01 \mathrm{WT}$ JNJ $v s$ WT vehicle, * $\mathrm{p}<0.05 \mathrm{GILZ}^{-/-} \mathrm{JNJ}$ vs $\mathrm{GILZ}^{-/-}$vehicle). Moreover our results indicate that in $\mathrm{GILZ}^{-/-}$mice treated with JNJ or DEXA there is an increase of the percentage of $\mathrm{CD}^{+}$and $\mathrm{CD}^{+} \mathrm{T}$ cells in comparison to WT $\mathrm{T}$ cells. 
In conclusion, characterization of the role of $\mathrm{H}_{4} \mathrm{R}$ and GILZ in relation to glucocorticoids could help develop innovative therapies to counteract pulmonary fibrosis.

Italian Ministry of Education, University and Research Grant, PRIN 2015.

Department of Neuroscience, Psychology, Drug Area and Child Health (NEUROFARBA), University of Florence, Italy.E-mail: silvia.sgambellone@stud.unifi.it

\section{HISTAMINE $\mathrm{H}_{3} / \mathrm{H}_{4}$ ANTAGONISTS HAVE AN IMPACT ON THE SYNTHESIS OF CYTOKINES, CHEMOKINES AND GROWTH FACTORS BY PERIPHERAL BLOOD MONONUCLEAR CELLS}

\section{R. Khanferyan, N. Milchenko, N. Riger}

Histamine plays a prominent role in the pathophysiology of allergic diseases, asthma, rhinitis and urticaria. The role of the histaminergic system and involvement of different types of histamine receptors, especially $\mathrm{H}_{1}$, in allergic reactions is well established. Several studies also demonstrate a prominent role of $\mathrm{H}_{4}$ receptors in allergic mechanisms and inflammation. After the discovery of histamine receptors types 3 and 4, the key role of these histamine receptors in the regulation of histaminergic system in CNS and growth and differentiation of hematopoietic progenitors was established. The aim of this investigation was the study of the influence of a dual $\mathrm{H}_{3} / \mathrm{H}_{4}$ receptor antagonist on the production of mediators of allergic and inflammatory reaction. Peripheral blood mononuclear cells (PBMC) of 10 healthy donors were cultivated in the presence of the dual $\mathrm{H}_{3 / 4}$ receptor antagonist Ciproxifan $\left(10^{-5}-10^{-8} \mathrm{M}\right)$. The concentrations of cytokines, chemokines and growth factors in 48-h supernatants of PBMC were assessed by Multiplex assays (45plex) using Luminex xMAP technology. Total IgE concentrations in 7-day cultures of PBMC supernatants were assayed by Phadia CAP method. The concentration of the key IgE-regulatory cytokines in the supernatants were assessed by ELISA. Our preliminary data demonstrated the decrease in IgE synthesis by PBMC of healthy donors cultivated in the presence of histamine $\left(10^{-5}\right.$ and $\left.10^{-8} \mathrm{M}\right)$. Further experiments demonstrated that Ciproxifan may have an impact on this effect of histamine. It was also demonstrated that Ciproxifan dose-dependently increased the synthesis of $\gamma$ IFN and IL4, but decreased IL-10 production by PBMC of healthy donors and ragweed sensitive patients $(\mathrm{P}<0.05)$. Further experiments demonstrated the multiple effects of Ciproxifan on the secretion of cytokines and growth factors. Ciproxifan significantly increases the secretion of IL $\alpha$, IL-4, IL-13, IL-18, IL-27 and IP-10 $(\mathrm{p}<0.01)$ and induces a noticeable inhibition of the secretion of SCF, GM-CSF, LIF, IL-2, IL-5, IL-6, IL-7, IL9, IL-15 and IL-31 ( $p<0.05)$. Cultivation of PBMC with Ciproxifan resulted in a high increase $(p<0.001)$ in the synthesis of the main chemokines (Eotaxin, RANTES, MIP- $1 \alpha$, MIP-1b, GRO- $\alpha$ ). The study demonstrated that dual $\mathrm{H}_{3 / 4}$ antagonists may have an impact not only on the central brain histaminergic mechanisms, but also has clinical relevance in IgE-mediated reactions and secretion of a multiple cytokines, chemokines and growth factors by PBMC in inflammatory reactions.

Peoples' Friendship University of Russia (RUDN University), Moscow, 117198, Russia. E-mail: khanfer1949@gmail.com

\section{EFFECTS OF HISTAMINE $\mathrm{H}_{4}$ RECEPTOR LIGANDS OF THE AMINOPYRIMIDINE CLASS ON A RAT MODEL OF AUTOIMMUNE MYOCARDITIS (EAM)}

\section{A. Stasiak, J. Gola, K. Kraszewska, M. Mussur, J. Kobos,} U. Mazurek, H. Stark, W. A. Fogel

At the end of 1999 and beginning of 2000, we found that histamine functions are mediated by four histamine receptors: $\mathrm{H}_{1} \mathrm{R}-\mathrm{H}_{4} \mathrm{R}$. The histamine $\mathrm{H}_{4}$ receptor $\left(\mathrm{H}_{4} \mathrm{R}\right)$, in keeping with its role in initiation and maintenance of inflammation, is present on eosinophils, mast cells, basophils and other immune cells and organs. Benefits of $\mathrm{H}_{4} \mathrm{R}$ inhibition have been shown in relevant animal models of human diseases suggesting it may have therapeutic indications in allergy, inflammation as well as in autoimmune diseases. From the $\mathrm{H}_{4} \mathrm{R}$ antagonists tested so far in clinical studies, the most successful is ZPL389 and by the end of 2019 we shall know the results of a Phase 2 clinical trial on the safety and efficacy of the drug in patients with moderate to severe atopic dermatitis. Our studies using a rat model of autoimmune myocarditis point to a possible clinical application of $\mathrm{H}_{4} \mathrm{R}$ antagonists in the corresponding human disease. In experimental autoimmune myocarditis (EAM) induced by porcine myosin injection to Lewis male rats $(n=10$ /group), therapy for 2 weeks with ST994, (N4-(4-methylbenzyl)-6-(4-methylpiperazin-1yl)pyrimidine-2,4-diamine), a neutral $\mathrm{H}_{4} \mathrm{R}$ antagonist, reduced plasma and tissue markers of inflammation (ceruloplasmin activity and TNF-alpha, MCP-1, respectively), and although it did not prevented left ventricle dilation it, preserved initial cardiac function as shown by echocardiography. In the following 2 weeks without therapy the heart function deteriorated in all EAM rats, however to a significantly lower degree in those treated with ST-994. Left ventricular ejection fraction was decreased respectively by $47 \%$ and $22 \%$. Accordingly, 
median survival times for EAM-ST994 and EAM rats significantly differed, being respectively, undefined and 22.5 days. The end point of the experiment was after 4 weeks and at autopsy macroscopic examination has shown smaller heart enlargement and less foci of fibrosis in still soft cardiac tissues in the EAM-ST994 group, while in untreated EAM rats deep fibrosis caused heart muscle to become inflexible and stiff. Histochemistry and hydroxyproline analyses further confirmed benefits of $\mathrm{H}_{4} \mathrm{R}$ blockade. Therefore, $\mathrm{H}_{4} \mathrm{R}$ inhibition should be considered for clinical application in EAM.

This work was gratefully supported by a National Science Centre grant HARMONY DEC-2012/04/M/NZ4/ 00212, Medical University of Lodz and COST Action CA15135.

Department of Hormone Biochemistry, Medical University of Lodz, Zeligowskiego 7/9, 90-752 Lodz, Poland; E-mail: anna.stasiak@umed.lodz.pl

\section{EVALUATION OF THE PHARMACOLOGICAL POTENTIAL OF A NEW $\mathrm{H}_{4}$ RECEPTOR ANTAGONIST IN CECAL LIGATION AND PUNCTURE-INDUCED SEPSIS IN MICE}

\section{K. Pociecha, E. Wyska, M. Więcek, K. Kieć-Kononowicz}

Histamine $\mathrm{H}_{4}$ receptors $\left(\mathrm{H}_{4} \mathrm{Rs}\right)$ are expressed on a variety of immune cells ( $\mathrm{T}$ cells, mast and, dendritic cells, eosinophils) and play a key role in the immune response. Data in the literature indicate that antagonism of histamine $\mathrm{H}_{4} \mathrm{R}$ inhibits the in vivo production of tumor necrosis factor $\alpha$ (TNF- $\alpha$ ) induced by LPS. It is well known that the levels of this cytokine are elevated in both animal and human sepsis. Amongst existing models of sepsis, the cecal ligation and puncture (CLP) model is believed to closely resemble the progression and characteristics of human sepsis compared to other models of this condition. The aim of this study was to evaluate the pharmacological activity of a new histamine $\mathrm{H}_{4} \mathrm{R}$ antagonist, KB4 (a 1,3,5-triazine derivative), compared with JNJ-7777120 (JNJ) (an indole derivative) as a reference compound, in CLP-induced sepsis in mice. CLP was performed in CD-1 male mice injected with $20 \mathrm{mg} / \mathrm{kg}$ i.p. of JNJ, KB-4 or vehicle (control group). Six hours postsurgery, mice were sacrificed and blood samples were collected. Serum concentrations of the cytokines TNF- $\alpha$, RANTES, MCP-1, MIP-1a, and HMGB1 were measured using ELISA. For a survival study, septic animals were injected with $20 \mathrm{mg} / \mathrm{kg}$ i.p. of either compound or vehicle and observed for $72 \mathrm{~h}$ at $12 \mathrm{~h}$ intervals. The results obtained were evaluated using Kaplan-Meier analysis. In groups injected with JNJ or KB-4, a significant decrease (up to $73 \%$ ) in serum TNF- $\alpha$ was observed compared with the control group. There were no significant differences in the levels of other cytokines studied among groups. Neither of the compounds studied influenced the survival of septic animals compared to the control group. In conclusion, both compounds studied inhibited the rise of serum TNF- $\alpha$ in mice with sepsis. Further studies on KB4 are warranted to evaluate its activity in other animal models of TNF- $\alpha$ mediated diseases.

This project was supported by the statutory activity of JUMC (K/DSC/004305).

Department of Pharmacokinetics and Physical Pharmacy, Jagiellonian University, 30-688 Kraków, Poland. E-mail: k.pociecha@uj.edu.pl

\section{A CNS-SPARING $\mathrm{H}_{3} \mathrm{R}$ ANTAGONIST AS A CANDIDATE FOR THE TREATMENT OF DIABETES-ASSOCIATED (GASTRO)INTESTINAL SYMPTOMS}

M. Gurrieri, P. Nardini, A. Dell'Accio, I. Obara, S. Liu, A. C. Rosa, A. Pini

Diabetes is frequently associated with symptoms such as diarrhoea, constipation and abdominal pain, which are often caused by gastrointestinal secretory and motility alterations related to enteric neuropathy. Among the different histamine receptors, the neuronal expression of histamine $\mathrm{H}_{3}$ receptor (H3R) is documented. Notably, this receptor has been previously implicated in neuropathic pain. Therefore, the H3R could be involved in diabetic microvascular complications such as enteric neuropathy.

The aim of the study was to investigate the potential beneficial effect of PF0086087, a CNS-sparing H3R antagonist, in counteracting intestinal secretory and motility alterations in a mouse model of diabetes. Diabetes was induced in male C57BL/6 mice by a single high-dose of streptozotocin $(200 \mathrm{mg} / \mathrm{kg})$. Colorectal specimens from control and diabetic mice randomized to receive vehicle alone or PF0086087 $(10,30,100 \mathrm{mg} / \mathrm{kg} / \mathrm{day})$ by oral gavage for 14 days were processed for morphological (Alcian blue, PAS staining) and immunohistochemical [neuronal nitric oxide synthase (nNOS), Substance P (SP)] analyses.

Morphometrical analysis revealed a significant increase in both Alcian blue and PAS-positive areas of intestinal mucosa of diabetic mice compared to controls, indicating acidification and over-production of mucus, respectively. PF0086087 was able to prevent mucin acidification at doses above $30 \mathrm{mg} / \mathrm{kg}$, and mucus over-production at the highest dose of $100 \mathrm{mg} / \mathrm{kg}$.

Immunohistochemistry demonstrated that diabetes caused a significant decrease in the inhibitory component 
of enteric motility, measured as the percentage of nNOSpositive neurons $(P<0.05)$. PF0086087 reduced the loss of nNOS neurons only at $100 \mathrm{mg} / \mathrm{kg}$. On the contrary, an increase in the excitatory component, measured as SPpositive area $(P<0.001)$ was observed in diabetic animals. The drug dose-dependently prevented this increase in the SP positive area.

In conclusion, PF0086087 is able to prevent intestinal alterations associated with diabetes-induced enteropathy. Dep. Scienza e Tecnologia del Farmaco (University of Turin), Via Pietro Giuria 9, 10125, Turin, Italy. E-mail: maura.gurrieri@edu.unito.it

\section{ANTINOCICEPTIVE AND ANTIPRURITIC EFFECTS OF THE HISTAMINE $\mathrm{H}_{3}$ RECEPTOR ANTAGONIST (DL-76) IN ACUTE, INFLAMMATORY AND NEUROPATHIC PAIN AND HISTAMINE-DEPENDENT AND -INDEPENDENT ITCH}

\section{S. Mogilski, D. Łażewska, M. Kubacka, M. Gtuch-Lutwin, B. Mordyl, B. Filipek, K. Kieć-Kononowicz}

The expression of histamine $\mathrm{H}_{3}$ receptors in the structures of the nervous system such as dorsal root ganglia, spinal cord or thalamic areas suggests their involvement in the two closely related, however distinct sensations such as pain and itch. DL76, is a new antagonist with a high affinity towards the $\mathrm{H}_{3} \mathrm{R}(\mathrm{hKi}=22 \pm 3 \mathrm{nM})$ and the high brain accumulation.

The goal of our study was to evaluate the activity of DL76 in the models of acute, inflammatory and neuropathic pain and itch induced by histamine or other pruritogenic agents. Moreover, we attempted to assess the involvement of the histamine receptors ${ }_{1}, 2$ and ${ }_{4}$ (H1R, $\mathrm{H} 2 \mathrm{R}$ and $\mathrm{H} 4 \mathrm{R}$ respectively) and muscarinic receptors in the overall effect.

We examined the antinociceptive effect of DL76 in the mouse models of inflammation induced by carrageenan, and in formalin, capsaicin and hot plate tests. We also assessed the impact on tactile allodynia in oxaliplatin-induced peripheral neuropathy and streptozocin-induced diabetic neuropathy. The antipruritic activity of DL76 was tested in the histamine, chloroquine and SLIGRL-NH2 induced model of murine itch. Each experimental group consisted of 8-10 animals. Moreover, we assessed the interaction of DL76 with $\mathrm{H}_{1} \mathrm{R}, \mathrm{H}_{2} \mathrm{R}, \mathrm{H}_{4} \mathrm{R}$ and muscarinic receptor antagonists. Additionally, we assessed the influence of DL-76 and Pitolisant on NO and ROS levels in LPS-stimulated glial BV-2 cells and RAW 264.7 macrophages. In statistical calculations repeated measures analysis of variance (ANOVA), followed by the Bonferroni post hoc test) or one-way ANOVA with Bonferroni's post hoc tests were used.

DL76 reduced mechanical and thermal hyperalgesia in the acute inflammation. The compound was also active in the second phase of formalin test and in both models of neuropathic pain. DL76 showed antipruritic activity in all models of itch, while $\mathrm{H}_{1} \mathrm{R}$ blockade resulted in decreased histamine-induced itch but not that induced by chloroquine or SLIGRL-NH2 indicating that $\mathrm{H}_{3} \mathrm{R}$ antagonism may be beneficial in the pruritus resistant for the classic antihistamines. The centrally acting $\mathrm{H}_{2} \mathrm{R}$ antagonist significantly attenuated the antipruritic effect of DL76, as well as the antinociceptive activity in the model of neuropathic pain but augmented the analgesic effect in the second phase of formalin test (inflammatory pain). $\mathrm{H}_{4} \mathrm{R}$ antagonist exerted antinociceptive and antipruritic effects itself, augmented the analgesic effect of $\mathrm{H}_{3} \mathrm{R}$ antagonist in inflammatory pain, attenuated the $\mathrm{H}_{3} \mathrm{R}$ antagonist-dependent analgesia in oxaliplatin-induced neuropathic pain and does not affect streptozotocin-induced neuropathy.

Our results show that the blockade of histamine $\mathrm{H}_{3} \mathrm{Rs}$ might have therapeutic utility for the treatment of pain as well as for the treatment of histamine-dependent and histamine-independent itch.

Department of Pharmacodynamics, Jagiellonian University Medical College, Medyczna 9, 30-688 Kraków, Poland. E-mail: szczepan.mogilski@uj.edu.pl

\section{NOVEL HISTAMINE $\mathrm{H}_{3}$ RECEPTOR LIGANDS- EFFECTIVE COMPOUNDS AS POTENTIAL ANTI- OBESITY AGENTS}

K. Mika, M. Kotańska, K. Szczepańska, K. Kuder, M. Bednarski. A. Olejarz-Maciej, M. Szafarz, K. Pociecha, A. Siwek, K. Kieć-Kononowicz

Obesity is one of the major health problems of 21st century. Therefore, successful obesity treatment has become one of the top healthcare topics. In fact, the World Health Organization (WHO), has declared obesity to a 21st century epidemic. Obese individuals appear more prone to cardiovascular diseases, diseases of the digestive system: gallstone disease, nonalcoholic fatty liver disease and increased risk of developing cancer: colorectal, gallbladder, and pancreas.

Since the stimulating effect of histamine via histamine $\mathrm{H}_{1}$ receptors located in Central Nervous System on food intake (e.g.: appetite reduction, white adipose tissue lipolysis increment and increment of motor activity) had been discovered, there is a strong need to search for an antiobesity drug which may increase the synthesis and release of histamine. Taking into consideration the location of the 
histamine $\mathrm{H}_{3}$ receptor $\left(\mathrm{H}_{3} \mathrm{R}\right)$, as well as their physiological functions the use of histamine $\mathrm{H}_{3}$ receptor ligands in treatment of diseases such as obesity has been postulated.

In order to determine potential anti-obesity properties of selected $\mathrm{H}_{3} \mathrm{R}$ ligands, preliminary pharmacological in vivo tests were performed ( $\mathrm{n}=6$ rats/group). In these studies, the influence on body weight, food and water intake, glucose and triglyceride plasma levels, and spontaneous activity on rats in the model of excessive eating of preferential feed was tested. We used three control groups: first, had free access to standard diet and received Tween $1 \%$, second control group, also received Tween $1 \%$ but had free access to palatable diet (chocolate, cheese, peanuts, condensed milk). The last control group had free access to palatable diet and received bupropion/naltrexone. Weight gain was studied over 28 days. The test groups (groups received the tested compounds which were all administered at $10 \mathrm{mg} / \mathrm{kg}$ )) were compared to the control groups receiving bupropion/naltrexone.

We kindly acknowledge the generous support of National Science Center, Poland granted on the basis of decision No. 2016/23/N/NZ7/00469 and 2016/23/B/NZ7/ 01063

Department of Pharmacodynamics, Jagiellonian University Medical College, 9 Medyczna Street, 30-688 Kraków, Poland.E-mail: kamil1991.mika@student.uj.edu.pl

\section{A MINI-G PROTEIN RECRUITMENT ASSAY FOR THE HUMAN HISTAMINE $\mathrm{H}_{\mathbf{4}}$ RECEPTOR}

\section{Höring, L. Grätz, A. Strasser, G. Bernhardt}

As the histamine $\mathrm{H}_{4}$ receptor $\left(\mathrm{H}_{4} \mathrm{R}\right)$, a prominent member of the Rhodopsin-like G-protein coupled receptors, is e.g. expressed by hemopoietic cells and by cells of the immune system, it has been considered as a target for the treatment of inflammatory diseases, such as asthma, allergic disorders, autoimmune diseases and pruritus. In drug discovery, complementary to binding assays to determine the affinities of ligands, their functional characterization at the $\mathrm{Ga}_{\mathrm{i}^{-}}$ coupled $\mathrm{H}_{4} \mathrm{R}$ is a prerequisite. Due to the shortage of commercially available qualitatively appropriate $\left[{ }^{35} \mathrm{~S}\right]$ GTP $\gamma \mathrm{S}$ in combination with a low expression level of the $\mathrm{H}_{4}$ receptor and the resulting very low signal-to-noise ratio, the formerly commonly used functional $\left[{ }^{35} \mathrm{~S}\right] \mathrm{GTP} \gamma \mathrm{S}$ binding assay has become impracticable.

Therefore, we developed a miniG protein recruitment assay for the histamine $\mathrm{H}_{4}$ receptor, inspired by a recent publication on the respective $G$ protein surrogates. The assay relies on the split-luciferase complementation technique and meets the demands of a sufficiently high dynamic range going without radioactivity. The miniG protein assay is performed with living HEK293T cells, stably co-expressing the human $\mathrm{H}_{4} \mathrm{R}$ fused to the C-terminal fragment and the $\operatorname{miniG}_{i}$ protein, tagged with the $\mathrm{N}$-terminal fragment of the NanoLuc. Upon activation of the $H_{4} R$, the miniG $G_{i}$ protein is recruited to the receptor, allowing the NanoLuc fragments to form a functional luciferase, giving concentration dependent luminescence signals. The intensity of the luminescence provides information on the potency and efficacy of test compounds. Within this assay, the dynamic range of the endogenous ligand histamine reached $300 \%$ and, hence, was twice as high as that of the $\left[{ }^{35} \mathrm{~S}\right] \mathrm{GTP} \gamma \mathrm{S}$ binding assay.

Institute of Pharmacy, University of Regensburg, D-93040 Regensburg, Germany. E-mail:carina.hoering@ur.de

\section{VIRTUAL SCREENING OF LIGANDS OF HISTAMINE $\mathrm{H}_{3}$ AND $\mathrm{H}_{4}$ RECEPTORS}

\section{P. Mehta, O. Michalak, P. Rzodkiewicz, S. Filipek}

Virtual screening methods represent one of the mostly wisely used bases for drug discovery and design processes. The appropriate choice of methodological options results in obtaining sets of appropriate compounds which can then be used for further optimization. The aim of this study was to perform virtual screening using homology models of inactive $\mathrm{H}_{3}$ and $\mathrm{H}_{4}$ histamine receptors employing the programs from the Schrodinger platform. The pharmacophore generation based on superimposed ligands alone was outperformed by pharmacophore based on homology models of histamine receptors. Since several models were built, the optimal ones were selected based on docking of active ligands and the best correlation with the assessed scoring function. Apart from the pharmacophore-guided virtual screening, the shape-based alignment was also performed. The screening protocols were validated through Receiver Operating Characteristic (ROC) curve (enrichment studies) using selective and nonselective known receptor antagonists and 1000 decoys provided by Schrodinger software. Plotting of ROC curve and calculating Area under the curve (AUC) values were accomplished using the Enrichment Calculator from Schrodinger Platform. Comparison of binding sites of $\mathrm{H}_{3}$ and $\mathrm{H}_{4}$ receptors additionally aided construction of pharmacophores aiming to find selective compounds.

Support from the Interdisciplinary Centre for Mathematical and Computational Modelling in Warsaw grant GA71-27; National Center of Science, Poland, grant OPUS 2017/25/B/NZ7/02788. S.F. participates in the European COST Action CA18133 (ERNEST). 
Faculty of Chemistry, Biological and Chemical Research Centre, University of Warsaw, ul. Pasteura 1, 02-093 Warsaw, Poland.E-mail: pakhurimehta@gmail.com

\section{E-153-THE NOVEL BIFUNCTIONAL $\mathrm{H}_{3}$ RECEPTOR ANTAGONIST/CHOLINESTERASE INHIBITOR REDUCES MEMORY IMPAIRMENT INDUCED BY SCOPOLAMINE AND MK-801}

\author{
S. Mogilski, K. Pytka, D. Łażewska, A. Świerczek, \\ B. Filipek, K. Kieć-Kononowicz
}

Histamine $\mathrm{H}_{3}$ antagonists/inverse agonists have the potential to improve cognitive performance and they can be a valuable therapeutic option in the treatment of different types of dementia, including Alzheimer's disease. E-153, (1-(5-(4-phenylphenoxy)pentyl)homopiperidine hydrogen oxalate), is a new non-imidazole $\mathrm{H}_{3} \mathrm{R}$ antagonist $\left(\mathrm{K}_{\mathrm{i}}\right.$ $=34 \mathrm{nM}$ ) with butyrylcholinesterase inhibitory activity $\left(\mathrm{IC}_{50}=588 \mathrm{nM}\right)$.

In our study in mice (Albino Swiss or C57BL/6 J; $\mathrm{n}=8-10$ ), we determined the influence of E-153 (at the doses ranging from $1.25 \mathrm{mg} / \mathrm{kg}$ to $30 \mathrm{mg} / \mathrm{kg}$ ) on memory processes in various paradigms, including Passive Avoidance Test (PAT) and Morris Water Maze (MWM) in which scopolamine $(1 \mathrm{mg} / \mathrm{kg})$ or MK-801 $(0.125 \mathrm{mg} / \mathrm{kg})$ were used to induce memory and learning impairments. We compared all results with the effect of the reference histamine $\mathrm{H}_{3} \mathrm{R}$ antagonist Pitolisant. Moreover, we assessed the interaction of E-153 with histamine $\mathrm{H}_{1} \mathrm{R}$ and $\mathrm{H}_{2} \mathrm{R}$ antagonists. We measured the concentration of brain histamine and acetylcholine after acute treatment with E153 as well as the concentration of brain p-CREB, BDNF and p-PKA after chronic (7 days) treatment with E-153. In the pharmacokinetic studies, the concentrations of the compound E-153 in serum and tissues were measured by an HPLC method with fluorescence detection. In statistical calculations, two-way ANOVA followed by the Bonferroni post hoc test or one-way ANOVA with Tukey's post hoc tests were used.

After the administration of E-153, we observed the significant improvement of scopolamine-induced memory deficits both in PAT and in MWM with the maximal effect obtained at the dose of $5 \mathrm{mg} / \mathrm{kg}$ and $15 \mathrm{mg} / \mathrm{kg}$ respectively and significantly decreasing at the higher doses. The amnestic effect of MK-801 was also attenuated, but not so efficiently. The procognitive effects of E-153 were significantly attenuated by the $\mathrm{H}_{1} \mathrm{R}$ antagonist and to a lesser extent by the $\mathrm{H}_{2} \mathrm{R}$ antagonist, which was statistically significant in the case of scopolamine-induced memory impairment but not in the MK-801 induced deficits. The single administration of E153 increased the histamine and acetylcholine level in hippocampus but not in the prefrontal cortex. However, administration of E-153 did not result in any changes in the levels of p-CREB and p-PKA in the hippocampus and in the prefrontal cortex. Pharmacokinetic analysis revealed an extensive distribution of the studied compound into the mouse brain.

These results confirm that the simultaneous blockade of histamine $\mathrm{H}_{3} \mathrm{Rs}$ and cholinesterase inhibition might have therapeutic utility for the treatment of memory deficits and learning disorders. We showed that secondary to $\mathrm{H}_{3} \mathrm{R}$ blockade, the release of histamine and subsequent activation of $\mathrm{H}_{1} \mathrm{R}$-dependent pathways might have a crucial role in the procognitive mechanism of action of E-153.

This study was supported by Jagiellonian University Medical College founds K/ZDS/007130 and K/ZDS/00713. Partly supported by National Science Center Poland granted on the basis of decision DEC-2016/23/B/NZ7/02327. Departament of Pharmacodynamics, Jagiellonian University Medical College, Medyczna 9, 30-688 Kraków, Poland. E-mail: szczepan.mogilski@uj.edu.pl

\section{DIFFERENTIAL EXPRESSION OF HISTAMINE $\mathrm{H}_{3}$ AND $\mathrm{H}_{4}$ RECEPTORS IN MURINE AND ZEBRAFISH RETINAS}

\section{N. Young, S, Grillo, S. L Stella Jn, H. Mahmudal, I. Obara,} V. Telezhkin, P. L. Chazot

Diabetic retinopathy is still one of the major causes of blindness worldwide. Collectively, data in the literature suggest that histamine could at least participate in the neural cell contribution to the diabetes-induced vascular leakage, through $\mathrm{H}_{1} \mathrm{Rs}$. Mice and zebrafish are common models for diabetic retinopathies. However, little is known regarding the most recently identified histamine receptors, $\mathrm{H}_{3}$ and $\mathrm{H}_{4}$, in the retina.

An immunological study was performed on fixed mouse (C57 strain) and zebrafish retinal sections, which revealed differential topological expression patterns. We have previously reported (47th EHRS conference, 2018) evidence for $\mathrm{H}_{4} \mathrm{R}$ expression on the end feet of retinal Müller cells in the mouse retina. On closer analysis, we also have new evidence for $\mathrm{H}_{3} \mathrm{R}$ expression on the cell bodies of murine Müller cells within the inner nuclear layer (INL) of the retina. $\mathrm{H}_{4} \mathrm{R}$ immunoreactivity was also found in the inner and outer plexiform layers (IPL and OPL). Using full mouse retinal sections, we have new evidence for $\mathrm{H}_{3} \mathrm{R}$, but not $\mathrm{H}_{4} \mathrm{R}$, expression in the retinal pigment epithelial (RPE) layer. In comparison, $\mathrm{H}_{4} \mathrm{R}$ is prominently expressed in Müller cell bodies, processes and endfeet of the zebrafish retina; in the outer limiting membrane, and shows strong expression in the OPL (likely photoreceptor pedicles or 
horizontal cell tips). $\mathrm{H}_{3} \mathrm{R}$ expression in zebrafish retina appears to co-localize with Müller cells in the IPL and their endfeet, and is present in the OPL (possibly in horizontal cells). These findings requires confirmation with $\mathrm{KO}$ mice and knockdown studies in zebrafish. Overall, there is a differential topological pattern of expression for $\mathrm{H}_{3}$ and $\mathrm{H}_{4}$ receptors in the murine and zebrafish retina. We also have early immunological and calcium imaging functional evidence for the presence of $\mathrm{H}_{4} \mathrm{R}$, and electrophysiological and calcium imaging evidence for $\mathrm{H}_{1}$ receptors in human Müller cells (Mio-M1 cell line) (this meeting) grown in high- and medium-glucose media, respectively.

Department of Neural and Behavioral Sciences, Pennsylvania State University-College of Medicine, Hershey, Pennsylvania, USA. E-mail: sgrillo@pennstatehealth.psu.eduor paul.chazot@durham.ac.uk 
Molecular and chemical aspects of histamine, its receptors and enzymes 


\section{EXPLOITING MULTIPLE TRAILS AS A TURNING POINT FOR DRUG DISCOVERY AND DEVELOPMENT FOR NEUORDEGENERATIVE DISEASES}

\section{F. Borges}

Neurodegenerative diseases (NDs) represent a group of different neurological disorders having an enormous impact on human health. The intricate network of regulatory mechanisms that trigger and sustain neurodegeneration remains largely elusive and, to date, no specific factor has yet been ascribed to have a direct causal role. NDs such as Alzheimer's (AD) and Parkinson's (PD) diseases, are associated with misfolding and dysfunctional trafficking of proteins. Nevertheless, induction of mitochondrial dysfunction and ferroptosis by oxidative stress, among others, has also been associated with neurodegeneration progression.

Drug discovery and development for neurodegenerative diseases has been focused on the single-target paradigm, pursuing selective ligands for specific-targets in order to avoid off-target binding and unwanted side effects. However, the lack of therapeutic efficacy of the current approved drugs and the multifactorial nature of NDs has boosted the multi-target-directed ligand approach. This procedure can hopefully pave the way of finding drugs able to reverse the progression of the disease.

In this context, our research group have been focused in the discovery of new chemical entities inspired by natural scaffolds and in strategies based on one target and multitarget approaches directed to classic and new targets linked to neurodegenerative diseases. The most relevant data obtained so far will be briefly described in this communication.

Funded by FEDER funds through the Operational Programme Competitiveness Factors-COMPETE and national funds by FCT-Foundation for Science and Technologyunder research grants (PEst-C/QUI/UI0081/2013, NORTE01-0145-FEDER-000028 and PTDC/DTP-FTO/2433/ 2014). COST action CA15135 (Multitarget Paradigm for Innovative Ligand Identification in the Drug Discovery Process) support is also acknowledged.

CIQUP/Department of Chemistry and Biochemistry, Faculty of Sciences, University of Porto, Portugal. E-mail: fborges@fc.up.pt

\section{SYNTHESIS AND PHARMACOLOGICAL CHARACTERIZATION OF CNS-PENETRATING $\mathrm{H}_{2} \mathrm{R}$ AGONISTS AND THEIR POSSIBLE USE FOR NEURODEGENERATIVE DISEASES}

\author{
M. Bresinsky, M. Nagl, N. Rosier, B. Sadek, S. Elz, \\ S. Pockes
}

Over the past 40 years the development of histamine $\mathrm{H}_{2}$ receptor $\left(\mathrm{H}_{2} \mathrm{R}\right)$ agonists led to different classes of potent ligands. Coming from 3-(1H-imidazol-4-yl)propylguanidine (SK\&F 91486), a weak partial agonist, imidazolecontaining dialkylated guanidines like impromidine and arpromidine brought highly potent full agonists for the $\mathrm{H}_{2} \mathrm{R}$. Beside their poor properties with respect to bioavailability, both compounds lacked selectivity towards the $\mathrm{H}_{1}, \mathrm{H}_{3}$ and $\mathrm{H}_{4}$ Rs. Bioisosteric replacement of the imidazole by 2-amino-4-methylthiazole eliminated the selectivity drawbacks, while modification of the alkylated guanidine group to acylated guanidines was a useful approach to improve bioavailability and blood-brain barrier (BBB) penetration. As the acylated compounds turned out to be vulnerable to hydrolytic cleavage further development to carbamoylguanidines led to highly stable, selective and potent $\mathrm{H}_{2} \mathrm{R}$ ligands.

In the past years, around one hundred compounds, including bivalent ligands, were prepared in our lab to further investigate SARs for the $\mathrm{H}_{2} \mathrm{R}$. In the latest projects, we focused on the development of CNS-penetrating $\mathrm{H}_{2} \mathrm{R}$ agonists, because little is known about the physiological role of the $\mathrm{H}_{2} \mathrm{R}$ in the brain. As the $\mathrm{H}_{2} \mathrm{R}$ is also described to be involved in the brain histaminergic neurotransmission and other central neurotransmitters (e.g. acetylcholine), a $\mathrm{H}_{2} \mathrm{R}$ agonist could have similar effects to treat cognitive disorders (e.g. Alzheimer's disease) as already reported for $\mathrm{H}_{3} \mathrm{R}$ antagonists. As $\mathrm{H}_{2} \mathrm{R}$ agonists are known to be very polar it is quite challenging to synthesize ligands with suitable properties to cross the $\mathrm{BBB}$, while maintaining selectivity towards the other HR subtypes. Our approach developed UR-Po563, an enantiopure (ee > 99\%) highly potent and selective agonist at the $\mathrm{H}_{2} \mathrm{R}\left(\mathrm{pK}_{\mathrm{i}}\left(\mathrm{hH}_{2}\right.\right.$ $\mathrm{R})=7.60 ; \mathrm{pEC}_{50}=8.12, E_{\max }=0.95\left(\mathrm{gpH}_{2} \mathrm{R}\right.$-atrium $)$, which is currently being tested in vivo in several behavioural models, including anxiety-related tests in mice. University of Regensburg, Regensburg, 93053, German. Email: steffen.pockes@ur.de. 
BRET-BASED BINDING ASSAYS: PYRYLIUMLABELED HISTAMINE RECEPTOR LIGANDS ALLOW FOR THE DETERMINATION OF BINDING CONSTANTS AT EQUILIBRIUM AND IN REAL TIME

L. Grätz, T. Littmann, E. Bartole, S. Biselli, K. Tropmann, M. Keller, A. Buschauer, G. Bernhardt

Luminescence-based live cell assays play an increasingly important role in research, especially in the field of drug discovery. Thus, we adopted a recently published BRETbased binding assay to the human histamine $\mathrm{H}_{2}$ and the human and the murine histamine $\mathrm{H}_{4}$ receptor by fusing the brightly blue-emitting NanoLuc $\left(\lambda_{\max }=460 \mathrm{~nm}\right)$ to the $\mathrm{N}$-termini of the respective GPCRs.

For fluorescence labeling of the ligands, we decided to use the pyrylium dyes Py- 1 and Py-5, because of their ideal spectral properties (e.g. Py-5: $\lambda_{\max }$ (ex.) $=469 \mathrm{~nm}, \lambda_{\max }$ $(\mathrm{em})=.645 \mathrm{~nm}$ ) with respect to a combination with the luciferase. We synthesized and characterized pyrylium-labelled fluorescent ligands for the aforementioned receptors, which all showed high receptor affinity (e.g. the Py-5-labeled $\mathrm{H}_{2}$ receptor antagonist UR-SB263: $\mathrm{K}_{\mathrm{i}}=18 \mathrm{nM}$ (radioligand competition binding)).

BRET-based binding assays were established for all receptors and equilibrium dissociation constants $\left(\mathrm{K}_{\mathrm{d}}\right.$-values) of the fluorescent ligands, determined by saturation binding, were all in very good agreement with binding constants from radioligand binding or flow cytometric assays. Using this assay, we also investigated standard ligands of all three receptors in competition binding experiments, yielding $\mathrm{K}_{\mathrm{i}}$-values in accordance to previously published data from radioligand binding assays. In addition to measurements at equilibrium, this assay also enabled the determination of binding kinetics in real time, providing more information on the binding process.

Generally, the presented approach-provided that appropriate fluorescent ligands are available—offers a robust and versatile test platform for the investigation of GPCR ligand binding.

Financial support by the DFG (Deutsche Forschungsgemeinschaft, GRK1910) is gratefully acknowledged.

Pharmaceutical/Medicinal Chemistry II, University of Regensburg, 93053 Regensburg, German. E-mail: Lukas.Graetz@ur.de

\section{B-ARRESTIN RECRUITMENT BY HISTAMINE $\mathbf{H}_{\mathbf{4}}$ RECEPTOR LIGANDS FROM THE GROUP OF NOVEL ARYL-1,3,5-TRIAZINE DERIVATIVES}

A. Olejarz-Maciej, K. Kamińska, M. Więcek, D. Łażewska, T. Karcz, T. Littmann, A. Buschauer, K. Kieć-Kononowic

The histamine $\mathrm{H}_{4}$ receptor $\left(\mathrm{H}_{4} \mathrm{R}\right)$ is considered as a potential drug target for the treatment of inflammatory and immunological diseases. The $\mathrm{H}_{4} \mathrm{R}$ is a $\mathrm{G}_{\mathrm{i}}$-coupled receptor that can independently activate the $\beta$-arrestin- 2 signaling pathway. Regarding the varied responses of $\mathrm{H}_{4} \mathrm{R}$ ligands in different native and culture cells, potential $\mathrm{H}_{4} \mathrm{R}$ ligands should be tested for their $\mathrm{G}_{\mathrm{i}}$ as well as $\beta$-arrestin-2 activity.

In the beginning, thanks to a cooperation with Professor A. Buschauer, the group of $\mathrm{H}_{4} \mathrm{R}$ ligands from aryl-1,3,5triazine-2-amines were chosen for testing in the $\beta$-arrestin2 recruitment assay. Results from these studies inspired us to establish a $\beta$-arrestin recruitment assay in our laboratory and continue the search for interesting ligands from this group of 1,3,5-triazine-2-amines.

$\beta$-arrestin recruitment was tested in two assays: (i) splitluciferase complementation (thanks to the cooperation with Professor A. Buschauer, HEK293T hH4R-ELucC ELucNßarr2 cell line was used in the assay; (ii) LiveBLAzerTMcell based assay (using Tango-H4-bla U2OS cells and LiveBLAzerTM technology).

Two compounds showed partial agonist activity, two displayed antagonist/inverse agonist activity, the rest showed antagonist activity in the $\beta$-arrestin pathway. The best compound (TR-DL-13) showed an $I C_{50}<10 \mathrm{nM}$. Aromatic derivatives showed weaker activity than aliphatic compounds. Interesting derivatives of thiophene were noted, where the position of substituents in the aromatic ring changed activity from antagonist to partial agonist.

This project was partially financed by grants from National Science Center Poland based on decisions No DEC-2011/02/A/NZ4/00031 and No DEC-2016/23/N/ NZ7/01906.

Department of Technology and Biotechnology of Drugs, Faculty of Pharmacy, Jagiellonian University Medical College, 30-688 Krakow, Poland. E-mail: agnieszka.olejarz@uj.edu.pl 


\section{EVALUATION AND SAR STUDY OF NOVEL SUBSTITUTED (DIHYDRO)BENZOFURANYL- PIPERAZINES AS HISTAMINE $\mathrm{H}_{3} R$ AND $\mathrm{H}_{4} R$ LIGANDS}

M. F. Corrêa, A. B. Silva, L. Penomian, S. C. Simões, G. A. B. Fernandes, C. M. S. Q. Aranha, M. T. Varela, C. M. Costa-Neto, J. P. S. Fernandes

Histamine acts through four different receptors $\left(\mathrm{H}_{1} \mathrm{R}-\mathrm{H}_{4} \mathrm{R}\right)$, the $\mathrm{H}_{3} \mathrm{R}$ and $\mathrm{H}_{4} \mathrm{R}$ being the most explored in the last few years as drug targets. The $\mathrm{H}_{3} \mathrm{R}$ is mainly expressed in the central nervous system (CNS), where it controls the production and release of histamine and other neurotransmitters, and thus antagonists of this receptor are promising agents to treat narcolepsy, Parkinson's disease, epilepsy, schizophrenia and several other CNS-related conditions. The $\mathrm{H}_{4} \mathrm{R}$ is expressed in several immune and inflammatory cells, and thus by blocking $\mathrm{H}_{4} \mathrm{R}$, anti-inflammatory and immunomodulatory effects can be achieved. Since our group has been evaluating dihydrobenzofuranyl-piperazines as $\mathrm{H}_{3} \mathrm{R}$ and $\mathrm{H}_{4} \mathrm{R}$ ligands, in this work, a novel set of compounds containing a different substitution pattern in the heterocycle region, is presented. A set of 17 compounds were synthesized from available (dihydro)benzofuran synthons through simple reactions with corresponding piperazines, giving moderate to high yields. The evaluation of the compounds versus the $\mathrm{H}_{3} \mathrm{R}$ and $\mathrm{H}_{4} \mathrm{R}$ was performed at a maximum concentration of $10 \mu \mathrm{M}$ following the previously reported method by our group. The compounds presented poor affinity for both receptors. The best $\mathrm{H}_{3} \mathrm{R}$ ligand was LINS01016 showing a $K_{\mathrm{i}} 116 \mathrm{nM}$, followed by the LINS01015 ( $\left.K_{\mathrm{i}} 1644 \mathrm{nM}\right)$. Regarding $\mathrm{H}_{4} \mathrm{R}$, the only modest ligand was LINS01018, which presented an affinity $K_{\mathrm{i}} 352 \mathrm{nM}$. In addition, the results suggest that all tested compounds act as antagonists of such receptors. The results suggested that bulky groups in the piperazine moiety are detrimental for the affinity to both receptors, while substituents in the (hetero)aromatic moiety lead to more $\mathrm{H}_{3} \mathrm{R}$-selective compounds. The presence of the benzofuran-carboxamide group leads to improved affinity for $\mathrm{H}_{4} \mathrm{R}$. Additionally, the dihydrobenzofuran core leads to better ligands than other aryl moieties. It is concluded that other substitution patterns should be tested in these prototypes to identify more potent compounds for both $\mathrm{H}_{3} \mathrm{R}$ and $\mathrm{H}_{4} \mathrm{R}$.

This work was supported by São Paulo Research Foundation-FAPESP (grants 2016/25028-3, 2018/044881, 2017/05441-6, 2018/03918-2 and 2016/23139-2) and National Council for Scientific and Technological Development-CNPq (grant 455411/2014-0 and 306055/2018$3)$.
Department of Pharmaceutical Sciences, Universidade Federal de São Paulo, Diadema-SP 09913-030, Brazil. E-mail: cecilia.aranha@unifesp.br or ceciliamaria95@hotmail.com

\section{NEW OXEPINE AND ALCAFTADINE DERIVED HISTAMINE $\mathrm{H}_{1}-\mathrm{H}_{\mathbf{4}}$-RECEPTOR LIGANDS AND THEIR PHARMACOLOGICAL CHARACTERIZATION}

\section{F. Naporra, H.-J. Wittmann, S. Elz, A. Straßer}

The discovery of a fourth histamine receptor $\left(\mathrm{H}_{4} \mathrm{R}\right)$ has initiated a re-evaluation of the effects of histamine and a possible synergy between histamine $\mathrm{H}_{1}$ and $\mathrm{H}_{4}$-receptor antagonists was suggested in targeting various inflammatory processes. To investigate this fact in more detail, compounds which address both receptors have to be synthesized and pharmacologically characterized.

Doxepine has a high affinity for $\mathrm{hH}_{1} \mathrm{R}$ but a weak affinity for $\mathrm{hH}_{4} \mathrm{R}$. Exchanging the tricyclic core, the basic moiety and the linker in between led to a library of compounds: For example, a high affinity ligand at the $\mathrm{hH}_{1} \mathrm{R}$ was identified in a derivative with a short piperazine containing linker and a terminal imidazole ring $\left(\mathrm{pK}_{\mathrm{i}}\left(\mathrm{hH}_{1} \mathrm{R}\right)=8.9, \mathrm{pK}_{\mathrm{i}}\left(\mathrm{hH}_{4} \mathrm{R}\right)<5\right)$. In contrast, by variation of the linker and the tricyclic core, a compound with increased affinity at the $\mathrm{hH}_{4} \mathrm{R}$ was identified $\left(\mathrm{pK}_{\mathrm{i}}\left(\mathrm{hH}_{1-}\right.\right.$ $\left.\mathrm{R})=5.5, \mathrm{pK}_{\mathrm{i}}\left(\mathrm{hH}_{4} \mathrm{R}\right)=6.4\right)$. Disadvantageously, doxepine derived compounds show also moderate affinity for the $\mathrm{hH}_{3} \mathrm{R}$. With alcaftadine, an antihistamine with combined antagonistic activity at histamine $\mathrm{hH}_{1} \mathrm{R}, \mathrm{hH}_{2} \mathrm{R}$ and to a lesser extent to the $\mathrm{hH}_{4} \mathrm{R}$, but only low affinity to $\mathrm{hH}_{3} \mathrm{R}$ $\left(\mathrm{pK}_{\mathrm{i}}<5\right)$ was described in literature. Considering these results, alcaftadine derivatives with varying substitution patterns at the tricyclic core were prepared resulting in a compound with high affinity for $\mathrm{hH}_{1} \mathrm{R}\left(\mathrm{pK}_{\mathrm{i}}\left(\mathrm{hH}_{1} \mathrm{R}\right)=8.8\right)$, but with only weak affinity $\left(\mathrm{pK}_{\mathrm{i}}<5\right)$ to the $\mathrm{hH}_{3} \mathrm{R}$ and $\mathrm{hH}_{4} \mathrm{R}$.

These results indicate that it may be a challenge to develop compounds with high affinity for both the $\mathrm{hH}_{1} \mathrm{R}$ and $\mathrm{hH}_{4} \mathrm{R}$. However, the present results provide important insights into structure activity relationships at $\mathrm{hH}_{1} \mathrm{R}$ and suggest further investigations, which combine advantages from both lead structures.

Institut für Pharm./Med. Chemie I, University of Regensburg, 93040 Regensburg, Germany. E-mail: franziska.naporra@chemie.ur.de 


\section{GUANIDINE DERIVATIVES AS HISTAMINE $\mathrm{H}_{3}$ RECEPTOR LIGANDS-DESIGN, SYNTHESIS, AND IN VITRO CHARACTERISATION OF PIPERAZINE AND PIPERIDINE ANALOGUES}

\author{
M. Staszewski, T. Karcz, D. McNaught Flores,
} K. Kieć-Kononowicz, R. Leurs, K. Walczyński

Over the past 15 years, the imidazole moiety has been successfully replaced with pyrrolidine, piperidine, piperazine and other basic tertiary amines. One of the first known histamine $\mathrm{H}_{3}$ receptor antagonists was a guanidine derivative-impromidine - which was found to be a potent agonist at the $\mathrm{H}_{2}$ receptor. It has appeared that the guanidine derivatives, i.e. 1-cyclohexylmethyl-3-[3-(1Himidazol-4-yl)propyl]guanidinine and non-imidazole-JB 98064-are potent and selective histamine $\mathrm{H}_{3}$ receptor antagonists.

Previously, we have reported the synthesis and preliminary pharmacological in vitro characterization of a series of potent histamine $\mathrm{H}_{3}$ receptor non-imidazole antagonists

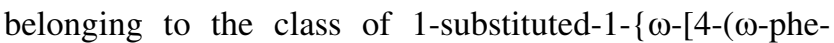
noxyalkyl)piperazin-1-yl]alkyl \}guanidines. The structural modifications led to replace the piperazine scaffold by piperidine ring and moving benzyl- or 4-trifluoromethylbenzyl substituents from position 1 to 3 of the guanidine moiety. The newly synthesized compounds were tested in vitro as histamine $\mathrm{H}_{3}$ and $\mathrm{H}_{1}$ receptor antagonists on the guinea pig isolated ileum evoked to the contractions electrically or by histamine. The most active derivatives were evaluated for their affinity at the recombinant rat histamine $\mathrm{H}_{3}$ receptor $\left(r \mathrm{H}_{3} \mathrm{R}\right)$ and human histamine $\mathrm{H}_{3}$ and $\mathrm{H}_{4}$ receptor $\left(h \mathrm{H}_{3} \mathrm{R}, h \mathrm{H}_{4} \mathrm{R}\right)$.

In both series-piperazine and piperidine derivativesthe 1-substituted-1-\{4-[4-(7-phenoxyalkyl)piperazin-1yl]butyl \}guanidine with the benzene ring substituted at position 4 , demonstrated the highest in vitro potency as a histamine $\mathrm{H}_{3}$ receptor antagonist. Additionally, radioligand binding studies at the human histamine $\mathrm{H}_{3}$ receptor showed good affinity for these compounds. Competition radioligand binding assay at $\mathrm{H}_{4}$ receptor revealed selectivity towards human histamine $\mathrm{H}_{3}$ receptor. The highest histamine $\mathrm{H}_{3}$ receptor selectivity has shown ratio $\mathrm{K}_{\mathrm{i}} \mathrm{H}_{4} /$ $\mathrm{K}_{\mathrm{i}} \mathrm{H}_{3}=20.9$.

Medical University of Lodz grant number 503/3-016-01/ 503-31-001 and COST Action CA 15135.

Department of Synthesis and Technology of Drugs, Medical University of Lodz, ul. Muszynskiego 1, 90-151 Lodz, Poland.E-mail: marek.staszewski@umed.lodz.pl

\section{STRUCTURAL MODIFICATIONS AND PHARMACOLOGICAL EVALUATION OF 4-PYRIDYLPIPERAZINE DERIVATIVES AS ACTIVE AND SELECTIVE HISTAMINE $\mathrm{H}_{3}$ RECEPTOR LIGANDS}

K. Szczepańska, T. Karcz, K. J. Kuder, G. Latacz, M. Kotańska, S. Hagenow, H. Stark, K. Kieć-Kononowicz.

The histamine $\mathrm{H}_{3}$ receptor $\left(\mathrm{H}_{3} \mathrm{R}\right)$, belongs to the superfamily of G-Protein coupled receptors (GPCRs) and is predominantly expressed in the central nervous system. Interaction with these receptors results in modulation of histamine levels as well as that of other neurotransmitters e.g. dopamine, acetylcholine, noradrenaline or serotonin. Therefore, a large number of $\mathrm{H}_{3} \mathrm{R}$ antagonists have been investigated for their potential therapeutic applicability in obesity, depression, mood disorders, neuropathic pain, and sleep-wake disorders (including narcolepsy) as well as cognitive and CNS-linked sensorimotor deficit disorders.

Undoubtedly, the imidazole ring replacement with other heterocyclic moieties was a milestone in the search for new histamine $\mathrm{H}_{3} \mathrm{R}$ ligands. The piperazine moiety is such a replacement, being a significant versatile chemical scaffold in rational drug design for numerous GPCR ligands.

Based on the results of the research so far, it is assumed that the 4-pyridylpiperazine moiety in the basic part of the compound determines high affinity at and selectivity for human $\mathrm{H}_{3} \mathrm{R}$. The position of the nitrogen atom in an aromatic ring attached to the piperazine moiety has turned out to be a key structural element for suitable interaction with its biological target. In order to determine the influence of substituents located in the "eastern part" of the molecule, structural modifications of previously obtained compounds including replacement of branched alkyl benzene substituents, with bulky aromatic groups were undertaken. Moreover, subsequent extension of alkyl linker in the range of five to eight methylene groups was also performed. Taking into account structural similarity of our compounds to other GPCR ligands, determination of affinity at histamine $H_{1}$, dopamine $D_{2}$ and $\alpha_{1}$ adrenergic receptors was also carried out.

We kindly acknowledge the generous support of National Science Center, Poland granted on the basis of decision No. 2016/23/N/NZ7/00469, DFG INST 208/690 as well as EU COST Action CA13135.

Department of Technology and Biotechnology of Drugs, and Department of Pharmacodynamics, Faculty of Pharmacy, Jagiellonian University Medical College, Medyczna 9, Kraków 30-688, Poland. E-mail: szczepanskatarzyna@gmail.com 


\section{FROM NATURAL COMPOUNDS TO SMALL MOLECULES TARGETING THE HISTAMINE $\mathrm{H}_{3}$ RECEPTORS}

\author{
A. Frank, F. Meza, C. O. Salas, A. Fierro, \\ C. Espinosa-Bustos, H. Stark
}

The histamine $\mathrm{H}_{3}$ receptor $\left(\mathrm{H}_{3} \mathrm{R}\right)$ and the $\mathrm{H}_{4}$ receptor $\left(\mathrm{H}_{4} \mathrm{R}\right)$ both belong to the same G-protein coupled receptor family and share a rather high degree of structural similarity. This may impede drug development by missing selectivity of novel compounds. On the other hand, this information may be used to optimize moderately active agents at one receptor for affinity towards the other. Thereby, natural compounds offer a reasonable resource for drug development.

Pyrrolo[2,3-d]pyrimidines are natural compounds that can be found in several marine organisms. However, up to now, no studies have been conducted to determine whether this class may be applied to neurodegenerative diseases like Alzheimer or Parkinson's disease involved in the histamine $\mathrm{H}_{3} \mathrm{R}$ pathway. Though twelve novel pyrrolo[2,3d]pyrimidine derivatives with reasonable pharmacophores for both receptors were synthesized using microwave-assisted synthesis. The compounds affinities towards the human $\mathrm{H}_{3} \mathrm{R}$ and $\mathrm{H}_{4} \mathrm{R}$ were evaluated by radioligand displacement assays. Most compounds showed only moderate activity at the $\mathrm{H}_{4} \mathrm{R}$ but promising activity at the $\mathrm{H}_{3} \mathrm{R}$. The most active compounds 1 and 2 displayed $K_{i}$ values of $120-150 \mathrm{nM}$ at the $\mathrm{H}_{3} \mathrm{R}$. By identifying these novel lead compounds, a structure-optimization approach was conducted and led to a new series of naturally inspired small molecules. Binding affinity at the $\mathrm{H}_{3} \mathrm{R}$ improved significantly compared to the lead structures with the most active compound displaying a $\mathrm{K}_{\mathrm{i}}$ value of $6.2 \mathrm{nM}$ (compound 3).

By that approach we could strengthen the relevance of natural compounds in recent drug development and expand the library of $\mathrm{H}_{3} \mathrm{R}$ ligands with one novel class of active agents. With this expanded set of compounds structureactivity-relationship can be investigated and aid in further optimization of this novel class of $\mathrm{H}_{3} \mathrm{R}$ ligands.

Supported by the DFG INST208/690-1 and by COST Actions CM15135 and CA18133.

Institute of Pharmaceutical and Medicinal Chemistry, Heinrich Heine University Düsseldorf, Dussseldorf, 40225, Germany.E-mail: A.Frank@hhu.de

\section{SYNTHESIS OF BIVALENT LIGANDS AND DEVELOPMENT OF PHARMACOLOGICAL ASSAYS FOR DOPAMINE D $_{1}$-HISTAMINE $\mathrm{H}_{3}$ RECEPTOR HETEROMERS}

N. Rosier, M. Nagl, L. Grätz, H. Schihada, M. Decker, R. Franco, S. Pockes

The formation of GPCR-heteromers (Hets) has been proven in transfected cells as well as in native tissues. The group of Franco et al. published the existence of a heteromerization between the $\mathrm{D}_{1} \mathrm{R}$ and $\mathrm{H}_{3} \mathrm{R}$ in rodent striatum and cortex, as well as a complex formation between the $\mathrm{D}_{1} \mathrm{R}-\mathrm{H}_{3} \mathrm{R}$-Het and subunits of the NMDA receptor. By inhibiting this Het the NMDA or $\mathrm{D}_{1}$ receptorinduced excitotoxic cell death as well as the $\beta_{1-42}$-amyloid induced toxicity could be reduced. Therefore, these Hets are promising targets to prevent neuronal cell death in neurodegenerative diseases, e.g. Alzheimer's disease, while highly selective bivalent ligands for the $\mathrm{D}_{1} \mathrm{R}-\mathrm{H}_{3} \mathrm{R}$ Het are promising structures for selective, neuroprotective agents.

For the synthesis of bivalent ligands derivatives of the known non-imidazole $\mathrm{H}_{3} \mathrm{R}$ antagonist JNJ5207852 were synthesized in three steps. An additional amino- or carboxy-functionality at the para-position of the piperidinemoiety allows the coupling of the pharmacophore to the linker. Afterwards a derivative of the $\mathrm{D}_{1} \mathrm{R}$ antagonist $\mathrm{SCH}-$ 23390 was synthesized in a five-step sequence with an amino group at the para-position of the aromatic ring. The linker will be coupled via a sulfonamide partial structure at this position. A five-step synthesis for a rigid linker based on piperazine and isophtalic acid was developed and accomplished.

For the pharmacological characterization of the bivalent ligands, radioligand binding assays on $\mathrm{Sf} 9$ cell membranes for all histamine receptor-subtypes are already established. Functional assays for the histamine as well as for the dopamine receptors, using biosensors (e.g. NanoLuc and HaloTag, or split luciferase complementation techniques) are currently being established.

These assays will be used to characterize the first bivalent ligands, which will be obtained soon by connecting the three above-mentioned structures via peptide coupling reactions.

Supports from the International Doctoral Program "Receptor Dynamics" Elite Network of Bavaria is gratefully acknowledged.

University of Regensburg, Regensburg, 93053, Germany. E-mail: niklas.rosier@ur.de. 


\section{COMPUTATIONAL AND PHARMACOLOGICAL EVALUATION OF PIPERAZINE DERIVATIVES IN SEARCH OF NOVEL, MULTIFUNCTIONAL, ANTIALZHEIMER'S AGENTS}

\author{
J. Jończyk, K. Lodarski, M. Staszewski, J. Godyń, \\ P. Zareba, O. Soukup, J. Janockova, J. Korabecny, \\ K. Sałat, N. Malikowska-Racia, M. Hebda, N. Szataj, \\ B. Filipek, K. Walczyński, B. Malawska, M. Bajda
}

Many strategies are used to search for new Multi-TargetDirected Ligands (MTDL). One of these strategies is to screen the library of compounds active against one biological target in search for other complementary activities. This synergistic combination of activities can be used to create a new therapeutic agent for complex disorders such as Alzheimer's disease. In the present study, we identify multifunctional activity among a library of non-imidazole histamine $\mathrm{H}_{3}$ receptor antagonists, derivatives of alkylpiperazine, using both molecular modeling and biological evaluation. Through the in vitro studies of AChE and BuChE inhibition, many compounds with the MTDL activity have been identified. We applied homology modeling to generate a model of the human $\mathrm{H}_{3}$ histamine receptor. With its help and using crystal structures of acetylcholinesterase (AChE) and butyrylcholinesterase $(\mathrm{BuChE})$, we revealed possible interactions between tested compounds and biological targets. Ligands with the MTDL profile were subjects of computational studies predicting drug-likeness. We have chosen the most drug-like compounds for the parallel artificial membrane permeation assay which proved outstanding blood-brain barrier penetration in test conditions. Based on all results, we selected four compounds for memory tests on mice. Compound A12, chemically methyl(4-phenylbutyl) \{2-[2-(4-propylpiperazin-1-yl)-1,3-thiazol-5-yl]ethyl \}amine, with $\mathrm{H}_{3}$ antagonist activity $\left(\mathrm{pA}_{2}=8.27\right)$ displayed inhibitory potency against $\mathrm{AChE}\left(\mathrm{IC}_{50}=13.96 \mu \mathrm{M}\right)$, and $\mathrm{BuChE}$ $\left(\mathrm{IC}_{50}=14.62 \mu \mathrm{M}\right)$. During the in vivo studies, A12 revealed the anti-amnestic properties in the passive avoidance test on mice with no impairment on locomotor activity and motor coordination. The activity of compound A12 prompts further testing of its effect on other known pathomechanisms associated with Alzheimer's disease. This result is a promising starting point, with $\mathbf{A 1 2}$ as a lead structure, for development of multifunctional, anti-Alzheimer's agents.

Financial support in the form of a research grant (UMO2014/15/N/NZ7/02965) from the National Science Center in Poland, the Jagiellonian University Medical College grant K/ZDS/007213, the European Cooperation in Science and Technology COST Action CA15135, European Regional Development Fund: Project "PharmaBrain" (no.
CZ.02.1.01/0.0/0.0/16_025/0007444) and support from MH CZ-DRO (UHHK, 00179906) are gratefully acknowledged.

Department of Physicochemical Drug Analysis, Faculty of Pharmacy, Jagiellonian University Medical College, Medyczna 9, 30-688 Kraków, Poland. E-mail: jakub.jonczyk@doctoral.uj.edu.pl

\section{UGI MUTICOMPONENT REACTION AS A TOOL TO IDENTIFY NEW LEAD COMPOUNDS FOR ALZHEIMER DISEASE}

L. Ismaili, I. Pachón-Angona, F. López-Muñoz, M. J. OsetGasque, B. Reouvelet, J. Marco-Contelles

Alzheimer's disease (AD) is a multifactorial neurodegenerative disorder characterized by a decline of the cholinergic function, dysregulation of other neurotransmitter systems, beta-amyloid $(\mathrm{A} \beta)$ fibril aggregation and neurofibrillary tangles, deposition associated with accumulation of biometal $(\mathrm{Cu}, \mathrm{Fe}, \mathrm{Zn})$ and oxidative stress (OS). As many different biological systems are involved in AD progression, the traditional monotarget approach has resulted in non-effective therapeutic treatments. In order to address the complex nature of this disease, multitarget directed ligands (MTDL) are being studied as new and potentially effective drugs, since they can bind diverse enzymatic systems and receptors simultaneously.

Accordingly, and based on our confidence that multicomponent reactions (MCRs) represent useful tools in medicinal chemistry and the most appropriate method for the synthesis of many different types of pharmacophores showing relevant biological properties, we have recently developed a series of new multi-target small molecules for Alzheimer's disease (AD) therapy, such as Tacrine-Ferulic Acid Hybrids in 2015, Ferulic (Lipoic) Acid + Melatonin Modified Tacrines in 2016 and Donepezil + Chromone + Melatonin Hybrids in 2019 where we have identified very promising hit-compounds for further development.

Neurosciences intégratives et cliniques, Pôle Chimie Organique et Thérapeutique, EA 481, Univ. Bourgogne Franche-Comté, UFR Santé, 19, rue Ambroise Paré, F25000 Besançon, France. E-mail : lhassane.ismaili@univfcomte.fr 
Histamine in the cardiovascular, renal, optic and gastro-intestinal systems. 


\section{INTERACTION OF $\mathrm{H}_{2}$-HISTAMINE AND 5-HT SEROTONIN RECEPTORS IN THE MAMMALIAN HEART AND EFFECTS OF AMITRYPTILINE}

\section{J. Neumann, D. Schwarzer, M. Binter, U. Gerg}

We have previously shown that histamine and serotonin can mediate positive inotropic and chronotropic effects on isolated atria from mono-transgenic mice expressing $\mathrm{H}_{2}-$ histamine receptors $(\mathrm{H} 2-\mathrm{TG})$ or $5-\mathrm{HT}_{4 \mathrm{a}}$-serotonin receptors (5-HT4-TG), respectively. We crossbred these mice to generate double transgenic mice overexpressing both $\mathrm{H}_{2}$ and $5-\mathrm{HT}_{4 \mathrm{a}}$ receptors (DT). Histamine did not increase contractility in atria from wild type (WT) or 5-HT4-TG mice. Similarly, serotonin did not increase contractility in atria from WT or H2-TG. However, both serotonin and histamine, subsequently applied, increased contractility in atria from DT. The potency of histamine in left atria of DT mice was not different from H2-TG mice $\left(\operatorname{logEC_{50}}=-\right.$ $7.56 \pm 0.26(n=5)$ vs. $\operatorname{logEC} C_{50}=-7.59 \pm 0.07(n=5)$, $\mathrm{p}>0.05)$. Serotonin showed a higher potency in left atria of 5-HT4-TG mice $\left(\operatorname{logEC} \mathrm{C}_{50}=-8.44 \pm 0.11, \mathrm{n}=5\right)$ compared with DT mice $\left(\operatorname{logEC} \mathrm{C}_{50}=-7.85 \pm 0.12, \mathrm{n}=4-5\right)$. The potency of isoprenaline on force of contraction was highest in left atria of WT mice $\left(\operatorname{logEC} \mathrm{C}_{50}=-8.06 \pm 0.13\right.$, $\mathrm{n}=8)$ and lowest in preparations of DT mice $\left(\log \mathrm{EC}_{50}=-\right.$ $6.78 \pm 0.19, \mathrm{n}=4)$. Amitryptiline has been reported to bind to recombinant $\mathrm{H}_{2}$ receptors, but functional data in the heart have not yet been reported. In our present work, we noted that amitryptiline $(1,3$, and $10 \mu \mathrm{M})$ antagonized the effect of histamine on force of contraction in left atria of H2-TG mice in a putative competitive fashion. In summary, we succeeded in co-expressing functionally the $\mathrm{H}_{2}$ and the $5-\mathrm{HT}_{4}$ receptor in the mouse heart. Moreover, we present functional data that the tricyclic antidepressant drug amitryptiline can block $\mathrm{H}_{2}$ receptors in the mammalian heart.

Institute for Pharmacology and Toxicology, Medical Faculty, Martin Luther University Halle-Wittenberg, 06097 Halle (Saale), Germany. E-mail: joachim.neumann@medizin.uni-halle.de

\section{TOWARDS ENDOTHEIAL PROFILING IN VIVO}

\section{S. Chlopicki}

The vascular endothelium is presently regarded as an important autocrine/paracrine/endocrine organ that regulates number of cardiovascular functions. Endothelial dysfunction leads to various pathologies and there are number of pharmacotherapeutic mechanisms of endothelium and vascular wall that could be exploited therapeutically. For example, NO-based therapy targeted to the liver by V-PYRRO/NO may be an interesting approach to treat liver steatosis. Pharmacology of $\mathrm{COX}-2 / \mathrm{PGI}_{2}$ pathway stimulated by 1-methylnicotinamide (MNA), affords anti-thrombotic, anti-inflammatory and vasoprotective activity ${ }^{6}$ that may be therapeutically useful in various diseases. Decades after the discoveries of vasoprotective endothelial mediators such as $\mathrm{PGI}_{2}$, and $\mathrm{NO}$, we have learnt to stimulate their vasoprotective activity with pharmacological tools. Multiple mechanisms of endothelial dysfunction have been described that offer immense possibilities to treat the pro-thrombotic, pro-inflammatory phenotype of endothelial dysfunction, a hallmark of cardiovascular diseases as well as an important contributor to many other pathologies. To translate the endeavours of pharmacology of endothelium into therapeutics, novel methods for comprehensive assessment of endothelial function in vivo are needed (endothelial profiling), that could be then successfully applied in humans for endothelial-guided therapy.

Jagiellonian Centre for Experimental Therapeutics (JCET), Jagiellonian University, Krakow, Poland. E-mail: s.chlopicki@uj.edu.pl

\section{HISTAMINE STIMULATES CFTR CL ${ }^{-}$CURRENT BY ACTIVATING $\mathrm{H}_{1} R-\mathrm{G}_{\mathrm{q} / 11}$ ALPHA PATHWAY IN HUMAN RETINAL GLIAL MULLER CELLS}

\section{Cliffe, I. Young, I. Obara, P. L. Chazot, V. Telezhkin}

Understanding of detailed histamine signalling through histamine receptors remains captivating. Here, using patchclamp electrophysiology in conventional whole-cell mode, we found that in human retinal glial Müller cells (Mio-M1) grown in $3.152 \mathrm{~g} / \mathrm{l}$ glucose-containing media, histamine dose-dependently stimulated a powerful current comprised of two components: a fast transient large amplitude followed by a slow steady low amplitude; the current was identified as chloride $\left(\mathrm{Cl}^{-}\right)$and at holding $0 \mathrm{mV}$ was inward $\left(\mathrm{EC}_{50}=0.8 \mu \mathrm{M}\right.$ for both components. We confirmed histamine binding to the histamine $\mathrm{H}_{1}$ receptors $\left(\mathrm{H}_{1} \mathrm{Rs}\right)$ characterised as an irreversible inhibition of histamine-induced current with pyrilamine $\left(\mathrm{H}_{1} \mathrm{R}\right.$ antagonist) $(10 \mu \mathrm{M}) . \mathrm{H}_{1} \mathrm{R}$ activation is known to initiate a downstream cascade via a $G_{\mathrm{q} / 11}$ protein $\alpha$ subunit that stimulates phospholipase C (PLC), which was determined with irreversible inhibition of histamine-induced current using PLC inhibitor U73122 $(10 \mu \mathrm{M})$. The PLC-induced release of $\mathrm{Ca}^{2+}$ from endoplasmic reticulum through inositol trisphosphate receptors $\left(\mathrm{IP}_{3} \mathrm{Rs}\right)$ was verified by inhibiting both the fast and slow components of histamine-induced current with the $\mathrm{IP}_{3} \mathrm{R}$ blocker 2-APB $(100 \mu \mathrm{M})$ and $\mathrm{Ca}^{2+}$ 
chelator BAPTA-AM $(100 \mu \mathrm{M})$. Also, subsequent $\mathrm{Ca}^{2+}$ influx through the plasma membrane cation channels was determined using reversible suppression of the slow component of the histamine-induced current with $\mathrm{Ca}^{2+}$ free solution and $\mathrm{NiCl}_{2}(100 \mu \mathrm{M}) . \mathrm{Ca}^{2+}$ release caused the resultant activation of $\mathrm{Cl}^{-}$current that was pharmacologically identified as cystic fibrosis transmembrane conductance regulator (CFTR) and was sensitive to niflumic acid and GlyH101 (both $100 \mu \mathrm{M}$ ). Finally, the expression of $\mathrm{H}_{1} \mathrm{R}$, CFTR and glial markers was confirmed using immunocytochemistry. Taken together, this study establishes a novel $\mathrm{H}_{1} \mathrm{R} / \mathrm{CFTR}$ mechanism that in human retinal glial Müller cells may play a crucial role in retinopathies such as fluid accumulation in macular oedema and neovascularisation in diabetic retinopathy.

Supported by funding from the School of Pharmacy, Newcastle University, UK, and Department of Biosciences, Durham University, UK. The Authors would like to thank Prof. Astrid Limb (UCL) for the kind gift of Mio-M1 cells. School of Dental Sciences, Newcastle University, Newcastle upon Tyne, NE2 4BW, UK. E-mail: Vsevolod.Telezhkin@newcastle.ac.uk

\section{EFFECT OF BILASTINE ON THE PROGRESSION OF DIABETIC NEPHROPATHY IN DBA2/J MICE}

\section{R. Verta, M. Gurrieri, S. Borga, M. Argenziano, P. Nardini, R. Cavalli, C. Grange, A. Pini, A. C. Rosa}

Recent studies suggest that $\mathrm{H}_{1} \mathrm{R}$ may be involved in the destruction of the filtration filter, a typical hallmark of diabetic nephropathy. However, the hypothesis that canonical anti- $\mathrm{H}_{1} \mathrm{R}$ drugs could be an add-on-therapy for diabetic nephropathy has not been completely tested. Therefore, this study investigated the effects of the selective $\mathrm{H}_{1} \mathrm{R}$-antagonist bilastine on renal function and morphology in a murine model of diabetic nephropathy.

Diabetes was induced in 5-6 weeks DBA2/J male mice by streptozotocin multiple injection $(40 \mathrm{mg} / \mathrm{kg}$ i.p. for 5 days). At the onset of diabetes bilastine $(1-30 \mathrm{mg} /$ $\mathrm{kg}$ /day) was administered by oral gavage for 14 weeks. Body weight, food and water intake were monitored through the experimental period. Urine, blood and kidneys were collected at the end of the study. The morphological analysis showed modest mesangial expansion and mild renal damage that was consistent with the evaluation of renal function. Among the major changes observed, a significant polyuria $(+50 \%$; $P<0.05)$ was shown by diabetic animals. The administration of bilastine dosedependently induced a further increase in water excretion ( $+66 \%$ bilastine30 group; $P<0.05$ ), sustained by a reduction in glycosylated aquaporin 1 expression.
Similarly, the albumin-to-creatinine ratio was increased by the drug. However, creatinine clearance was restored in a dose-dependent manner by bilastine, thus suggesting a positive effect on glomerular filtration. The electron microscope analysis showed a preserved junctional integrity. Changes in p-cadherin expression could explain this effect.

In conclusion, bilastine does not completely prevent the progression of diabetic nephropathy, however, it prevents the mechanical glomerular damage, as demonstrated by the prevention of $\mathrm{CrCl}$ drop and $\mathrm{p}$-cadherin expression loss induced by hyperglycemia. Therefore, these data further strengthen the hypothesis that histamine via $\mathrm{H}_{1} \mathrm{R}$ could be a detrimental stimulus for glomerular integrity.

Dep. Scienza e Tecnologia del Farmaco, University of Turin, Via Pietro Giuria 9, 10125, Turin, Italy. E-mail: roberta.verta@edu.unito.it,robertaverta94@gmail.com

\section{THE ROLE OF THE GASTROINTESTINAL BARRIER IN SEPSIS}

\section{B. Y. De Winter, P. Plaeke, P. J. Jorens, J. G. De Man, G. Hubens, A. Smet}

The gastrointestinal barrier represents a physical, anatomical and immunological barrier that is metabolically active. Gastrointestinal barrier disturbances, also referred to as a 'leaky gut', are postulated to play an important role in the pathogenesis of a wide range of diseases including sepsis. The intestinal barrier comprises a thick layer of mucus and a single layer of epithelial cells separating the gastrointestinal lumen from the underlying mucosa, thereby balancing between selective permeability and maintaining a barrier for harmful molecules. In the domain of sepsis there is evidence for increased intestinal permeability that was originally linked to bacterial translocation. The clinical relevance of bacterial translocation and its treatment was, however, challenged since several clinical studies failed to detect endotoxins or bacteria in the portal blood of septic patients. Not only pathogens and endotoxins but also inflammatory mediators, gut-derived toxic factors, damage molecules and microbiota-derived metabolites can enter the internal environment and spread throughout the body initiating a local and systemic immune activation. Currently, no approved therapeutic agents are available targeting the epithelial intestinal barrier. Therefore, there is a significant need to study the potential of specific compounds that allow therapeutic modulation of the interplay between the intestinal barrier and immune activation in an experimental model of sepsis. Histamine is a potential modulator and is postulated to play a role in sepsis-induced lung, liver and kidney organ damage. Histamine $\mathrm{H}_{2}$ 
receptor antagonists are also still recommended as prophylaxis against stress ulcers but only if there is an increased risk of gastrointestinal bleeding in sepsis patients. The role of histamine and histamine receptors in sepsis will be discussed, more specifically the potential mechanisms of intestinal epithelial homeostasis as well as their repercussions for inflammation and the microbiome. University of Antwerp \& University Hospital Antwerp, Antwerp, Belgium. E-mail:benedicte.dewinter@ uantwerpen.be

\section{VEGETAL DIAMINE OXIDASE TO CONTROL THE INTESTINAL LEVEL OF HISTAMINE}

\section{A. Mateescu, P. Ispas-Szabo, A. T. Neree,}

P. Pietrangeli, L. Marcocci

Exogenous histamine may induce food histaminosis and trigger pseudo-allergic phenomena. It may also exert proinflammatory effects, particularly damaging for subjects with Inflammatory Bowel Diseases (IBD). An enzymatic strategy was proposed using oral vegetal diamine oxidase (DAO, also called histaminase) to decrease histamine levels and prevent allergic reactions to food and damage in IBD.

Therapeutic concept: DAO will decrease the level of histamine in the intestinal lumen by oxidative deamination. Since the by-product of DAO activity is hydrogen peroxide $\left(\mathrm{H}_{2} \mathrm{O}_{2}\right)$, catalase (CAT) was added to DAO to create a bienzymatic product. Not only will CAT decompose $\mathrm{H}_{2} \mathrm{O}_{2}$ but it will also generate more oxygen in situ, thus favoring histamine degradation.

Tablets containing the two enzymes were prepared using excipients able to protect enzymes and provide colonic delivery. The catalytic stability of vegetal DAO in various simulated intestinal media with different $\mathrm{pH}$ values and containing bile acids, pancreatic proteolytic enzymes, phospholipids, or alcohol was investigated. A study was also conducted in mice using the DAO-CAT combination.

The data showed that a polymeric matrix based on carboxymethylstarch and chitosan (CMS:Chi) offered good protection to DAO and CAT after $2 \mathrm{~h}$ in simulated gastric fluid, with maximal release of therapeutic enzymes in simulated intestinal fluid at about $8 \mathrm{~h}$ (enough time for tablets to reach the colon).

Cholic acid and lipids protected DAO in simulated intestinal fluids but they were not able to protect against the inhibitory effect of $20-40 \%$ ethanol. The bi-enzymatic DAO-CAT protected intestinal Caco-2 cells against damage induced by histamine. Histology data confirmed DAOCAT association was also able to treat colonic inflammation induced in mice.
In conclusion, this bi-enzymatic approach might be relevant for oral administration of enzymes as food supplements or as therapeutic bioactive agents and may contribute to improved treatment of histamine-related disorders.

Financial support from NSERC (Natural Sciences and Engineering Research Council) of Canada (Discovery Grant No. 38642), from Foundation Courtois (Canada) and from Regione Lazio of Italy (FILAS RU-2014-1020) is gratefully acknowledged.

Department of Chemistry, Université du Québec à Montréal, C.P. 8888, Succ. Centre-Ville, Montréal, Québec H3C 3P8, Canada. E-mail: mateescu.malexandru@uqam.ca

\section{VEGETAL DIAMINE OXIDASE INHIBITS THE INTESTINAL SMOOTH MUSCLE CONTRACTIONS INDUCED BY HISTAMINE}

\author{
A. T. Neree, R. Soret, M. Koudoufio, L. Marcocci, \\ P. Pietrangeli, N. Pilon, M. A. Mateescu
}

Exogenous histamine, when it is in excess, may induce various dysfunctions including dysregulation of intestinal motility. Some histamine receptor antagonist drugs generate side effects. As an alternative, we propose the use of a vegetal diamine oxidase (DAO, also called histaminase), which is able to eliminate histamine. The main objective of the current study was thus to investigate, ex vivo, the effect of vegetal DAO on smooth muscle contractions induced by histamine.

The distal colons of 4 week old mice were mounted in an organ bath filled with oxygenated Krebs solution and treated with histamine $(0-100 \mu \mathrm{M})$. At concentrations of histamine that induced contraction, the colons were treated with DAO or pyridoxal phosphate (PLP) or both. The effect of PLP on DAO activity and conformation was also investigated by zymography and by circular dichroism (CD) spectroscopy, respectively.

The results confirmed that histamine enhanced the contraction of colonic smooth muscle. Conversely, smooth muscle contraction induced by histamine was decreased by DAO. At a DAO concentration of $1.25 \mathrm{mg} / \mathrm{mL}$, contraction intensity was decreased by $50 \%$. This effect of DAO was about twice as large than that of other commercial antihistamine drugs.

It was also found that the added PLP plays a role as an enhancer of anticontractile DAO activity.

In order to understand its effect on DAO activity, the secondary conformation was analysed by $\mathrm{CD}$. The results showed a slight increase in alpha helical conformation. Furthermore, DAO retention in the gut mucosa was 
investigated in vivo following rectal administration of the enzyme. The presence of DAO in gut mucosal tissue was evidenced by fluorescence microscopy.

In conclusion, vegetal DAO was found to inhibit the contractile effect of histamine on intestinal smooth muscle. In addition, DAO activity was increased by PLP. The enzyme was found to be retained on intestinal mucosa; it is not excluded that this retention occurs via a covalent binding involving lysyl $\varepsilon$-amino group. DAO therefore appears to be a viable bioactive agent that could limit histamine-related intestinal dysfunction.

Financial support from NSERC (Natural Sciences and Engineering Research Council) of Canada (Discovery Grant No. 38642), from Foundation Courtois (Canada) and from Regione Lazio of Italy (FILAS RU-2014-1020) is gratefully acknowledged.

Department of Chemistry, Université du Québec à Montréal; Research Chair in Enteric Dysfunctions "Allerdys", Centres Pharmaqam and CERMO-FC, Université du Québec à Montréal, C.P. 8888, Montréal, Québec H3C 3P8, Canada. E-mail: mateescu.m-alexandru@uqam.ca

\section{DIET PREVENTS SOCIAL DEFEAT STRESS- INDUCED COGNITIVE AND NEUROPHYSIOLOGIC MODIFICATIONS BY ACTIVATING THE CENTRAL HISTAMINE SYSTEM}

\section{B. Rani, F. Bonfiglio, G. Provensi, S. D. Schmidt, P. Blandina, R. Corradetti, M. B. Passani, A. Costa}

Evidence indicates that a diet rich in polyunsaturated $\omega-3$ fatty acids ( $\omega-3$ PUFA) has positive effects on cognitive function and resilience to stress. Here, we investigated the effect of a $\omega$-3 PUFA $(0.545 \mathrm{~g} / 100 \mathrm{~g}) / \mathrm{Vitamin}-\mathrm{A}(45 \mathrm{IU} / \mathrm{g})$ enriched diet $(E D)$ in the modification of cognitive function and synaptic plasticity induced by chronic social defeat stress (CSDS), focusing on the role of the central histaminergic system.

We evaluated the effect of the $E D$ on the cognitive performance of histamine-deficient mice lacking histidine decarboxylase $\left(\mathrm{HDC}^{-/-}\right)$or wild type littermates $\left(\mathrm{HDC}^{+\prime}\right.$ ${ }^{+}$) subjected to CSDS. Non-stressed mice of both genotypes served as controls. CSDS consisted of antagonistic social confrontations between an aggressive CD-1 and an experimental C57BL6/J mouse, repeated daily for 10 days. At the end of the stress protocol, social avoidance of the aggressive mouse by subordinate animals was measured as a reduction in the time spent in the proximity of the CD-1 mouse encased in a wire cage. In addition, we estimated synaptic plasticity in the CA1 region of the hippocampus by measuring the magnitude of fast excitatory postsynaptic potential long-term potentiation (fEPSP LTP) induced by theta bursts in vitro. The expression of hippocampal synaptophysin was also measured.

We found that social interaction (i.e., the time experimental mice spend in the proximity of the aggressive CD-1 mouse) of stressed $\mathrm{HDC}^{+/+}$and $\mathrm{HDC}^{-/-}$mice was significantly diminished relative to non-stressed mice. The $E D$ reduced the stress-induced social aversion of $\mathrm{HDC}^{+/+}$mice but was ineffective in $\mathrm{HDC}^{-1-}$ mice. Furthermore, the CSDS protocol worsened recognition memory, tested using a novel object recognition test, of both genotypes and the $E D$ prevented this cognitive deficit only in $\mathrm{HDC}^{+/+}$mice. Consistently, stress increased LTP in $\mathrm{HDC}^{-1-}$ mice, an effect not reversed by $E D$. Finally, the $E D$ increased synaptophysin expression only in stressed $\mathrm{HDC}^{+/+}$, but not in stressed $\mathrm{HDC}^{-1-}$ mice.

Our data suggest that brain histamine is essential for a $\omega-3 /$ PUFA/Vit.A enriched diet to prevent stress-induced cognitive and neurophysiological impairments.

Ambrosiac-JPI a healthy diet for a healthy life.

Department of Neurosciences, Psychology, Drug Research and Child Health, University of Florence, 50139, Florence, Italy; E-mail; barbara.rani@unifi.it

\section{NATURAL CUBAN ZEOLITE AND ITS HISTAMINE BINDING CAPACITY AS WELL AS ITS EFFECT FOR ORAL AND TOPICAL APPLICATION IN HUMAN BEINGS}

\section{W. Dathe, T. Selvam, W. Schwieger, T. Langbein,} R. P. Baum, A. A. Torres

Zeolites are naturally occurring microporous crystalline aluminosilicates, which are composed of different crystal lattices. Clinoptilolite, a medium-pore 10-membered ring zeolite, is most commonly used for medical purposes. Cuban zeolite also contains the large-pore 12-membered ring zeolite mordenite. Histamine uptake capacity was studied using zeolites of different origin, mineralogical composition and particle size. Histamine adsorption on zeolites with smaller particle sizes and containing both minerals clinoptilolite and mordenite is significantly higher than those with larger particle sizes or clinoptilolite alone ( $3 \mu \mathrm{m}$ particle size-about $16-22 \mathrm{mg}$ histamine/g zeolite; $40 \mu \mathrm{m}$-about $15 \mathrm{mg}$ histamine/g zeolite; clinoptilolite alone, corresponding to $40 \mu \mathrm{m}$-about $10 \mathrm{mg}$ histamine/g zeolite). Based on these results and some other basic conditions the Cuban zeolite $\pm 40 \mu \mathrm{m}$ was chosen for oral application (Detoxsan ${ }^{\circledR}$ powder) and for topical application in dermatological diseases (Detoxsan ${ }^{\circledR}$ paste).

Clinoptilolite acts as an anti-diarrhoeal agent, with potential gastroprotective benefits. Detoxsan ${ }^{\circledR}$ powder was 
administered to 20 patients with midgut neuroendocrine tumours (carcinoids) suffering from treatment-resistant diarrhoea. In ca. $70 \%$ of patients, bowel movements were reduced from numerous defecations to a normal level (1-2 bowel movements per day), thereby increasing quality of life. Some of these patients had high peripheral blood levels of serotonin (1.0-2.5 $\mathrm{g}$ histamine/L). Therefore, we investigated the serotonin uptake capacity of Cuban zeolite and obtained similar results but lower adsorption to those with histamine (about $10 \mathrm{mg}$ serotonin/g zeolite).

Detoxsan ${ }^{\circledR}$ paste contains Cuban zeolite, Vaseline (petroleum jelly) and squalane as a natural lipid component, which adheres to the skin surface and forms a thin mineral layer. The paste reduces skin inflammation e.g. in mycosis and intertrigo within 1-2 weeks; clinically the symptoms disappeared completely in the 31 patients tested. This may be due to adsorption of histamine and water (prerequisite of microbial growth). For psoriasis, longer treatment periods (weeks to months) are necessary depending on the magnitude of the damaged skin area.

Heck Bio-Pharma GmbH, D-73650 Winterbach, Germany; E-mail: daweidoc@gmx.de

\section{HISTAMINE AND FLAVONOIDS IN WINES}

\section{F. Diel, R. Khanferyan, N. Ageeva, V. Markosov, A. Galstyan}

Histamine is not only produced in the body, but also occurs naturally in many common foods. Large amounts of histamine are found in microbially produced or fermented foods (cheese, sauerkraut, wine), as well as in high protein foods, such as fish and meat. Wines are a source of high concentrations of biologically active factors, like flavonoid antioxidants, as well as several biogenic amines, which may induce allergy and inflammatory symptoms. Histamine is one of the most active substances and is thought to be the main cause of adverse reactions to wines. Consumption of foods and wines with high levels of histamine can lead to clinically relevant symptoms, like headaches, nausea, vomiting, diarrhea, hypotension, facial flushing, rash, edema, localized inflammation, as well as an intolerance reaction to histamine. From the clinical point of view, the analysis of the histamine concentration in fermented products, including wines, is very important. Some countries set limits to the amounts of histamine. For example, Switzerland recommends $10 \mathrm{mg} / \mathrm{l}$ as a maximal level, Germany-2 mg/L, while Belgium and France$5 \mathrm{mg} / \mathrm{l}$ and $8 \mathrm{mg} / \mathrm{ml}$, respectively. The aim of this study was to investigate the concentration of the most important biologically active components (flavonoids, histamine) in different types of wines. Histamine concentrations were assessed photometrically after HPLC-separation. The concentration of histidine and histamine in different nonbottled barrel wines (red, white, Champaign and Jerez) produced in Russia (Krasnodar and Krymea regions) were assessed. It has been demonstrated that different wines contain multiple different phenolic compounds with high antioxidant activity. The mass concentration of phenolic compounds in red wines differs depending on the type of wine (Cabernet, Merlo, Saperavi etc.) and time of fermentation. The highest concentration was in Saperavi wine $\left(8300 \mathrm{mg} / \mathrm{dm}^{3}\right)$. The phenolic compounds were represented by catechins (1026), epicatechin (274), quercetin (21.8), gallic acid (124.2), rutin (16.8), trans resveratrol (6.26), procyanidin B1 $(116,7)$ and procyanidin B2 $(136,4)$. Total antioxidant activity in terms of TROLOX was 4680. The level of histamine in red wines (Cabernet, Saperavi and Merlo) was higher than in white wines (Chardonnay and Riesling). The concentration of histidine in wines was elevated due to increasing fermentation time. The highest concentration of histamine was determined in Jerez wines and it was significantly increased (up to $2.8-6.5 \mathrm{mg} / \mathrm{ml}$ ) with time after stopping fermentation. Thus in 6 months the concentration of histidine in Jerez increased from 3 to 4 times as a result of its production by yeasts during continuous fermentation. Thus, it is important to investigate the concentration of histamine in wines, especially after longterm fermentation, because elevated concentration may be a cause of clinically relevant symptoms, especially in allergic patients.

Peoples' Friendship University of Russia (RUDN University), Moscow, 117198, Russia. E-mail: fdiel@gmx.de 